\title{
Food Selection by
}

\section{Northern Yellow-cheeked Crested Gibbons (Nomascus annamensis)in Northern Cambodia}

\section{Naven Hon}

\author{
A thesis \\ submitted to Victoria University of Wellington \\ in partial fulfilment of the requirements \\ for the degree of \\ Master of Science in Ecology and Biodiversity
}

\section{School of Biological Sciences}

Victoria University of Wellington

New Zealand

2016 


\begin{abstract}
Tropical regions have extremely high plant diversity, which in turn supports a high diversity of animals. However, not all plant species are selected by animals as food sources, with some herbivores selecting only specific plants as food as not all plants have the same nutrient make up. Animals must select which food items to include in their diets, as the amount and type of nutrients in their diet can affect lifespan, health, fitness, and reproduction.

Gibbon populations have declined significantly in recent years due to habitat destruction and hunting. Northern yellow-cheeked crested gibbon (Nomascus annamensis) is a newly described species, and has a limited distribution restricted to Cambodia, Laos and Vietnam. The northern yellow-cheeked crested gibbons play an important role in seed dispersal, yet little is currently known about this species, including its food selection and nutritional needs. However, data on food selection and nutritional composition of selected food items would greatly inform the conservation of both wild and captive populations of this species.
\end{abstract}

This study aims to quantify food selection by the northern yellow-cheeked crested gibbons by investigating the main plant species consumed and the influence of the availability of food items on their selection. The study also explores the nutritional composition of food items consumed by this gibbon species and identifying key plant species that provide these significant nutrients.

A habituated group of the northern yellow-cheeked crested gibbons with five members located in northern Cambodia was studied for 12 weeks during the dry season, and focal animal sampling was used to observe individual feeding behaviours. Four main activity categories were recorded including resting, feeding, travelling and socializing. Phenological data was recorded from transect lines, and plant densities from 20 vegetation plots inside the home range of this group of gibbons were also measured. Seventy-four plant samples from 20 tree and liana species that were consumed by this group of gibbons were collected for nutritional analyses. These samples were initially dried in sunlight, and then oven dried before levels of protein, total non-structural carbohydrates, lipids, fibres and condensed tannins were measured at the Nutritional Ecology Lab at Hunter College of the City University of New York, New York. 
The northern yellow-cheeked crested gibbon individuals spent most of the time resting, followed by feeding, travelling and socializing. Their main diet was fruit, supplemented with young leaves, flowers, mature leaves, and occasionally insects. Individuals selected food from 37 plant species, but predominately fed on just 16 of these species. The three most-consumed species were fruit from Ilex umbellulata (tree), Ficus. sp (liana), and young leaves from Lithocarpus elegans (tree). There was a significant relationship between feeding time and the availability of flowers, indicating that flowers were actively selected for when present. However, there was no significant relationship between feeding time and the availability of fruit or young leaves. Only a small number of plants bore fruit, with very low densities in the home range of this gibbon study group, but these plants produced a large abundance of fruit. These findings clearly indicate that fruit is the main diet for northern yellow-cheeked crested gibbons in the dry season, with young leaves, flowers, mature leaves and insects acting as secondary food sources. The northern yellow-cheeked crested gibbons selected only a small number of specific plants in their territory for food sources, indicating that any selective logging targeting these plant species would reduce food availability, and restrict the diet of these animals.

Fruits consumed by the northern yellow-cheeked crested gibbons were rich in carbohydrates and lipids, while young leaves were richest concentration of protein. Mature leaves had a high moisture content, whereas flowers contained condensed tannins more often than other plant tissues. All plant tissues consumed had similar amount of fibres. Generally, the food items consumed had higher concentrations of carbohydrate than protein or lipids. The overall diet of this group of gibbons was low in lipids. These results indicate that northern yellow-cheeked crested gibbon consumed food items with high concentrations of carbohydrate, and only selected a few food sources with high level of protein.

Overall, these findings have contributed important knowledge that can be used for long-term conservation of this gibbon species. There are a small number of key food species in the home range which need special protection. The northern yellow-cheeked crested gibbons consumed food items from different plant species, and as a consequence, all plant species selected play an important role for nutritional requirements by this gibbon species. When considering feeding requirement by the northern yellow-cheeked crested gibbons for captive breeding programs, diets should include fruit, which is rich in carbohydrates, and young leaves, which have high levels of protein. 


\section{Acknowledgements}

Firstly, I would like to thank New Zealand ASEAN Scholarship Program, and the New Zealand government through the New Zealand Aid Program for a three-year scholarship to study at Victoria University of Wellington (VUW), New Zealand. This has been a great opportunity to upgrade my knowledge in science and in particularly biodiversity research and conservation. I also would like to thank the Primate Conservation Incorporated (PCI) and Primate Action Fund (PAF) with Conservation International (CI) for supporting this project. Without the support of these agencies, I would not have chance to become involved in primate research and conservation.

This thesis would not have been possible without the encouragement and support of my supervisors, Associate Professor Dr Ken Ryan (VUW) and Dr Alison Behie (Australian National University, Canberra, Australia). I highly appreciate what both of you have contributed to this thesis. Without both of you, I would not have had the chance to conduct the field work and laboratory analysis for this thesis. Ken, thank you very much for accepting me as your student. Your suggestion and reviews as well as the detail of your corrections of this thesis were always highly appreciated, and all of these have contributed to the quality of this thesis. Alison, I have no words to say besides thank you very much for your help during my study in New Zealand. Without your help, I might not have completed this Master's degree smoothly in a country where the education system is so different from my own. More importantly, thank you very much for agreeing to be my supervisor, and for guiding me in this research. Although you are very busy with your lovely daughters and family, you always spent your time reviewing this thesis from the beginning until it was ready for submitting. I also thank Sonja Hampel and Dr Lisa Woods for their guidance in checking grammatical errors and statistical analyses through this thesis.

I also extend my thanks to Assistant Professor Dr Jessica Rothman (Hunter College of the City University of New York) who allowed me to do plant nutritional analyses in her lab in New York, and helped to analyse the rest of my plant samples. I also thank Jenny Paltan, Ketti Barateli, Caley Johnson, Santiago Cassalett and all the people who helped me during 
the time I was working in the lab. I especially thank Ishmael Deen who drove and guided me around New York City.

I also would like to thank Dr Ben Rawson and Dr Jackson Frechette for their expertise and guidance during and after my data collection. This research would not have been possible in the field without the contribution of my local assistants: Mr. Noy, Mr. Vath, Mr. Soulit, Mr. Sie and the local people from I-tube village. I thank Mr. Hieng and Mr .Poy for their help in data collection, climbing trees and lianas to get plant samples. Some local assistants rose early in the morning (4:00 am) with me and walked to the gibbon site (site A). Thanks again to Mr. Vath who was not only a local assistant, but also was the village volunteer doctor who helped me when I contracted malaria, and made sure I was taken to the hospital on time.

The project would not have been completed without the collaboration of the Forestry Administration (FA), Ministry of Agriculture, Forestry and Fisheries of the Royal Government of Cambodia, and their permission to conduct the study and export plant samples to the United States of America. In particular, I would like to thank Mr. Vong Sokserey and Mr. Pov Samanak for coordinating these permission letters. I also thank CI, in particular Mr. Seng Bunra, Mr. Cheap Chanthon, and everyone at the Veun-Sai Siem Pang Conservation Area (VSSPCA) including Mr. Nget, Mr. Pheak, Mr. Earn, Mr. Puthy, and Mr. Pisey for your care and time in protection the forests as well as the gibbons at the study site.

Lastly, I would like to thank my lovely parents and my wife, Lim Sotheary, for their love, care, and patience during the time I was studying in New Zealand. Your encouragement is an effective medicine that also encourage me to finish this study. I also thank my sisters and brothers, relatives and friends for your support and encouragement while I was away from home, and those friends who live and study in New Zealand. I also thank Wellington Khmer Association who always invited me during Khmer New Year and many special occasions, your warm welcome had reduced what we called "homesickness". I also would like to thank to Linsell Richards and Catherine Guo, who always looked after me while I was living in New Zealand, thanks for your patience and suggestions. 


\section{Table of Contents}

Abstract.

\section{Chapter 1: General introduction}

1.1 Global threat to wildlife populations.......................................................................

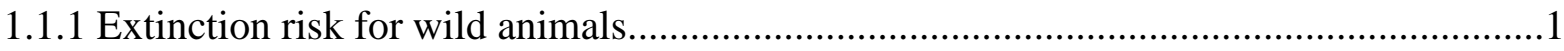

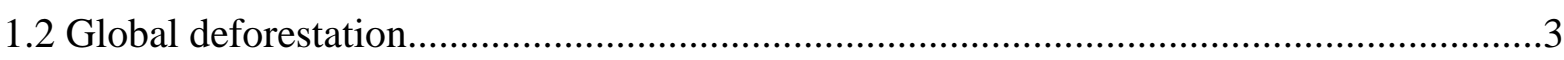

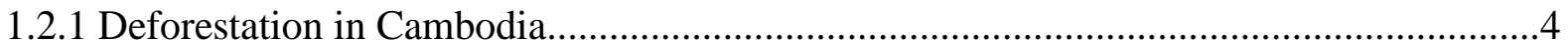

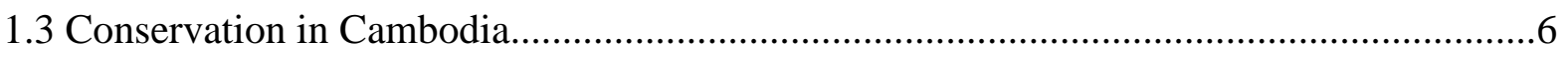

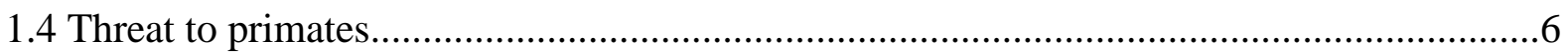

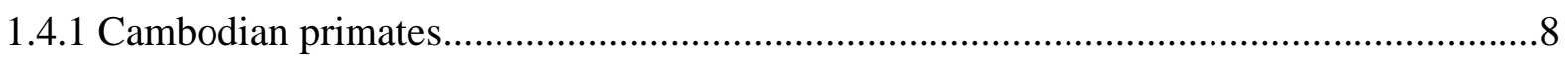

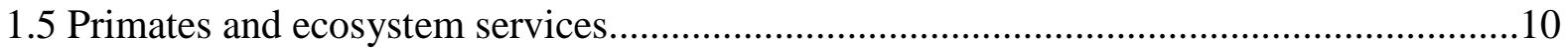

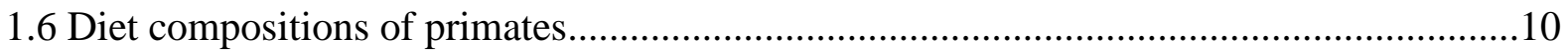

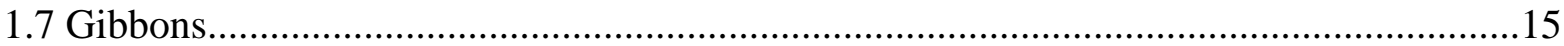

1.7.1 The genus Symphalangus, Hylobates and Hoolock .................................................16

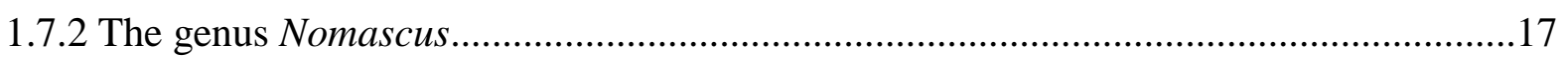

1.7.2.1 The northern yellow-cheeked crested gibbons....................................................19

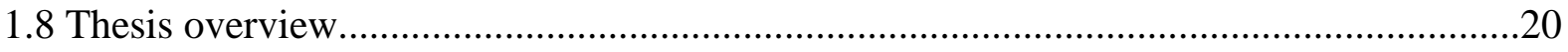




\section{Chapter 2: Behavioural ecology and food plant selection}

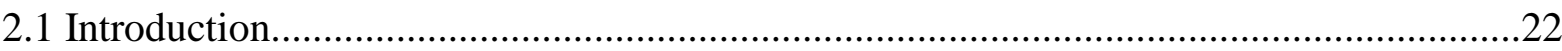

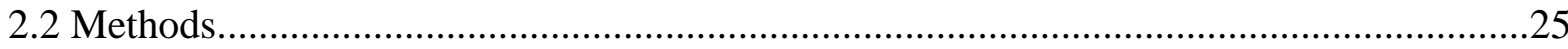

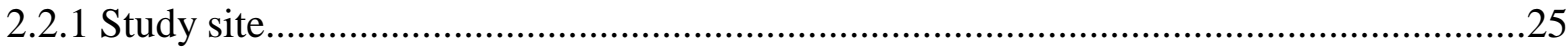

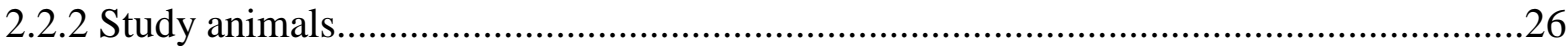

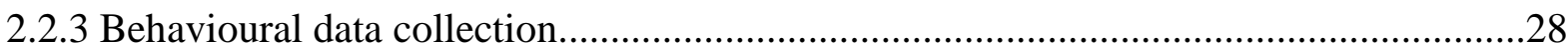

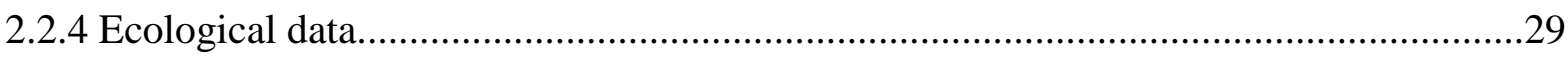

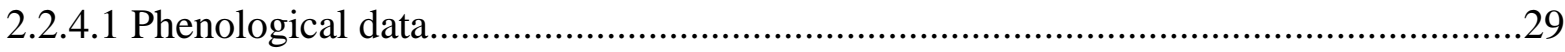

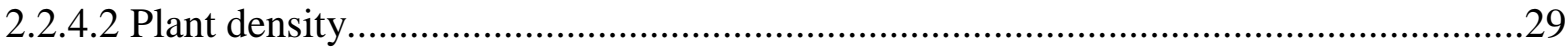

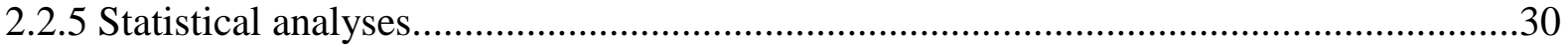

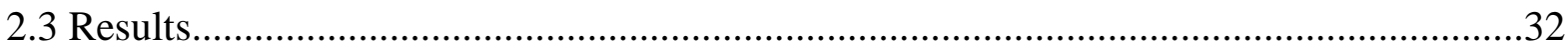

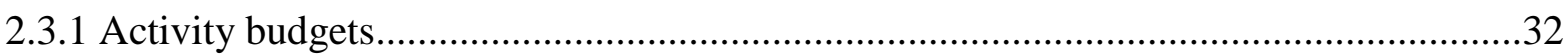

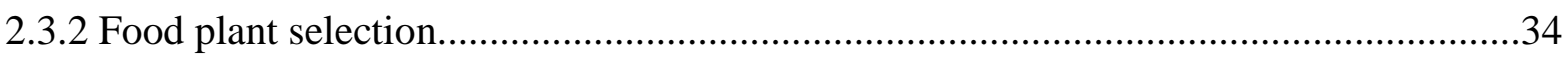

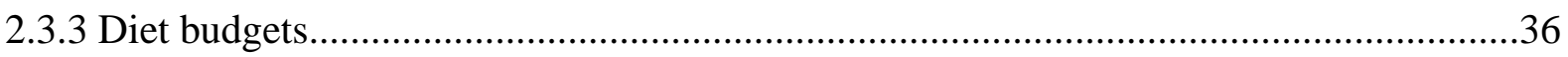

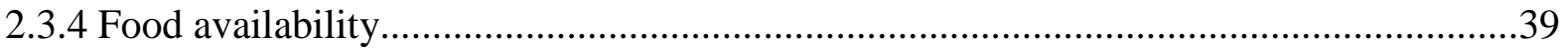

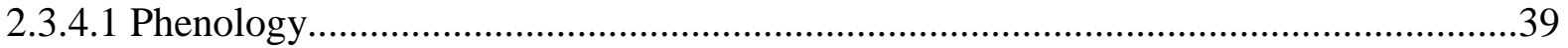

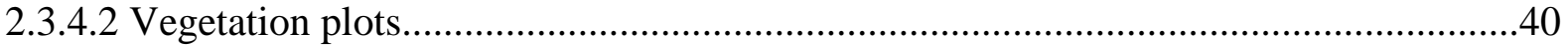

2.3.4.3 Relationship between food availability and food consumption...............................45

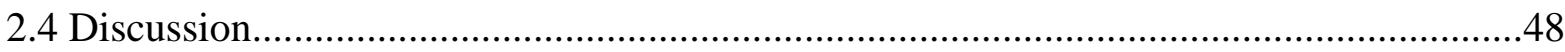

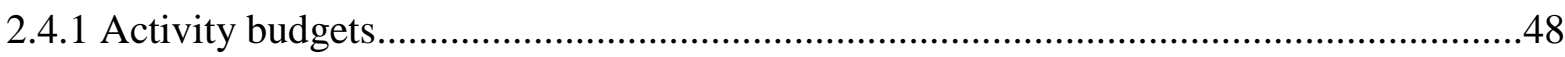

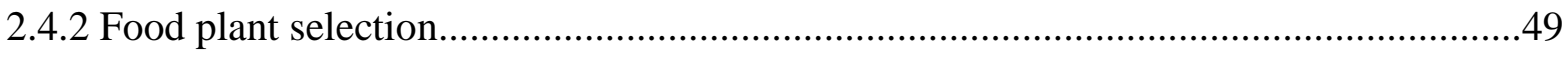

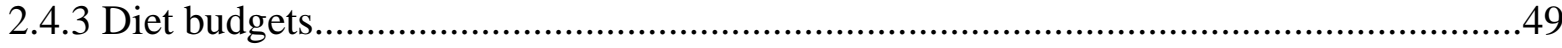

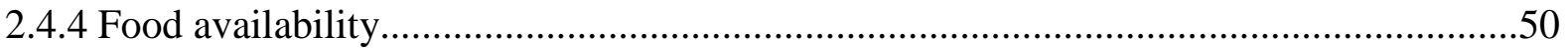

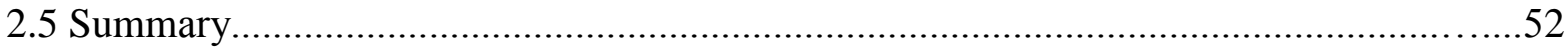

\section{Chapter 3: Nutritional composition of Nomascus annamensis diets}

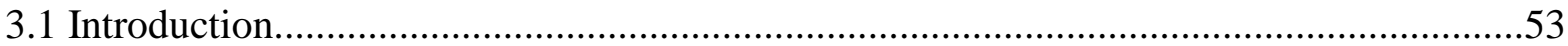

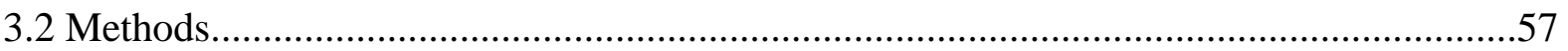

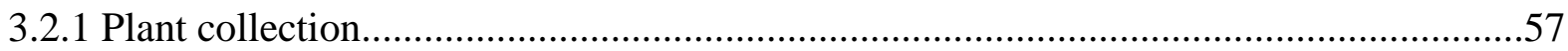

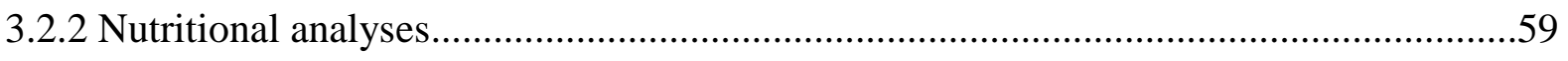

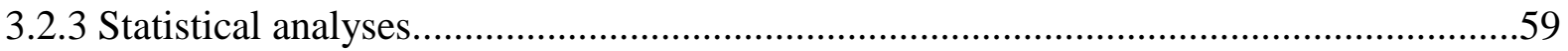

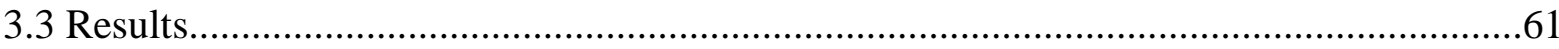




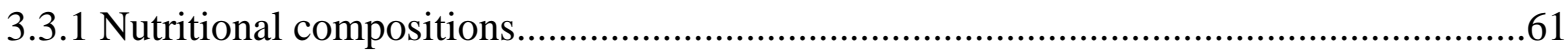

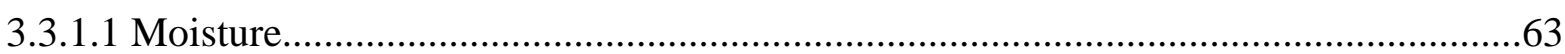

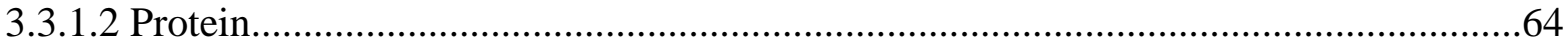

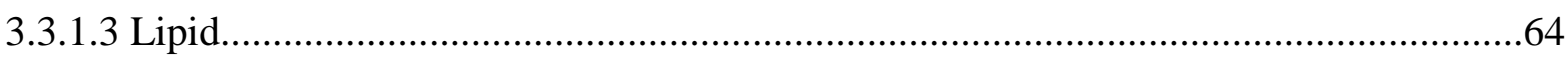

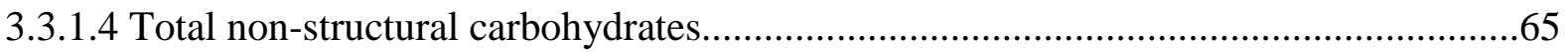

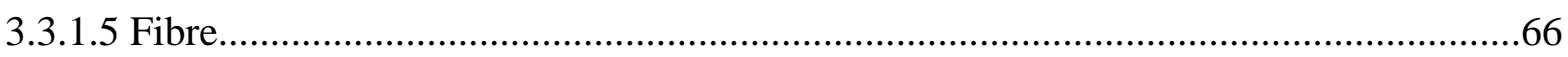

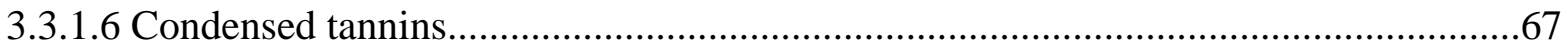

3.3.2 Balance of nutrients in foods eaten by Nomascus annamensis....................................67

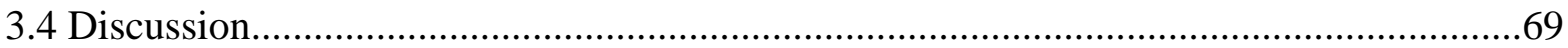

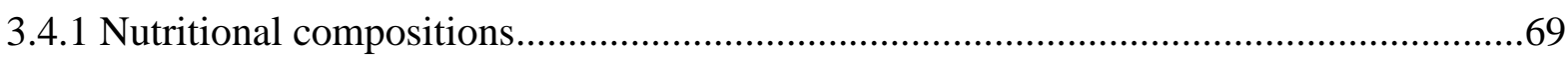

3.4.2 Balance of nutrients in foods eaten by Nomascus annamensis .....................................71

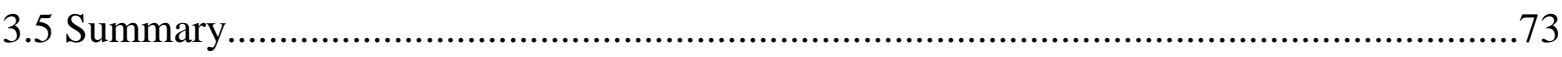

\section{Chapter 4: General conclusions and implications for conservation}

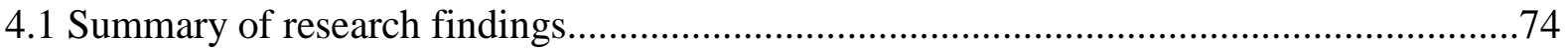

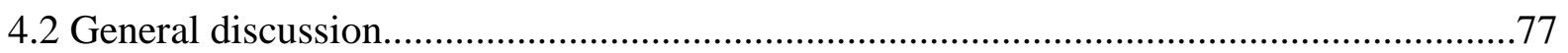

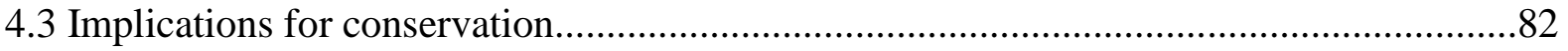

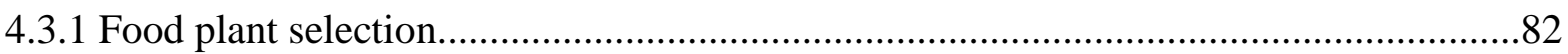

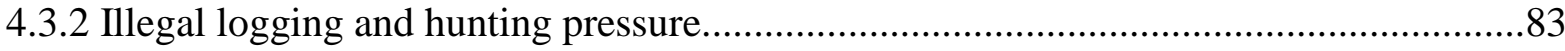

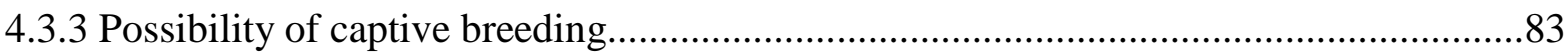

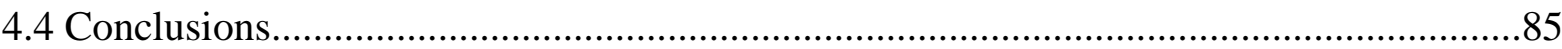

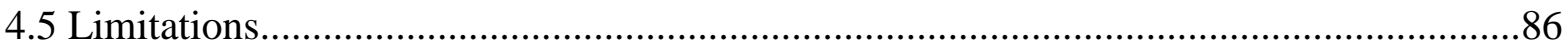

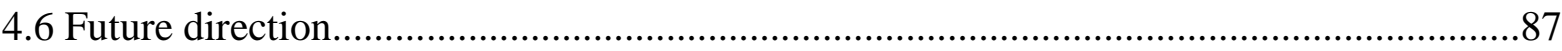

Bibliography

Appendix 


\section{List of Figures}

\section{Chapter 1: General introduction}

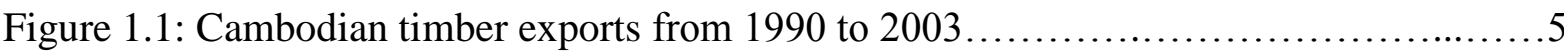

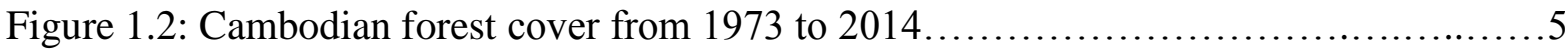

Figure 1.3: Export of wild caught and captive-breeding primates......................... 8

Figure 1.4: The geographical distributions of gibbons............................... 15

Figure 1.5: Distribution of Nomascus. spp ................................................ 18

\section{Chapter 2: Behavioural ecology and food plant selection}

Figure 2.1: The Veun Sai-Siem Pang Conservation Area, northern Cambodia.............25

Figure 2.2: Study group (group A) of Nomascus annamensis...........................27

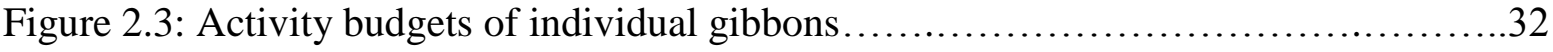

Figure 2.4: Time spent by individual gibbons consuming food items.....................34

Figure 2.5: Distribution of food plants selected by the group of Nomascus annamensis......36

Figure 2.6: Individual gibbons spent consuming food items............................37

Figure 2.7: Time spent by individual gibbons consuming foods from January to March......39

Figure 2.8: The percentage cover of fruit, flowers, young leaves and mature leaves.........40

Figure 2.9: Scatter plots showing the relationships between feeding and $\mathrm{FAI}_{(\mathrm{s})} \ldots \ldots \ldots \ldots . .47$

\section{Chapter 3: Nutritional compositions in Nomascus annamensis}

Figure 3.1: Schematic diagram of a right-angled mixture triangle (RMT) ................55

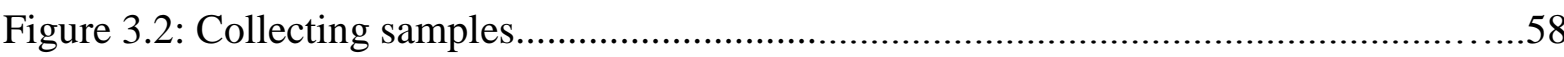

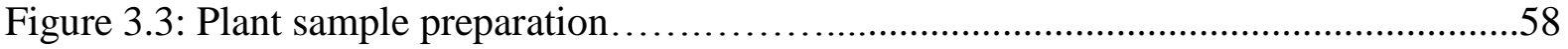

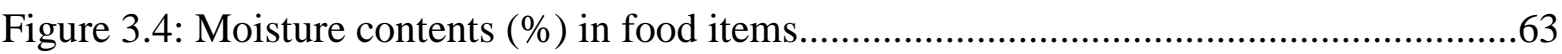

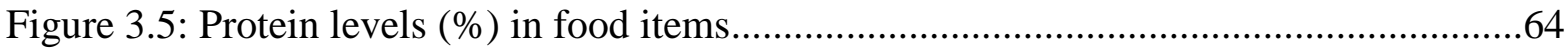

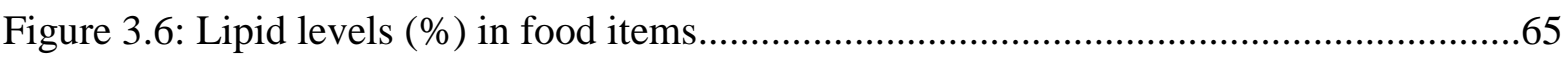

Figure 3.7: Total non-structural carbohydrates $(\%)$ in food items........................................66

Figure 3.8: Combined ADL, ADF, and NDF content (\%) in food items..............................67

Figure 3.9: The right-angled mixture triangle (RMT) ....................................................68 


\section{List of Tables}

\section{Chapter 1: General introduction}

Table 1.1: Global forest cover lost between 2000 and 2012 ................................................

Table 1.2: Volume and value of Cambodian timber exports and government revenue.............4

Table 1.3: Cambodian primates and their conservation status.............................................

\section{Chapter 2: Behavioural ecology and food plant selection}

Table 2.1: Comparing the mean percentage of time spent on each gibbon.............................32

Table 2.2: Comparing the mean percentage of time spent on each activity...........................33

Table 2.3: Plant species selected by the gibbons in group A................................................35

Table 2.4: Comparing the mean percentage of time spent feeding each food items................37

Table 2.5: .Comparing the mean percentage of time spent feeding by each gibbon.................38

Table 2.6: The relative density of plant species in the 20 vegetation plots............................42

Table 2.7: Food availability index for each of the top 10 plant species.................................46

\section{Chapter 3: Nutritional composition in Nomascus annamensis diets}

Table 3.1: Mean amount of nutrients in plant tissues..........................................................61

Table 3.2: Mean nutritional compositions from the 20 plant samples..................................62

Table 3.3: Result of Mann-Whitney $U$ tests......................................................................66 


\section{List of Abbreviations}

ADB

ADF

ADL

ASEAN

CI

CITES

DBH

FA

FAO

FAI

GPS

ICEM

ITTO

IUCN

$\mathrm{L}$

Laos PDR

NDF

NGOs

NRC

ODC

$\mathrm{P}$

PAF

PCI

RMT

SSC

TNC

UNDP

VSSPCA

WCS
Asian Development Bank

Acid Detergent Fibre

Acid Detergent Lignin

Association of Southeast Asian Nations

Conservation International

Convention on International Trade in Endangered Species

Diameter at Breast Height

Forestry Administration

Food and Agriculture Organization

Food Availability Index

Global Position System

International Centre for Environmental Management

International Tropical Timber Association

International Union for the Conservation of Nature

Lipids

Laos' People Democratic Republic

Neutral Detergent Fibre

Non-Governmental Organizations

National Research Council

Open Development Cambodia

Protein

Primate Action Fund

Primate Conservation Incorporated

Right-angled Mixture Triangle

Species Survival Commission

Total non-structural carbohydrates

United Nation Development Program

Veun Sai-Siem Pang Conservation Area

Wildlife Conservation Society 


\section{Chapter 1}

\section{General introduction}

\subsection{Global threat to wildlife populations}

\subsubsection{Extinction risks for wild animals}

Global wildlife populations have declined at an alarming rate in the last few decades (Pimm \& Raven 2000; Schipper et al. 2008). Twenty-five percent of all mammalian species whose status have been recorded are faced with extinction, while other species have already gone extinct (Brooks et al. 2002; Galbreath et al. 2006; Schipper et al. 2008). The highest declines in global wildlife populations have been from areas of high species richness such as biodiversity hotspots in Southeast Asia and Africa (Ceballos \& Ehrlich 2002; Schipper et al. 2008; Duckworth et al. 2012). Terrestrial mammals in South and Southeast Asia face a higher extinction risk compared to other regions (Schipper et al. 2008; Duckworth et al. 2012) and Ceballos and Ehrlich (2002) argue that the extinction rate of mammals in Southeast Asia is between 75 and $100 \%$. This is primarily due to anthropogenic pressures, such as deforestation, land use changes and hunting (Brook et al. 2003; Nakamura et al. 2014; Sharma et al. 2014). For example, due to anthropogenic pressure, both Pere David's deer (Elaphurus davidianus) native to the subtropics of China (Ceballos \& Ehrlich 2002) and the Vietnamese sika deer (Cervus nippon pseudaxis) (Thévenon et al. 2003) are now extinct in the wild. The extinction of these species signals serious threats to global biodiversity (Ceballos \& Ehrlich 2002). Without conservation and research efforts, and the reduction of pressure on wildlife and their habitats, other species listed as Critically Endangered or Endangered by the International Union for the Conservation of Nature (IUCN) Red List as well as species with small geographical ranges will probably go extinct in the near future (Ceballos et al. 2005; Schipper et al. 2008).

\subsubsection{Decline in wildlife populations in Cambodia}

Cambodian wildlife populations have declined significantly from 1953 to 2005, with the most rapid period of decline occurring during the 1970s (Loucks et al. 2009), and with a continued decline in the last few decades (Walston et al. 2010; O'Kelly 2013). Armed conflict and civil war were the root of these declines, particularly during the Lon Nol (19701975) and Pol Pot (1975-1979) regimes (Loucks et al. 2009; Gray et al. 2012). Hunting with 
machine guns, increasingly available after the conflicts, and internal and external wildlife trade were the main reasons for declining wildlife populations in Cambodia (Loucks et al. 2009). Large mammals including tigers (Panthera tigris), leopards (Panthera pardus), Asian elephants (Elephas maximus), wild cattle (gaur Bos gaurus, banteng Bos javanicus, kouprey Bos sauveli, and wild water buffalos Bubalus arnee), eld's deer (Rucervus eldii) and hog deer (Hyelaphus porcinus) were the most targeted species during these periods (Gray et al. 2012). These hunting pressures might have driven at least one species, the kouprey (B. sauveli), which is the Cambodian national mammal, to extinction in the past few decades (Galbreath et al. 2006; Hassanin et al. 2006). Tigers are also likely to become extinct in most regions in Cambodia, due to similar pressures (Walston et al. 2010; O'Kelly et al. 2012). Tigers were confirmed to be present in some important areas in 2001 (Lynam 2010). However, since 2005, camera trap surveys have not recorded tigers in the Virachey National Park (Walston et al. 2010), and only a single photograph has been recorded in Cardamom Mountain (Lynam 2010).

Due to poverty and the demand for basic food resources, Cambodian wildlife provides a source of protein and traditional medicine for local people who live near wildlife habitats (Hon et al. 2010; Starr et al. 2010; Starr et al. 2011; Alves et al. 2013; Clements et al. 2013a). Wild animals are being hunted not only for personal consumption, but also to sell at local markets (Hon et al. 2010; Starr et al. 2010), particularly in remote provinces. Asian small-clawed otters (Aonyx cinerea) and smooth-coated otters (Lutrogale perspicillata) are hunted in the remote areas of northern Cambodia for meat, and skins are sold for traditional medicine at local markets (Hon et al. 2010). Similarly, one of the rarest primates in Cambodia, pygmy slow lorises (Nycticebus pygmaeus) are hunted by local people for traditional medicine (Starr et al. 2011). The impacts of these activities can be seen on the IUCN Red List, which lists 45 mammals (seven Critically Endangered or Endangered), 17 reptiles (nine Critically Endangered or Endangered), and 46 birds (12 Critically Endangered or Endangered) in Cambodia (WCS 2009; Clements et al. 2010). 


\subsection{Global deforestation}

Habitat loss through deforestation and degradation are the main threats to mammals worldwide (Pimm \& Raven 2000; Brooks et al. 2002; Nakamura et al. 2014), and this particularly affects Asia, the Americas, and Africa (Schipper et al. 2008). Globally, 5.2 million hectares of tropical forests lost per year (FAO 2010). Fewer than 5\% of tropical forests are protected around the world, and even these protected forests are often illegally exploited (Chapman et al. 2000). In addition, 403 million hectares of tropical forests were recently proposed for selective logging (Putz et al. 2012). Moreover, a vast majority of felled forests are cleared and transformed into agricultural areas (Bender et al. 1998; Oates et al. 2000), including cattle farms in Brazil (Malhi et al. 2008), rubber plantations in China (Li et al. 2007), tea and coffee farms in Sri Lanka (Wickramagamage 1998), pine plantations (Cheyne et al. 2008) and palm oil plantations in Malaysia and Indonesia (Fargione et al. 2008). Globally, Brazil and Indonesia have the highest levels of forest cover loss, and Brazil has had a huge decline in forest loss in the last few years (Harris et al. 2012; Hansen et al. 2013). Table 1.1 shows the global forest cover loss between 2000 and 2012 (Hansen et al. 2013). The annual forest loss in Brazil was 40,000 km².year'-1 between 2003 and 2004, but declined to $20,000 \mathrm{~km}^{2}$.year ${ }^{-1}$ in 2010 to 2011 , while in Indonesia it was $10,000 \mathrm{~km}^{2}$.year ${ }^{-1}$ between 2003 and 2004, and increased to 20,000 km².year ${ }^{-1}$ from 2011 to 2012 (Hansen et al. 2013).

Table 1.1: Global forest cover lost between 2000 and 2012.

\begin{tabular}{llr}
\hline Regions & Forest types & Forest cover loss $\mathbf{K m}^{\mathbf{2}} \mathbf{. \mathbf { e a r }} \mathbf{- 1}$ \\
\hline Eurasia & Tropical rainforests & 1393 \\
Africa & Tropical moist deciduous forests & 536 \\
South America & Dry tropical forests & 459 \\
Eurasia & Tropical moist deciduous forests & 221 \\
Eurasia & Tropical dry forests & 123 \\
\hline
\end{tabular}

Source: Hansen et al. (2013) 


\subsubsection{Deforestation in Cambodia}

The natural forest resources in Cambodia have been exploited since the late 1980s, starting at the end of the civil war in 1979 (Le Billon 2002). Forest cover in Cambodia was estimated at approximately 60\% in 1991 and 55.7\% in 1995, as recorded by the Food and Agriculture Organization (FAO)/United Nation Development Program (UNDP) (Lang 2001; Le Billon 2002). Logging was particularly high during the 1980s and 1990s, with large quantities of timber exported to neighbouring countries including Thailand and Vietnam (Le Billon 2000, 2002). Table 1.2 shows the volume of timber export (thousands $\mathrm{m}^{3}$ ) and the estimate value (millions \$USD) of those timbers in the 1990s (Le Billon 2000). The Cambodian timber export increased dramatically from 1990 to 1994, and gradually declined from 1995 until 2003 (Figure 1.1) (Le Billon 2000; ITTO 2003; Barney 2005). Consequently, Cambodia has lost approximately $29 \%$ of its forest cover, which is the highest rate of deforestation in mainland Southeast Asia (Cambodia, Laos and Vietnam) (Avtar et al. 2012), with an annual deforestation rate of $0.7 \%$ between 1973 and 2003 (Sasaki 2006) and 1.2\% per year between 2005 and 2010 (Lambrick et al. 2014). Figure 1.2 demonstrates the latest updated trends in Cambodian forest cover between 1973 and 2014 (ODC 2014a).

Table 1.2: Volume (thousand $\mathrm{m}^{3}$ ) and value (millions USD) of Cambodian timber exports and government revenue (millions USD) from these exports between 1990 and 1998

\begin{tabular}{lrrrrrrrrr}
\hline & $\mathbf{1 9 9 0}$ & $\mathbf{1 9 9 1}$ & $\mathbf{1 9 9 2}$ & $\mathbf{1 9 9 3}$ & $\mathbf{1 9 9 4}$ & $\mathbf{1 9 9 5}$ & $\mathbf{1 9 9 6}$ & $\mathbf{1 9 9 7}$ & $\mathbf{1 9 9 8}$ \\
\hline $\begin{array}{l}\text { Volume of timber exports } \\
\text { (thousand } \mathrm{m}^{3} \text { ) }\end{array}$ & 515 & 848 & 1,393 & 1,360 & 1,495 & 1,691 & 992 & 1,045 & 1,090 \\
$\begin{array}{l}\text { Estimated value (US\$ } \\
\text { million) }\end{array}$ & 77 & 170 & 348 & 340 & 374 & 423 & 248 & 188 & 218 \\
$\begin{array}{l}\text { Forestry government } \\
\text { revenue (US\$ million) }\end{array}$ & n.a.* & n.a.* & 1.5 & 3.3 & 39 & 27 & 11 & 12 & 5 \\
\hline
\end{tabular}

Original reports from the Royal Government of Cambodia, Thai Forestry Department, and Global Witness. n.a. ${ }^{*}=$ no available data.

Source: Le Billon (2000) 


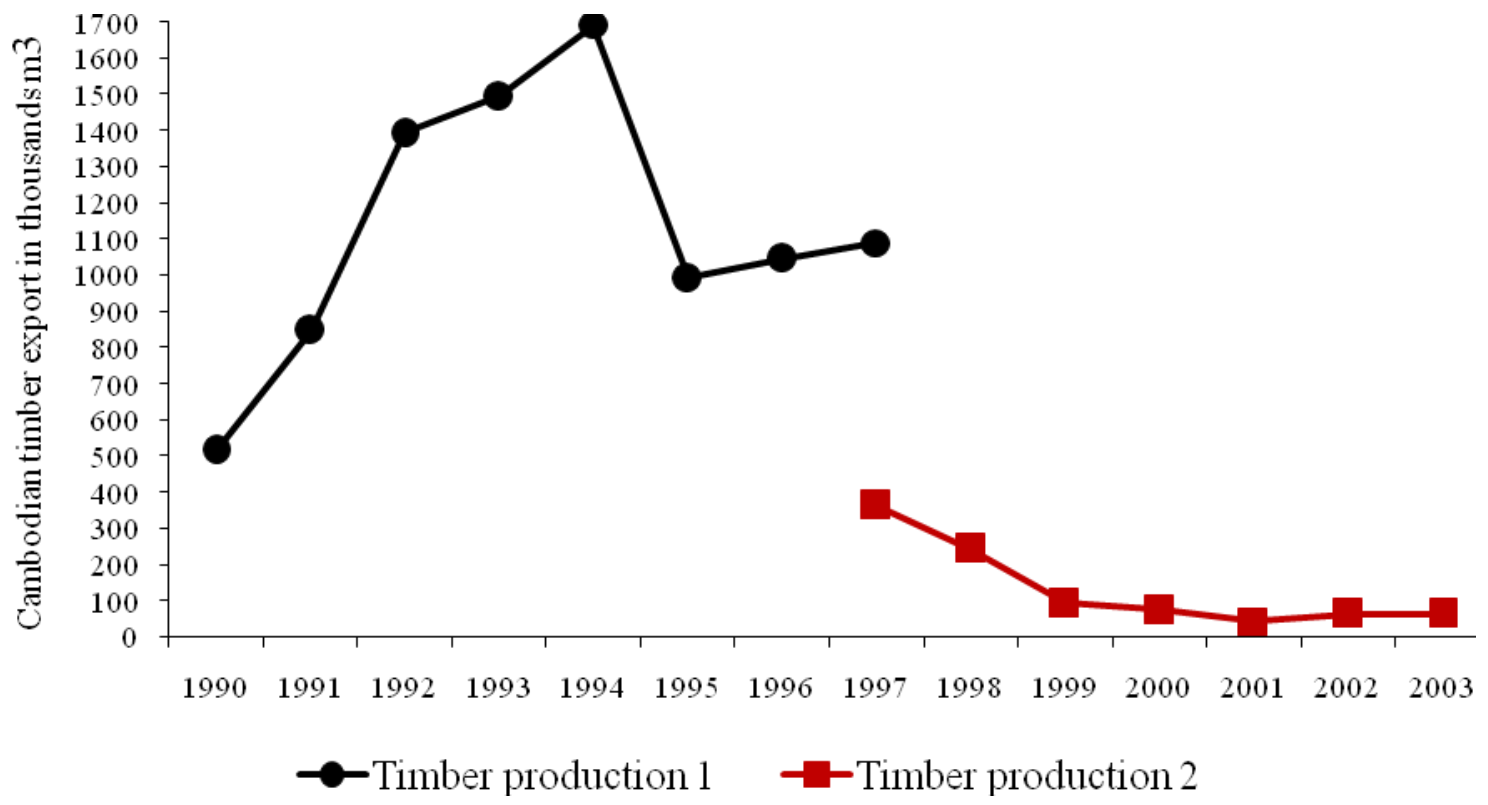

Figure 1.1: Cambodian timber exports (thousands $\mathrm{m}^{3}$ ) from 1990 to 2003. Timber production 1 (circle symbols) indicates the volume of timber export from 1990 to 1997 [original data from the Royal Government of Cambodia, Thai Forestry Department, and Global Witness, cited in Le Billon (2000)]. Timber production 2 (square symbols) indicates the total export timbers including logs, tropical sawnwood, veneer, and plywood from 1997 until 2003 [original source data from ITTO (2003) cited in Barney (2005)].

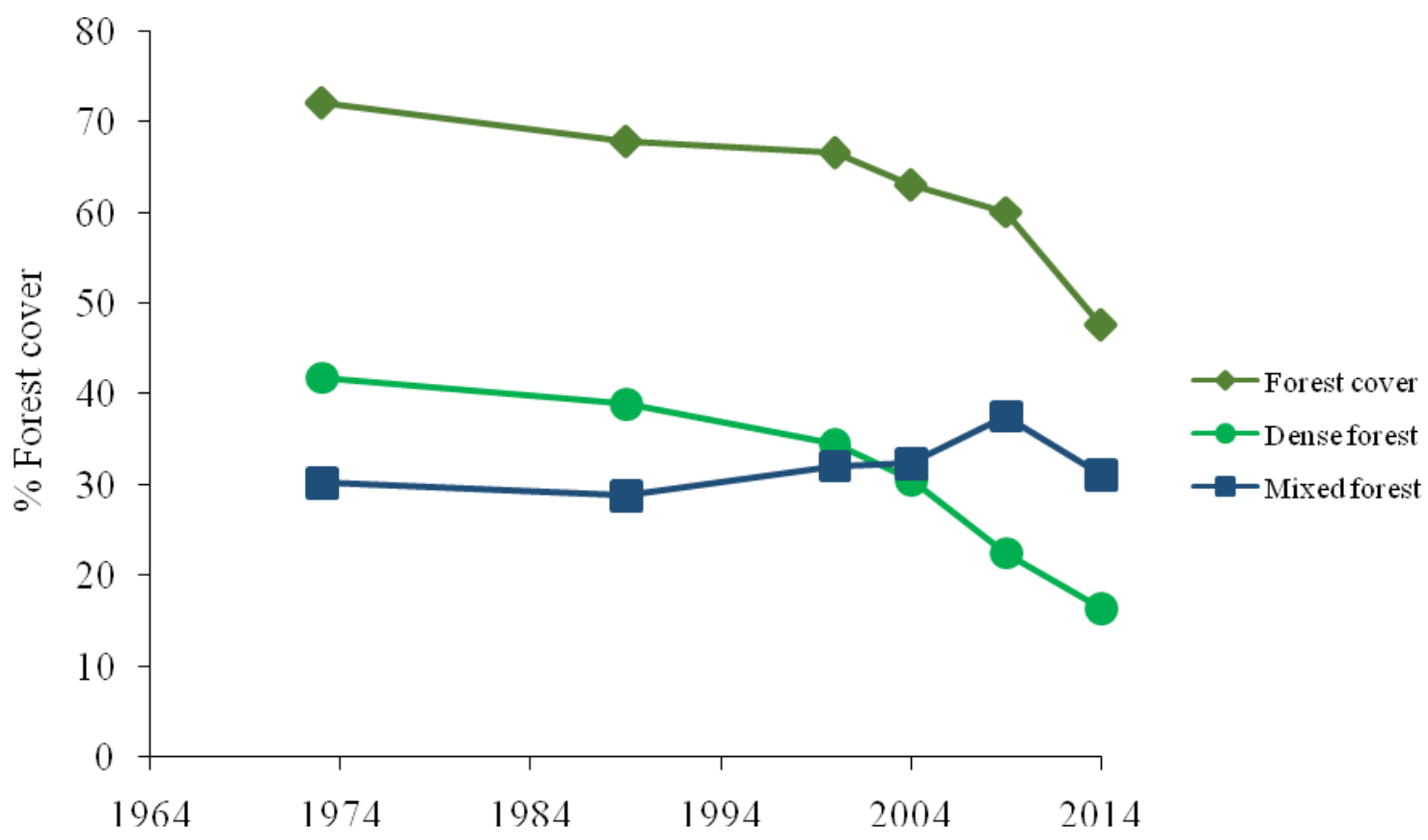

Figure 1.2: Cambodian Forest Cover from 1973 to 2014. Forest cover (diamond symbols) is the total tree canopy, and a combination of dense and mixed forest. Dense forests (circle symbols) are defined as evergreen and semi-evergreen forests. Mixed forests (square symbols) mainly refer to mixed deciduous forests, but these also include regrowth forests, mangrove forests, inundated forests, stunted forests, bamboo, and forest plantations, which include rubbers, acacia, eucalyptus or other tree crops.

Source: Open Development Cambodia (2014a). 


\subsection{Conservation in Cambodia}

Since wildlife populations, including primates, have declined significantly, the Cambodian government has cooperated with international non-governmental organizations (NGOs) to protect and increase species-specific research. Because of this strong commitment, Cambodia has developed at least 23 protected areas including seven national parks, 10 wildlife sanctuaries, three landscape protected areas, and three multi-purpose areas (ICEM 2003; ODC 2014b), which is about $18 \%$ of the total land area (ODC 2014b). Such initiatives are needed to increase wildlife conservation in Cambodia. Cambodia has enacted many programs designed to protect key species. For example, the Cambodian national bird, the giant ibis (Thaumatibis gigantea), declined to less than 250 individuals in 1997 (Keo et al. 2009), but due to conservation efforts (Clements et al. 2010; Clements et al. 2013b), its populationis now estimated at 345 individuals (BirdLife-International 2015).

Despite these conservation efforts, the challenges of conservation in Cambodia remain undeniable. The two main factors that lead to challenges to conservation in Cambodia are poverty (ADB 2014) and poor law enforcement (Clements et al. 2010). Cambodia is one of the poorest nations in Association of Southeast Asian Nations (ASEAN), with the vast majority of people rely on natural resources for their livelihoods, and most living under the poverty line (ADB 2014), leading to illegal activities occurring even in protected areas. Shifting cultivation is still being practiced, which adds to conservation concerns as it disrupts forest habitats (Baird \& Dearden 2003). Although Cambodia has forestry, fisheries, and environmental laws, there are still weaknesses in putting this legislation into practice (De Lopez 2002; McKenney et al. 2004; Ratner 2006; Clements et al. 2010). There is not enough financial support to ensure adequate protection of natural resources by law enforcement teams, necessitating funding for biodiversity conservation by international NGOs (Milne \& Niesten 2009; Clements et al. 2010; Clements et al. 2013b). However, the cost of setting up these areas and ensuring their protection is such that it is likely to be only a short-term solution, and external financial contributions are unlikely to be feasible long-term (Clements et al. 2010).

\subsection{Threats to primates}

Non-human primates are distributed mainly in Asia, Africa, and South and Central America (Mittermeier 1986; Cowlishaw \& Dunbar 2000). For all the reasons described above, along with global warming, primate populations in all regions have significantly 
declined in the last few decades (Wiederholt \& Post 2010). Habitat destruction has received particular attention, as removing trees from inside the range of primates can negatively affect population size and reduce the overall food supply (Chapman \& Onderdonk 1998). For example, the population size of the olive baboon (Papio anubis) and common chimpanzee (Pan troglodytes) in Uganda were lower in logged forested areas than non-logged forested areas (Plumptre \& Reynolds 1994). Similarly, the population size of the Ugandan red colobus monkey (Piliocolobus tephrosceles) decreased as forest fragmentation increased (Chapman et al. 2006), which may be, in part, due to selective logging (Chapman et al. 2000). Food scarcity caused by logging forces primates to consume food of lower nutritional value, leading to the overall consumption of lower quality diets, which in turn can lower milk production by lactating females (Altmann et al. 1977). The reduced food supply that results from logging may also modify the ecological behaviour and activity budgets of primates (Johns 1986). For example, when food tree density is low, primates must spend comparatively more time travelling or searching for food, and less time resting (Hardus et al. 2012). This was seen following El Niño events that reduced food availability, in a population of spider monkeys (Ateles. spp) and woolly monkeys (Lagothrix. spp), both of which declined as a result (Wiederholt \& Post 2010). It is clear that reduction of food availability affects lifespans of primates (Mattison et al. 2012) and reproductive success (Thompson \& Wrangham 2008). Due to the pressures described above, the Miss Waldron's red colobus monkey (Piliocolobus badius) is probably extinct in Ghana (Oates et al. 2000).

Primate populations have also declined significantly due to wildlife trade for biomedical experimentation (Maldonado et al. 2009; Shepherd 2010). During the late 1960s and early 1970s, demand for primates for research by the biomedical and pharmaceutical industries was particularly high, and India and Peru exported approximately 20,000 to 50,000 primates per annum (Nijman et al. 2011). Similarly, between 2007 and 2008, 4,000 night- monkeys (Aotus. $s p$ ) were illegally traded in Brazil, Colombia and Peru for use in biomedical laboratories (Maldonado et al. 2009). The United States of America is the highest importer of primates for biomedical research (26\%), followed by Japan (14\%) and China (13\%) (Nijman et al. 2011). These exports involved both legal and illegal trade across primate habitat countries (Shepherd 2010). Figure 1.3 shows the export of primates for biomedical research and other purposes, involving both captive and wild-caught animals (Nijman et al. 2011). Indonesia is a member of the Convention on International Trade in Endangered Species (CITES), but the international trade includes not only the legally 
exported long-tailed macaque (Macaca fascicularis), but also the highly endangered primates listed in CITES Appendix I, which need the highest level of protection (Shepherd 2010). These include orang-utans (Pongo. spp) and gibbons (Hylobates. spp), the majority of which were caught in the wild (Nijman \& Asia 2009; Shepherd 2010). The export of these wildcaptured, highly endangered individuals would have been particularly damaging for local

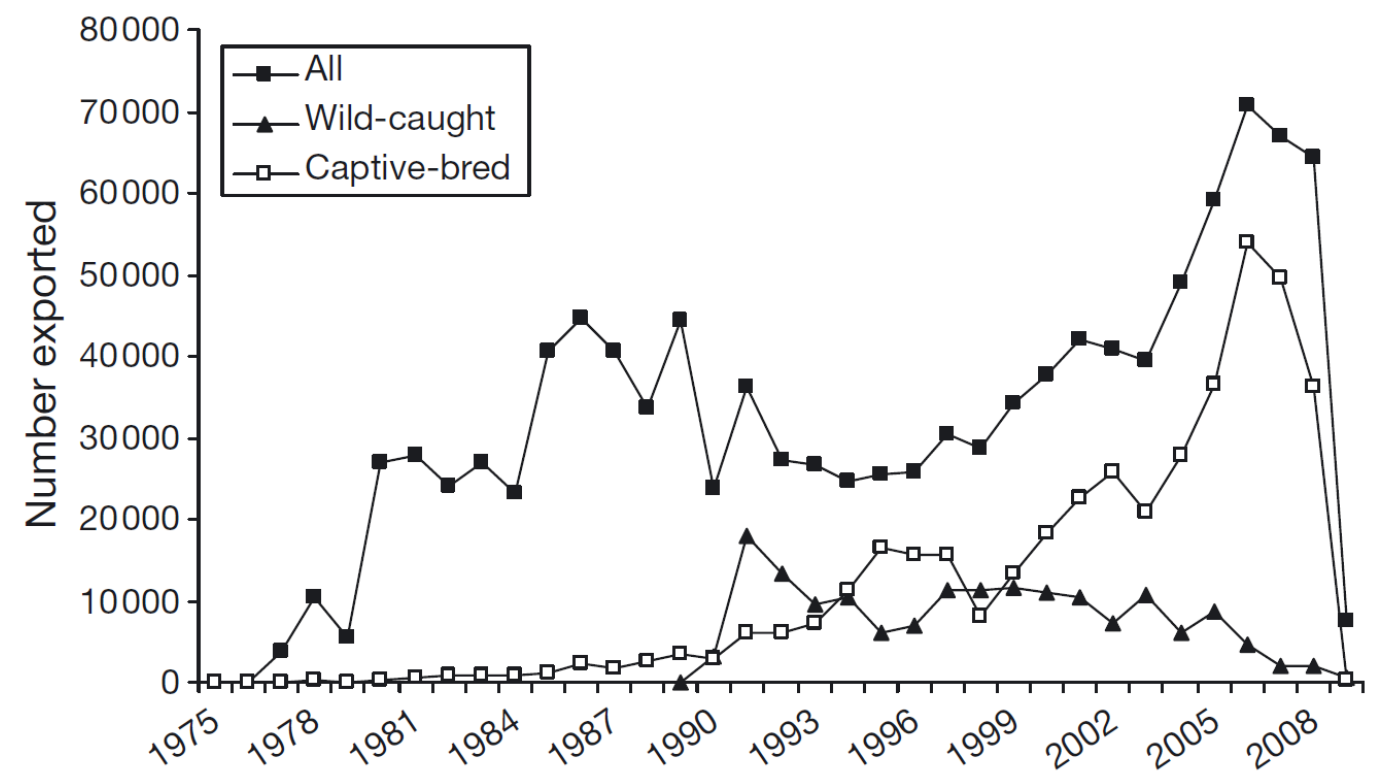

Figure 1.3: Export of wild caught and captive-breeding primates as reported by exporting parties to the CITES secretariat. The total export amounts to 1.1 million live individuals. In many years, the total number of animals actually exported is higher than the numbers wild caught or captive animals that were report as being exported to CITES.

Source: Nijman et al. (2011).

\subsubsection{Cambodian primates}

Knowledge of the distribution, abundance and status of Cambodian wildlife is limited (Coudrat et al. 2011), although at least 12 species of primates are found across the country (Table 1.3) (Rawson \& Roos 2008; Nadler et al. 2010). However, like other primates around the world, Cambodian primates are now under threat (Nadler et al. 2010) (Table 1.3). Illegal logging, deforestation, agricultural development, hunting, illegal trade, mine development, and poor law enforcement all contribute to declining primate populations (Coudrat et al. 2011; Starr et al. 2011). Cambodian Primates are among the most poorly studied wild animals in Cambodia, with only a few species having been studied, such as the genera Nomascus (Frechette 2014; Nelson 2014; Frechette et al. in prep), Nycticebus, and Hylobates (Konrad 2004; Traeholt et al. 2006; Rawson \& Roos 2008; Coudrat et al. 2011; Starr et al. 2011). 
Table 1.3: Cambodian primates and their conservation status

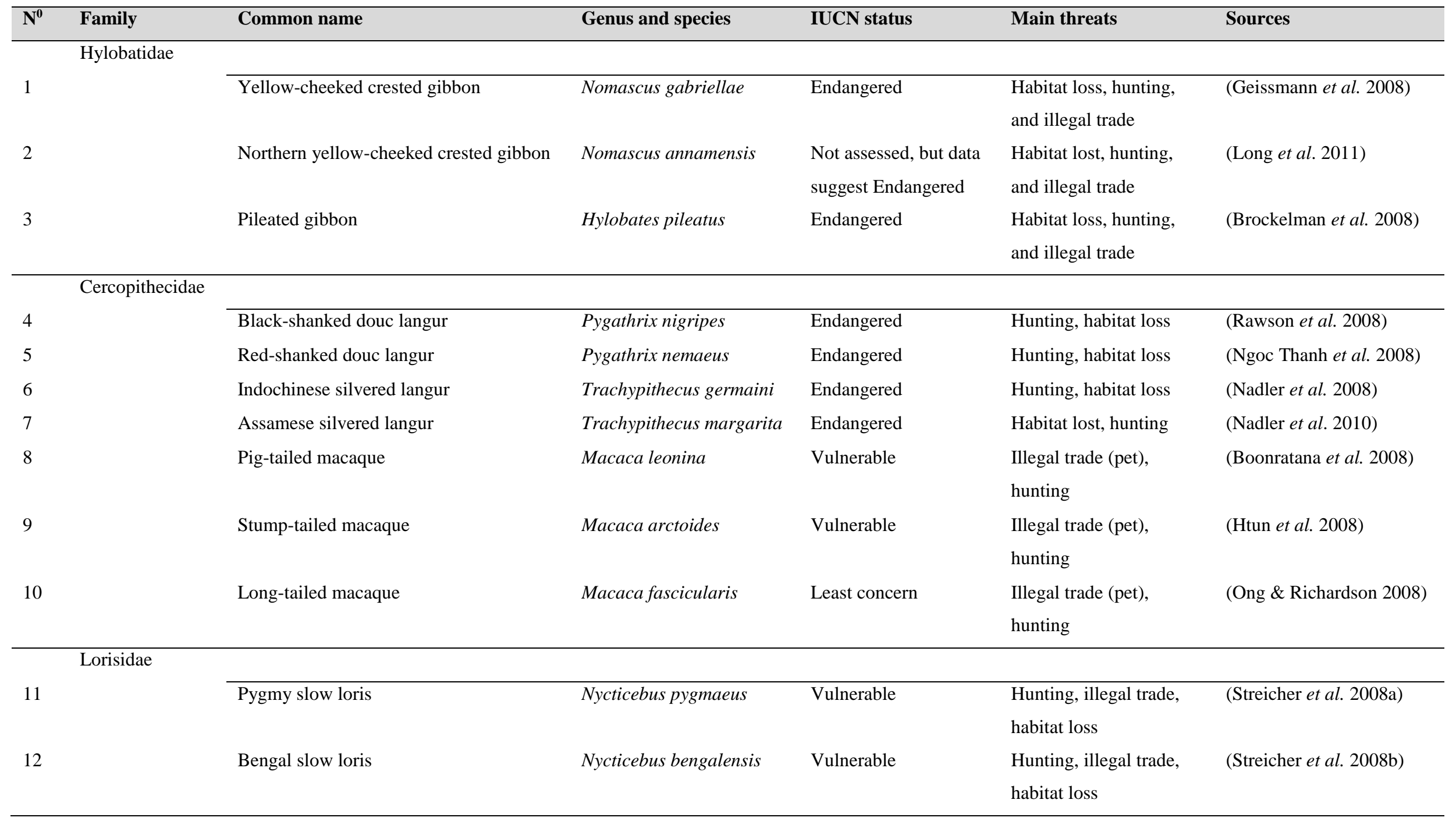




\subsection{Primates and ecosystem services}

Fruit eating primates play very important roles in maintaining ecosystems in tropical forests through seed dispersal and seed germination (Garber 1986; Chapman 1989; Stevenson 2000; Frechette 2014). They consume large quantities of fruit, and defecate or spit most of the seeds in areas where those seeds can survive, avoiding seed predators and distancing seeds from the shade and competition of their parent (Chapman \& Onderdonk 1998). For example, more than $98 \%$ of chimpanzee dung (Pan troglodytes) in Kibale National Park, Uganda contained seeds, sometimes larger than $2 \mathrm{~mm}$, suggesting they could disperse approximately 350 large seeds per km.day ${ }^{-1}$ (Wrangham et al. 1994). There is a strong relationship between primate seed dispersal and plant distributions (Russo et al. 2005). Some plant species produce large seeds, which would be difficult to disperse by other agents beside primates (Russo et al. 2005; Nuñez-Iturri \& Howe 2007). For example, the large seed of Virola. spp in Panama can only be dispersed by spider monkeys (Ateles. spp) (Russo et al. 2005). A study on seed dispersal by gibbons in northern Cambodia revealed that northern yellow-cheeked crested gibbons (Nomascus annamensis) play an important role in long distance seed dispersal (Frechette 2014). Germination of seeds dispersed by the genus Alouatta and Lagothrix is higher than seed germination without primate assistance, indicating that primate digestion improves seed germination (Stevenson et al. 2002). Consequently, any decline in primate populations may reduce seed dispersal that may in turn alter forest compositions (Nuñez-Iturri \& Howe 2007).

\subsection{Diet composition of primates}

The dietary and nutritional requirements of non-human primates are very complex and variable among species (Chivers 1998; Strier 2007; Felton et al. 2009a). Primates are found in a diverse range of tropical forest habitats, their diets being primarily tree exudates (gummivory) (Yepez et al. 2005), leaves (folivory) (Davies et al. 1988; Kool 1992; Smith et al. 2013; Hanya \& Bernard 2015), fruit (frugivory) (Whitington \& Treesucon 1991; Laska et al. 2000; Fan et al. 2009) and/or insects (insectivory) (Goodall 1986; Fan et al. 2009). Different regions inhabited by primates provide particular food sources, and primates have evolved specific morphologies to exploit this diverse range of food sources (Strier 2007). Frugivores have a comparatively long small intestines, folivores have a 
shorter intestine and some have a sacculated stomachs, gummivores have a proportionally long caecum, and insectivores have a short gut (Strier 2007).

Fruit or leaves alone are unlikely to meet all nutritional requirements of an animal (Chivers 1998) and very few species of plants, with some exceptions (e.g. figs), bear fruit all year round and instead produce fruit, leaves and flowers in a distinct seasonal pattern, with availability varying by season (Hamilton \& Galdikas 1994; Wendeln et al. 2000; Hanya \& Bernard 2012). Fruit production may also vary widely over time: for example, between 1998 and 2000, fruit production in Borneo was very low, with only a few tree species fruiting each month, and only one peak season in September 1998 (Te Wong et al. 2005). In contrast, fruit production in the same location was high between 2004 and 2008, with more than $98 \%$ of trees bearing fruit (Hanya \& Bernard 2012). Primates need to be able to shift their diets from fruit to young leaves, mature leaves, flowers, or insects from season to season or year to year to meet their nutritional requirements when favoured food sources become scarce (Fan et al. 2009; Behie \& Pavelka 2012a; Hanya \& Bernard 2012).

Different parts of plants (fruit, leaves, flowers and seeds) contain a variety of nutrients, both favoured (proteins, carbohydrates, and lipids) and less favoured (fibres, tannins and alkaloids) by primates (Hamilton \& Galdikas 1994; Rothman et al. 2006; Behie \& Pavelka 2012a; Hanya \& Bernard 2012, 2015). Consequently, every potential food item is a medley of favourable and unfavourable compounds, in varying combinations (Barton \& Whiten 1994). It has been suggested that during a peak season of food availability, primates should favour high quality diets (easily digested, rich in protein and/or sugar) over poor quality diets that are difficult to digest (Strier 2007; Rothman et al. 2011). The Colobinaeselect food with higher protein and lower fibre content (Simmen et al. 2013), which leads to them ingesting mainly young leaves and seeds (Davies et al. 1988; Kool 1992) while avoiding mature leaves, which are more difficult to digest as they contain more fibre and secondary compounds (Davies et al. 1988). On the other hand, black howler monkeys (Alouatta pigra) select mature leaves over young leaves due to their high concentration of sugar, however, this selection may be due to the fact that this was found following a hurricane, which wiped out the majority of preferred food sources (Behie \& Pavelka 2012a). This suggests that primate food preferences are highly dependent on species, environment (Smith et al. 2013) and morphology (Strier 2007). 
Our knowledge of what drives food selection in wild and captive primates is limited to relatively few studies (Milton 1979; Rothman et al. 2006; Rothman et al. 2008b; Felton et al. 2009a; Felton et al. 2009c; Rothman et al. 2011; Behie \& Pavelka 2012b; Simmen et al. 2013), yet this information is necessary to understand how best to preserve key food resources for wild populations and to ensure the best long-term care is given to captive populations and rehabilitation programs. For example, several studies show that figs play a very important role in maintaining food balance for many species of gibbons and monkeys (Wendeln et al. 2000; Serio-Silva et al. 2002; Felton et al. 2009c). Figs are a common food source in spider monkey habitats, as some species bear fruit for 8 to 9 months of the year (Felton et al. 2008). But, as the nutritional content of figs differs between species, they may provide different benefits (Serio-Silva et al. 2002). Some species contain high levels of inorganic materials (Felton et al. 2009c), while others are a rich source of calcium (Duhan et al. 1992; Behie \& Pavelka 2012a), or have high levels of protein and low levels of fibre (Wendeln et al. 2000). This information is necessary to inform conservation programs to increase the protection of fig species. Although fig species are not commercially valuable, they play a crucial role in food security for primates and other wildlife (Duhan et al. 1992).

Many studies on food selection by primates suggest that nutritional composition of plant tissues (mainly protein) influences food selection (Davies et al. 1988; Kool 1992; Koenig et al. 1997; Behie \& Pavelka 2012a; Smith et al. 2013), and food selection in turn influences health (Givens \& Shingfield 2004), lifespan (Fernandes et al. 1976; Grandison et al. 2009; Trepanowski et al. 2011), social relationships, fitness, and reproduction (Koenig et al. 1997; Harris et al. 2010). For example, consuming low-protein diets can potentially increase the mortality rate of juvenile primates (Altmann et al. 1977), and caloric restrictions can have a negative effect on a lifespan of the normally long-lived rhesus monkeys (Macaca mulatta) (Mattison et al. 2012). In cases where food is available and of high quality, there is a positive correlation in chimpanzees between birth rates and the availability and quality of food sources (Thompson \& Wrangham 2008). Savannah baboons (Papio cynocephalus) shows a positive correlation between food selection and population growth rates (Altmann \& Alberts 2005). This suggests that both the quality and availability of food sources (Strier 2007; Felton et al. 2009b; Felton et al. 2009c) may influence food selection by primates (McConkey et al. 2002; Serio-Silva et al. 2002). 
The consumption of a variety of food items by primate species may be representative of their attempt to target specific nutritional goals to survive (Felton et al. 2009a). Felton et al. (2009a) and others (Schoener 1971; Freeland \& Janzen 1974; Milton 1979; Mattson 1980; Raubenheimer \& Simpson 2004) propose five main models for primate nutritional goals: (i) maximising nitrogen (protein), (ii) maximising energy, (iii) limiting fibre content, (iv) avoiding secondary compounds and (v) balancing nutritional values.

Protein is one of the most important nutrients for primates (Milton 1979; Rothman et al. 2008b; Felton et al. 2009a; Rothman et al. 2011; Hanya \& Bernard 2015), even though it may be consumed in low quantities by some primate species (Felton et al. 2009b). This is because a lack of nitrogen in the form of amino acids can affect health, reproduction, growth, and survival rates (Mattson 1980; Yiming 2006; Felton et al. 2009a; Felton et al. 2009b). As a consequence, some primate species need to maintain a minimum daily intake of protein, while allowing the relative proportion of other nutritional components in their diet to fluctuate, indicating that they select items based on protein contents that can help them reach their minimum requirement (Felton et al. 2009b).

The idea of energy maximization originated from optimal foraging theory (MacArthur \& Pianka 1966). Animals may maximize energy intake per unit time feeding (Cowles et al. 1988; Belovsky 1997; Felton et al. 2009a). This hypothesis is usually tested in herbivores, mainly grazers (Belovsky 1984, 1997). Although it is rarely tested in primates due to the complexity of their diets (Milton 1979), some primate species may also maximise energy by allowing other nutrients to vary while keeping energy intake at a constant level (Strier 1992).

Dietary fibre generally refers to plant cell walls made up of cellulose, hemicellulose and pectin (Milton 1999). Most animals do not produce enzymes to breakdown cell walls to produce beneficial fatty acids and microbial proteins (Milton 1999; Felton et al. 2009a), which is why most primate species tend to minimize food items with high level of fibre contents in their diets (Davies et al. 1988; Barton \& Whiten 1994; Yiming 2006; Hanya \& Bernard 2015). An exception to this are the Colobines, who have a variety of anatomical specialisations to break down fibres into high quality fatty acids that can be used for energy (Dasilva 1992; Wasserman \& Chapman 2003).

Plants have evolved secondary compounds to defend against a wide range of herbivores (Biere et al. 2004; Rosenthal \& Berenbaum 2012). As a consequence, most 
herbivores, including primates, tend to avoid food items with high concentrations of these compounds (Mckey et al. 1981; Glander 1982; Barton \& Whiten 1994). This is due to the fact that most of secondary compounds are bitter-tasting and even toxic when consumed by animals (Acamovic \& Brooker 2005). Although flowers (nectar and pollen), fruit, young leaves and mature leaves sometimes contain low to moderate concentrations of secondary metabolites including alkaloids, glycosides, tannins, and phenolics, some primate species have been observed feeding on these food items (Glander 1982; Barton \& Whiten 1994). Some primates include secondary compounds such as particular tannins and alkaloids in their diet, which may be a form of self-medication, although this idea needs further investigation (Barton \& Whiten 1994; Carrai et al. 2003).

Balancing nutritional intake is crucial to animal survival (Raubenheimer \& Simpson 1997). As a result, animals (including primates) need to consume a variety of food sources to keep this balance (Whiten et al. 1991; Behie \& Pavelka 2012b). Fruit and young leaves provide highly concentrated sources of simple sugar and protein, respectively (Felton et al. 2009c; Rothman et al. 2011; Hanya \& Bernard 2015), but some primate species may also need to consume seeds to balance lipid concentrations (Whiten et al. 1991; Hanya \& Bernard 2015). This need to balance nutrients often results in animals switching between food sources at different times of year to meet their nutritional targets, to ensure continued survival and reproduction (Felton et al. 2009c; Rothman et al. 2011; Behie \& Pavelka 2012a).

\subsection{Gibbons}

Gibbons (Family: Hylobatidae) are the smallest apes, and are distributed in tropical forests in Asia (Mootnick \& Fan 2011; Carbone et al. 2014; Veeramah et al. 2015). Their habitats are evergreen and semi-evergreen forests (Gray et al. 2010; Fan et al. 2011). They belong to the superfamily Hominoidea along with humans and the great apes (Carbone et al. 2014). There are 17 species of gibbons from four genera: Symphalangus, Hylobates, Hoolock, and Nomascus (Chatterjee 2009; Carbone et al. 2014; Veeramah et al. 2015), and are distributed across south China to Southeast Asia (Figure 1.4). 


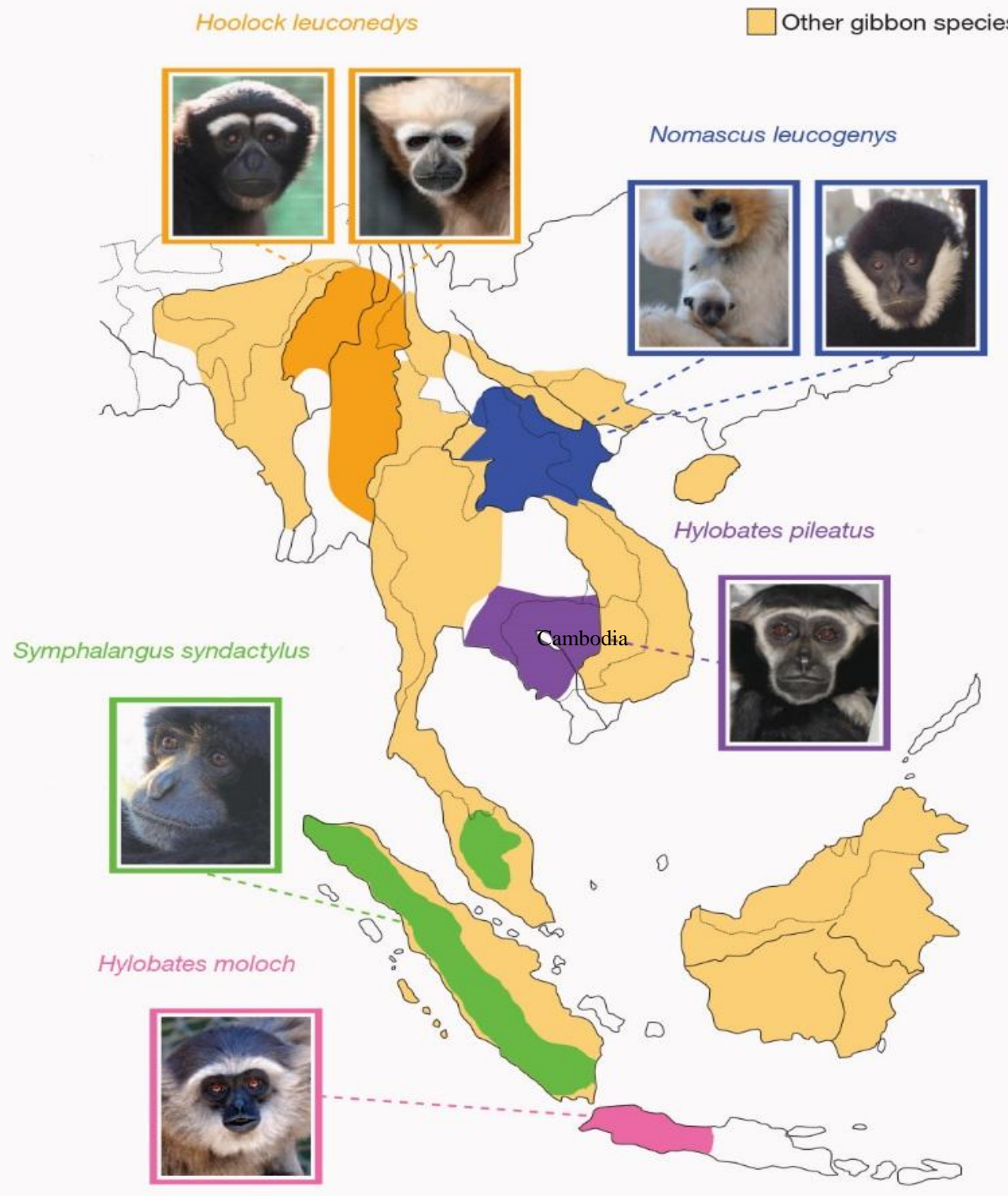

Figure 1.4: The geographical distributions of gibbons in south China to Southeast Asia. Cambodia has three species of gibbons from the genera Nomascus and Hylobates.

Source: Modified from Carboneet al. (2014). 
Gibbon populations have declined significantly over the past three to four decades (Cheyne et al. 2008) and most species are listed as Critically Endangered or Endangered by the IUCN Red List (Gray et al. 2010) and CITES Appendix I (Geissmann 2007) due to the threats discussed above (Geissmann 2007; Cheyne et al. 2008; Phoonjampa \& Brockelman 2008; Peng-Fei et al. 2009; Gray et al. 2010; Malone et al. 2014). For example, the total population of western hoolock gibbons (Hoolock hoolock) in India has declined by approximately $90 \%$ due to human disturbance, including habitat destruction, land use changes, and hunting (Kumar et al. 2009). The majority of threats to the yellowchecked crested gibbon ( N. gabriellae) and pileated gibbon (H. pileatus) in Cambodia are habitat fragmentation, while hunting for meat and the pet trade are a secondary concern (Nadler et al. 2010; Rawson 2010b). Gibbons use trees not only for food sources, but also for calling (Nelson 2014), travelling and sleeping (Fan \& Jiang 2008). Logging inside gibbons' habitat disturbs all of these behaviours (Peng-Fei et al. 2009). Sleeping trees selected by gibbons are generally tall, thick trees (Fan \& Jiang 2008), and these are normally the target of loggers (Nelson 2014). This suggests that knowledge of tree and habitats selection by gibbons is urgently needed in order to allow governments or conservation agencies to protect these resources (Fan et al. 2011; Nelson 2014).

Fruit makes up the vast majority of gibbon diets, followed by young leaves, flowers, and seeds (McConkey et al. 2002; Fan et al. 2009; Fan et al. 2013), and occasionally insects (McConkey et al. 2002; Fan et al. 2013; Borah et al. 2014). Gibbons mainly select fruit that is yellow-orange in colour with small seeds and soft, juicy pulp (McConkey et al. 2002), but during times when fruit is scarce or unavailable, gibbons tend to shift their diet to leaves and flowers (Fan et al. 2013). The western black crested gibbons (Nomascus concolor) in Southern Yunnan have diets that consist of more than $70 \%$ fruit, while leaves only make up less than $20 \%$ of their diet (Fan et al. 2009). Similarly, most Hylobates consumes more fruit than leaves, flowers and insects (McConkey et al. 2002). Gibbons also spend time searching for insects (mainly cicadas, lepidopterans, and miscellaneous larvae) and the occasional bird chick as an alternative source of protein (Fan et al. 2013; Borah et al. 2014). 


\subsubsection{The genera Symphalangus, Hylobates, and Hoolock}

The genus Symphalangus has only one species, siamang (Symphalangus syndactylus). However, due to the similarity between the morphology of S. syndactylus and H. klossii, particularly their shared black colouration, both species were initially thought to be the same genus (Geissmann 2002). The genus Symphalangus is distributed in peninsular Malaysia and Sumatra, Indonesia (O'Brien et al. 2004). S. syndactylus has the largest body weight (10-12 kg) compared to other gibbons, with both males and females reaching a similar size (Gittins \& Raemaekers 1980). Moreover, the siamang produces a loud group call, and has a smaller home range than other gibbons (Chivers \& MacKinnon 1977). Most female gibbons take care of an infant and are frugivorous, while male siamangs take responsibility for carrying offspring (Lappan 2008) and are folivorous (Elder 2009).

The genus Hylobates consists of seven species including the agile gibbon (H. agilis), kloss's gibbon (H. klossii), white-handed gibbon (H. lar), Javan gibbon $(H$. moloch), Bornean gibbon (H. muelleri), white-bearded gibbon (H. albibarbis) and the pileated gibbon (H. pileatus) (Strier 2007; Chatterjee 2009). This genus is distributed across south China to Cambodia, Thailand, Malaysia, and Indonesia (Ma et al. 1988; Geissmann 2007). The Hylobates are similar to other gibbons being frugivorous and monogamous (Chatterjee 2009; Elder 2009).

The genus Hoolock consists of two species, the western hoolock gibbon (H. hoolock) and the eastern hoolock gibbon (H. leuconedys) (Strier 2007). This genus is distributed in India, Myanmar and Yunnan province in China (Chetry et al. 2008), and is monogamous and frugivorous (Zhang et al. 2008). When young both males and females are black, but upon reaching maturity at age of five or six, females turn yellowish grey in colour (Islam \& Feeroz 1992).

\subsubsection{The genus Nomascus}

The genus Nomascus was initially thought to only contain one species, $N$. concolor (Monda et al. 2007). However, seven species have since been identified: the western black crested gibbon ( $N$. concolor), eastern black crested gibbon ( $N$. nasutus), yellow-cheeked crested gibbon ( $N$. gabriellae), white-cheeked crested gibbons ( $N$. siki), hainan gibbon ( $N$. hainanus), northern white-cheeked crested gibbons ( $N$. leucogenys), and northern yellow-cheeked crested gibbons (N. annamensis) (Geissmann 2002; Thinh et al. 2010; 
Mootnick \& Fan 2011). There are four sub species of N. concolor: N. c. concolor, N. c. lu, N. c. furvogaster, and N. c. jingdongensis (Mootnick \& Fan 2011). The crested gibbons (Nomascus. spp) have shorter and denser hair than other gibbons, and are distributed across Cambodia, South China, Loas and Vietnam (Figure 1.5) (Mootnick \& Fan 2011). The crested gibbons calls are slightly different from other species, in that mated pairs sing together, while non-mated individuals produce solo songs (Konrad \& Geissmann 2006). They typically live in small family groups consisting of an adult male, an adult female, and any offspring (Fan et al. 2010). All crested gibbons are listed as Endangered or Critically Endangered by IUCN Red List (Gray et al. 2010; IUCN 2015), except N. annamensis, which has not yet been assessed, but it is thought to be Endangered (Vinh et al. 2010).

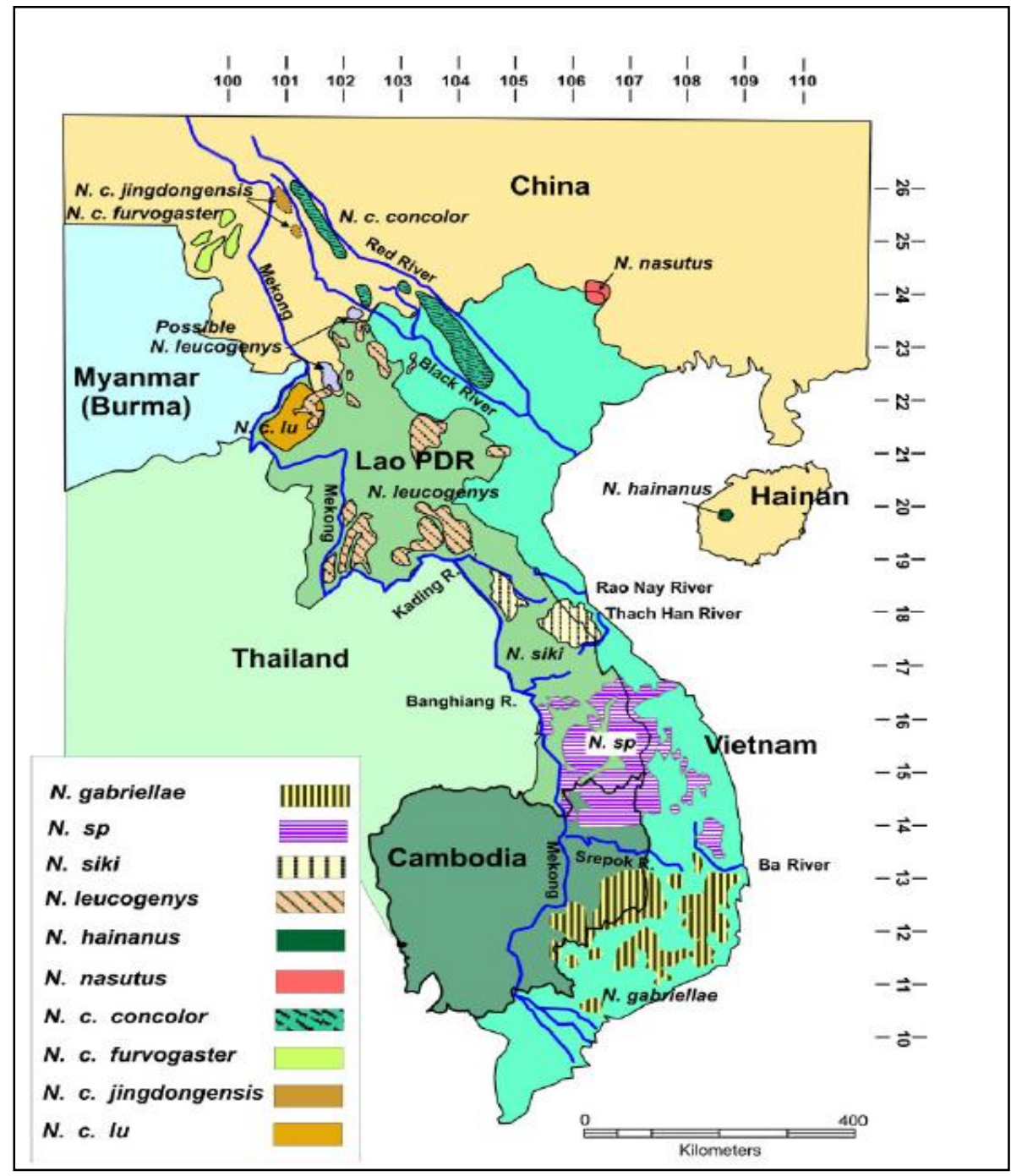

Figure 1.5: Distribution of Nomascus. spp in South China and Indochina regions.

This map was created by M. Swartz and N. Ambar from IUCN Red List range maps, and surveys conducted by Pan P-F in South China.

Source: Mootnick \& Pan (2011). 


\subsubsection{The northern yellow-cheeked crested gibbon (Nomascus annamensis)}

The northern yellow-cheeked crested gibbon is a newly-recognized species (Thinh et al. 2010). This species was thought to be $N$. gabriellae due the similarity of physical appearance; males of both species are black in colour with a yellowish-gold cheek patch and females are fully yellow in colour (Thinh et al. 2010; Vinh et al. 2010). However, northern yellow-cheeked crested gibbon is now recognised as a separate species distributed in northern Cambodia, Laos and Vietnam (Thinh et al. 2010), and most populations are declining due to habitat destruction and hunting (Long et al. 2011). Of these three countries, the largest population occurs in Cambodia (Rawson 2010a). They inhabits evergreen and semi-evergreen forests (Vinh et al. 2010), and plays a crucial role in seed dispersal (Frechette 2014).

Fruit is the main diet for $N$. annamensis, followed by young leaves, flowers and occasionally mature leaves and insects (Frechette et al. in prep). This species spends a considerable period of time resting, and the peak time for travelling and feeding occurs between 7 am and $10 \mathrm{am}$, and entering sleeping trees generally occurs around 4pm, in the late afternoon (Frechette et al. in prep). Gibbons, including crested gibbons, differ from other apes in that they do not build nests, but they use trees as their sleeping sites (Fan \& Jiang 2008). A recent survey on sleeping tree selection by $N$. annamensis reveals that individuals select 11 species of trees to sleep in, with the most used species being Dipterocarpus costatus, Shorea thorelii, and Anisoptera costata (Nelson 2014). Of these, the family Dipterocarpaceae has economic value and is targeted for both timbers and resin by humans (Kao \& Iida 2006), which puts this gibbon species in conflict with humans for this resource. These illustrating points of conflict and risk between humans and gibbons, is important for conservation measures, and will indicate those species that need protecting.

As with other endangered gibbon species, data about resource use and food selection are needed in order to create a successful long-term conservation plan for $N$. annamensis. Although it is known that $N$. annamensis selects predominately fruit, followed by young leaves and flowers, for their food sources (Frechette et al. in prep), knowledge is lacking on why they choose those specific plant species, what the main food plant species for this gibbon are, and what nutritional values these food sources have. The lack of this information creates difficulties for conservation planning. By increasing our understanding of food selection in $N$. annamensis, we will know which plant species are key resources and which main nutritional compositions are needed by this species. These 
results will inform conservationists of those plant species that provide high quality food sources for $N$. annamensis in the wild, and the optimum nutritional composition of food that should be given to animals in captivity. Moreover, as the habitats of this species have been destroyed, these data will help the regeneration of habitats by growing specific key resources for this gibbon species. This will save time, money, and have a long-term positive effect on primate conservation. Providing this type of data for conservation efforts has helped the white-handed gibbon $(H$. lar), which became locally extinct in Phuket Island, Thailand in the 1980s (Osterberg et al. 2014). Eight families (30 individuals) of this species were reintroduced to the island in 2002 (Osterberg et al. 2015). When reintroducing a species to a habitat, knowledge of food availability and resource use by that species is key to supporting the new population (Tutin et al. 2001; IUCN/SSC 2013). In the case of the $H$. lar reintroduction, 10 years after the reintroduction just over half (16 individuals, 53\%) of the original recolonizing population have survived on the island (Osterberg et al. 2015). Although many factors influence the failure and success of reintroduced populations, the availability of food sources could be one of the main factors (Taylor et al. 2005; Detedcc \& Courchamp 2007). Therefore to best inform conservation of $N$. annamensis, data on food selection and resource availability are greatly needed.

\subsection{Thesis overview}

This is the first study on food selection by gibbons in Cambodia and to my knowledge is also one of the first on gibbons in general. This study was conducted at Veun Sai-Siem Pang Conservation Area (VSSPCA), northern Cambodia. This area has high biodiversity, with 60 species of mammals, 130 birds, and 60 reptiles (CI unpublished data). At least six species of primates were found in this area including red-shanked douc langurs (Pygathrix nemaeus), silvered langurs (Trachypithecus germaini) (Rawson \& Bach 2011), long-tailed macaque (Macaca fascicularis), pig-tailed macaque (Macaca leonina), pygmy slow lorises (Nycticebus pygmaeus) (Hill 2011), and the study species, northern yellow-cheeked crested gibbon (N. annamensis) (Thinh et al. 2010). As a result of these findings, the status of this area should be updated to "protected forest" in the near future. However, the area is currently under threat due to the impact of logging, hunting and pressure of over-use of natural resources inside the VSSPCA (pers. observation). By focusing on food selection in $N$. annamensis, we will gain a better understanding of the main diet of this species and what the key food resources and preferences are. As the 
species is also threatened by illegal logging and habitat destruction, this information will increase and improve conservation by identifying important food resources that need to be protected. These data will also benefit captive rehabilitation and breeding programs and wildlife rescue centres, and help determine food types that have similar nutritional value to wild food sources for this species.

This thesis is organized into four chapters. As the two data chapters are formatted for publication, there is some repetition of material.

Chapter 1: General introduction

Chapter 2: Feeding behaviour and food plant selection

This chapter will address three basic questions. (1) Are there any differences in activity budgets among gibbons in the same group? (2) What are the main diets and key food species for the study group, and are there any differences in the group? (3) Does food availability influence food selection by this group?

Chapter 3: Nutritional values of food selected by N. annamensis.

This chapter focuses on the nutritional values of selected plant tissues and how nutritional values influence food selection. This chapter aims to answer two basic questions. (1) What are nutritional compositions of food items consumed by $N$. annamensis? This will focus on key food items consumed by $N$. annamensis, and the respective proportions of proteins, lipids, fibres, and some condensed tannins in each food item. Knowing the nutritional profile of food items can help identify why some species are eaten and others are not, and will identify important food species. (2) Using the "rightangled mixture triangle model" (Raubenheimer et al. 2015), what food items and nutritional compositions are targeted by $N$. annamensis? Answers to these questions will reveal for the first time the nutritional values of food items consumed by this group of $N$. annamensis. This chapter will also identify those plant species that should be protected, and which nutritional compositions should be given to the gibbons in captivity.

Chapter 4: General discussion. This chapter brings together the results of Chapters 2 and 3 , discusses the results of food selection by $N$. annamensis with regard to other studies on food selection by primates, compares these findings with other relevant studies, and provides suggestions and recommendations for future research. 


\section{Chapter 2}

\section{Behavioural ecology and food plant selection}

\subsection{Introduction}

Tropical regions exist extremely high plant diversity, with a large number of plant species in turn supporting a high density and diversity of other species (Gentry 1988; Clinebell II et al. 1995; Novotny et al. 2006). This is due to the diversity of food resources that these plant species provide all year round, including fruits, seeds, leaves, and flowers (Terborgh 1986). Between them, tropical plant species provide a diverse range of potential food sources, but not all plant species are selected by animals, with herbivores often selecting only specific plant species as food sources (Westoby 1974; Oates et al. 1980). This food selection by herbivores is guided in part by plant defence mechanisms (Palo \& Robbins 1991). Some plant species have evolved both chemical and physical defences, which can render some plant species unsuitable for consumption by some herbivores (Wittstock et al. 2004; Rosenthal \& Berenbaum 2012). To avoid foraging activity by herbivores, some plant species have evolved leaves with low nutritional quality and/or an increased range of unpalatable secondary compounds (Ryan 1989; Speiser \& RowellRahier 1991; Coley \& Barone 1996), while others have developed thorns and trichomes to defend against numerous herbivores (Feeny 1976). Consequently, herbivores need to adapt to those defences, and select particular species for their food sources; some species even develop mutualisms with their hosts (Westoby 1974; Price et al. 1980; Wittstock et al. 2004).

The diets of the majority of primates include fruit, young leaves, flowers, seeds, and mature leaves (Cowles et al. 1988; Laska et al. 2000; Behie \& Pavelka 2012a; Smith et al. 2013). However, primate diets differ dramatically among species (Davies et al. 1988; Strier 2007; Smith et al. 2013) depending on digestive physiology, habitat quality, nutritional needs and food availability. For example, both the Hylobatidae (gibbons) and Hominidae families (including orang-utans, chimpanzees, and gorillas) prefer fruit (Goodall 1986; McConkey et al. 2002; Boesch et al. 2006; Fan et al. 2009), whereas the specialised anatomy of the Colobinae allow them to ingest mainly young leaves (Hanya \& Bernard 2012; Smith et al. 2013), and due to environmental pressure, some species even select mature leaves over other plant tissues (Behie \& Pavelka 2012a). Generally, primates 
are highly selective feeders, choosing not only specific plant tissues, but also specific plant species as their food sources (Davies et al. 1988; Fan et al. 2013; Smith et al. 2013). For example, a population of red leaf monkey (Presbytis rubicunda) in Malaysia predominantly feeds on rarer species, and the five dominant tree species in its home range, which make up over $80 \%$ of the total forest composition, comprise less than $7 \%$ of its diet (Davies et al. 1988). These illustrate that reasons for food selection in primates vary both among and within species, with some selecting food sources based on the availability of plant species, while others deliberately seek out comparatively rare plant species (Davies et al. 1988; Serio-Silva et al. 2002; Smith et al. 2013).

The northern yellow-cheeked crested gibbon (Nomascus annamensis) is a recently discovered species (Thinh et al. 2010) that is distributed across Cambodia, Laos, and Vietnam (Thinh et al. 2010; Long et al. 2011). There is a lack of data about this species, and furthermore, populations of $N$. annamensis have declined significantly due to habitat destruction and hunting (Rawson 2010b; Long et al. 2011). N. annamensisis similar to other gibbons in that fruit forms the majority of its diet, followed by young leaves, flowers, mature leaves, and insects (Frechette et al. in prep). Although Frechette et al. (in prep) report on diet composition of this gibbon species, plant species selected are not identified and the relationship between food selection and food availability is also not mentioned.

An understanding of food resource use by threatened species like $N$. annamensisis needed in order to create a long-term conservation plan. For example, knowledge of feeding tree selection contributed to the success of re-introductions of white-handed gibbons (Hylobates lar) into their natural habitats in Thailand (Osterberg et al. 2014). Frugivores like $N$. annamensisare especially under threat. It is due to the fact that the seasonal fluctuation of fruit production (Te Wong et al. 2005) and the removal of feeding trees inside gibbon territories can affect their populations (Johns 1986; Nijman 2001; Buckley et al. 2006). Scarcity of food could then in turn affect reproduction success and lifespan, having implications for population health (Thompson \& Wrangham 2008; Mattison et al. 2012). This study focuses on food plant selection by N. annamensis, as well as addressing whether food availability influences food selection. With these objectives, three research questions have arisen. (1) Are there any differences in the activity budgets of gibbons in the same group? (2) What are the main plant parts and key food species selected by this gibbon group, and are there any differences among group members? (3) 
Does food availability influence food selection by group members? The answers to these questions will show how many plant species are selected by this gibbon species, and whether they prefer rare or common plant species in their territory. This information can then be used to inform governmental agencies which plant species that need protection to assist the conservation of $N$. annamensis, not only in Cambodia, but also in all areas inhabited by this endangered gibbon. This information also can be used for gibbon rehabilitation programs, especially in areas where captive breeding of $N$. annamensis may be re-introduced. 


\subsection{Methods}

\subsubsection{Study site}

The study was conducted at Veun Sai-Siem Pang Conservation Area (VSSPCA; $14^{\circ} 01^{\prime} \mathrm{N}, 106^{\circ} 44^{\prime} \mathrm{E}$ ), a 55,000-ha site with an elevation between $100-400 \mathrm{~m}$ in Ratanakiri and Stung Treng provinces in northern Cambodia. This area is composed of evergreen and semi-evergreen forest, deciduous forest and grassland (Figure 2.1) (Geissler et al. 2012), and is located within the Indo-Burma biodiversity hotspot (Myers et al. 2000). The rainy season begins in May and lasts until October, while the dry season occurs from November to April. In the dry season, the mean minimum temperature is $15.5^{\circ} \mathrm{C}$ and the mean maximum temperature is $25.5^{\circ} \mathrm{C}$, while in the rainy season the mean minimum temperature is $18^{\circ} \mathrm{C}$ and the mean maximum temperature is $23.5^{\circ} \mathrm{C}$ (Nelson 2014). The mean monthly rainfall in the rainy season is $189 \mathrm{~mm}$ (King et al. in review).

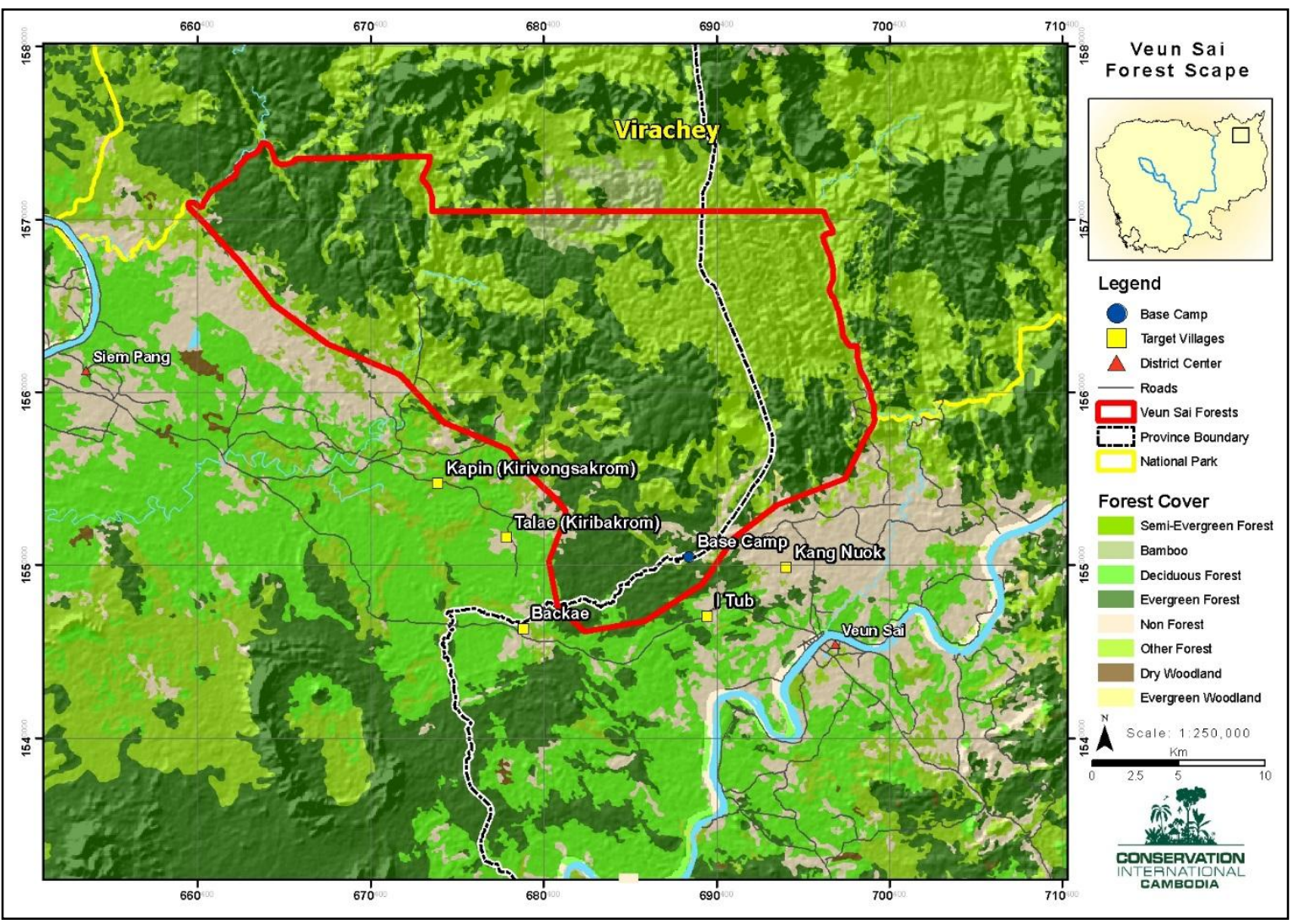

Figure 2.1: The Veun Sai-Siem Pang Conservation Area (VSSPCA), northern Cambodia $\left(14^{\circ} 01^{\prime}\right.$ $\mathrm{N}, 106^{\circ} 44^{\prime} \mathrm{E}$ ), outlined in red. Currently, this site is protected by the cooperation between Forestry Administration and Conservation International.

Image credit: Ben Rawson/Conservation International 


\subsubsection{Study Animals}

A recent population survey of $N$. annamensis at VSSPCA revealed approximately 450 groups at the site (Rawson unpublished data). Due to a lack of data on this gibbon species, the first long-term study on its behaviour was established on one group of gibbons (called group A) in 2007 involving local, national and international researchers (Frechette et al. in prep). Currently, group A consists of five members: an adult male, an adult female, a sub-adult male, a juvenile male and an infant that was approximately 8 months old at the start of the study period (Figure 2.2). This group is now habituated to humans, which provides opportunities to observe them with minimum impact on their natural behaviours. The adults are easily distinguished, as the male is black and the female is yellow. Both the sub-adult male and juvenile male are black, but they can be distinguished by their body size. Group A is usually located about one hour walk from the main research station, and their territory is approximately 50 hectares in size. 

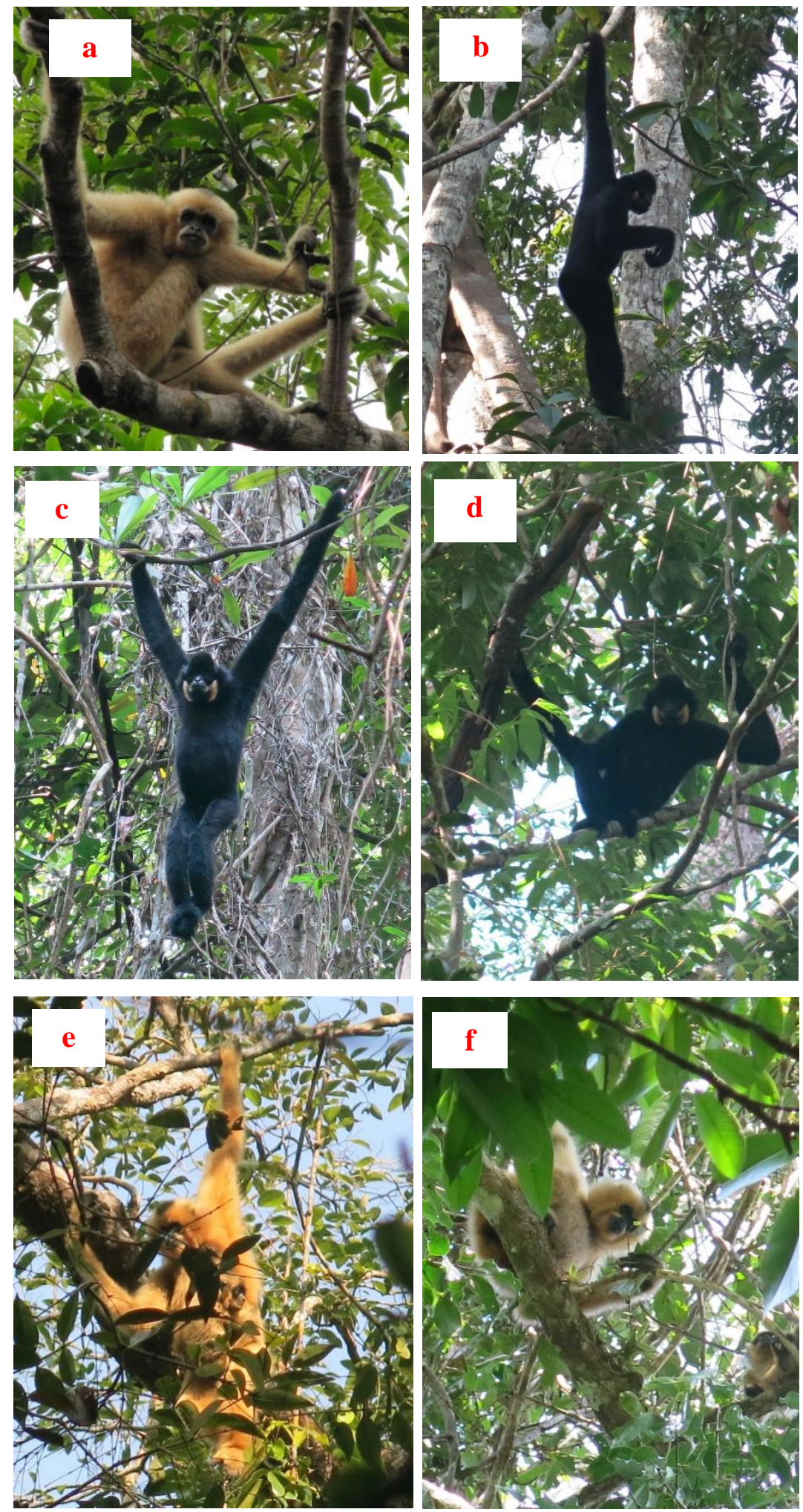

Figure 2.2: Study group (Group A) of northern yellow-cheeked crested gibbons (N. annamensis) from Veun Sai-Siem Pang Conservation Area (VSSPCA), northern Cambodia. (a) the adult female, (b) the adult male, (c), the sub-adult male, and (d), the juvenile male, (e and f), the adult female and her baby. The colour of the adult female is changed according to the reflection of sun-light.

Photo: Naven Hon 


\subsubsection{Behavioural data collection}

In total, 235 hours of focal animal data was collected over 40 days on group A. Four members of the group were observed for the study, and the infant was not included, as it was not weaned at the time of data collection. The study was conducted from midJanuary until early April 2015. As gibbon groups are located by their morning vocalisations, behavioural observations began at 5:30 - 7:10 (calling time) until 11:00 or 16:00. Each individual gibbon was observed for two different time periods, a half day from calling time to mid-day and a full day from calling time to early evening (sleeping time normally at 16:00). Each individual was observed equally for 5 half days and 5 full days $(N=10)$.

For each observation, the behaviours of the gibbons were recorded for 45 min per hour with a 15 min break before the next observation started. During observation, any change in behaviour was recorded. This allowed the exact time spent on each particular activity to be calculated. Activities recorded were resting, feeding, travelling, socializing, and 'out of observation. Feeding was recorded when an individual gibbon was seen directly picking, chewing, swallowing and handling any food item (Fan et al. 2009). Resting was recorded in any situation where the focal gibbon did not move or was inactive. Travelling was recorded whenever the focal gibbon was moving. Socializing was noted when the focal animal saw playing, grooming and calling (for more detail, see Appendix 1). 'Out of observation' was noted when the focal animal could not be seen directly.

When the focal animal was feeding, the types of food item (species, and part of plant eaten) were recorded. The locations of those trees and lianas were marked with a handheld Global Position System (GPS) device (Garmin GPSMAP 62S) and the trees and lianas were labelled with species name and GPS waypoint. Photographs were taken of those species that could not be identified, for later identification by local people and to compare with a guide book (Phon 2000). If those plant species still could not be identified, they were named as unknown species. If the plant species still could not be identified, they were named as unknown species. Any illegal logging activities and human disturbance were noted during the observation period. 


\subsubsection{Ecological data}

\subsubsection{Phenological data}

Phenological data were recorded in January, February and March 2015. Three transect lines within the home range of the gibbon study group were created by researchers from Conservation International (CI) and Forestry Administration (FA), and were used to collect phenological data in this study. These data included the percentage coverage $(0 \%$, $25 \%, 50 \%, 75 \%$, and $100 \%$ ) of plant tissues (fruit, flowers, young, and mature leaves). The percentage coverage of each tree and liana was assumed to be $100 \%$ including all those plant tissues. The percentage cover of each plant tissue was estimated by direct observation. For example, one tree could include 25\% fruit, 25\% flowers, $25 \%$ young leaves and $25 \%$ mature leaves, and another tree could be $100 \%$ mature leaves. For the purposes of this analysis, the contribution of branches and trunks to the total plant mass was ignored, as these tissues were not consumed by N. annamensis. Herbs and small shrubs were also not included in this analysis. Leaves were classified as young leaves from bud emergence until they reached full size and were lighter in colour (Behie \& Pavelka 2012a), while mature leaves were fully expanded and darker in colour (Coley 1983). Ripe fruit and unripe fruit were identified based on their colours and physical examinations to determine if they were ripe or unripe.

\subsubsection{Plant density}

To estimate plant density and food availability, 20 vegetation plots $(25 \times 25 \mathrm{~m})$ were randomly placed throughout the home range of group A during the study period (January-April 2015). Plant density was estimated from the 20 vegetation plots rather than from the transect lines because the trees and lianas on the transect line were biased towards feeding species, and therefore were not an accurate representation of the habitat. However, both plots and transect lines were located inside the home range of the gibbon study group. In each plot, all trees with a diameter at breast height $(\mathrm{DBH})$ greater than $10 \mathrm{~cm}$ and liana species with a DBH greater $5 \mathrm{~cm}$ were measured and identified (Gerwing et al. 2006). These data were analysed to provide abundance, density, and dominance information on all tree and liana species throughout the home range of $N$. annamensis. Each tree and liana in each plot was tagged with a unique code number and recorded with GPS location. This 
will be used for future research. Tree and liana species were identified by local researchers, with help from a guide book (Phon 2000). Local knowledge built up over seven years of studying this group of $N$. annamensis at this site allowed accurate identification of tree and liana species, particularly those used as food sources.

A food availability index (FAI) was calculated for the top 10 food species as recorded in this study. The gibbons fed on 37 different plant species (Table 2.3), but only the top 10 food plant species were selected for FAI analysis because only these 10 species overlapped inside the three transect lines and in the 20 vegetation plots. The FAI was determined for each plant tissue (fruit, flowers, and young leaves) for species $i$ (Silver et al 1998), and defined (e.g. for fruit) as

$$
\mathrm{FAI}_{\mathrm{fr}}=\sum_{1-\mathrm{i}}\left(\mathrm{D} i \times \mathrm{C}_{\mathrm{fr}, \mathrm{i}}\right)
$$

where $\mathrm{FAI}_{\mathrm{fr}}$ is the FAI for fruit, $\mathrm{D} i$ is the density of tree or liana species $i$, and $\mathrm{C}_{\mathrm{fr}, \mathrm{i}}$ is the average monthly coverage percentage for the fruit of that species. Similar FAIs were calculated for flowers $\left(\mathrm{FAI}_{\mathrm{fl}}\right)$ and young leaves $\left(\mathrm{FAI}_{\mathrm{yl}}\right)$. Gibbons did not feed on mature leaves from the top 10 plant species, so $\mathrm{FAI}_{\mathrm{ml}}$ was not included in the analyses. However, the gibbons did consume mature leaves from other plant species. The density of species $i$ was calculated as

$$
\mathrm{D} i=\mathrm{N} i / \mathrm{N} t
$$

where $\mathrm{N} i$ is the total number of stems of species $i$, and $\mathrm{N} t$ is the total number of stems in the 20 vegetation plots.

\subsubsection{Statistical analyses}

The mean percentage time spent feeding, resting, travelling and socializing per day was calculated for each individual gibbon in the group. Similarly, the mean percentage of food type (fruit, flowers, young leaves, and mature leaves) each gibbon consumed per day was calculated. Both sets of data were non-normally distributed, thus non-parametric Kruskal-Wallis Tests were used to assess any differences between the time each individual spent on each activity, and any differences in food selection between individuals. Mann- 
Whitney $U$-Tests were used to test the significance of the differences between each pair of activities (eg: resting and feeding) of individual gibbons, and to test the difference between time spent feeding in each pair food items (eg: fruit and young leaves). To assess the relationship between feeding time and food availability of fruit, young leaves, and flowers, Spearman's rank correlation tests were performed (Silver et al. 1998). All statistical analyses were performed in SPSS version 22, and in all cases $\alpha=0.05$. A Bonferroni correction $(0.05 / N$, i.e., $\alpha=0.0125)$ was used to adjust for multiple tests (Rice 1989). 


\subsection{Results}

\subsubsection{Activity budgets}

The gibbons in group A generally spent similar amount of time on each activity together, and there was no statistically significant difference between the members of the group in their activity budgets (Kruskal-Wallis $H$ test: all $P \geq 0.35$, Table 2.1. Figure 2.3). On average, the gibbons in group A spent most of their time resting (42.89\%) and feeding (37.78\%), with less time spent travelling (17.61\%). The least amount of time was spent in social activities $(1.72 \%)$ (Figure 2.3).

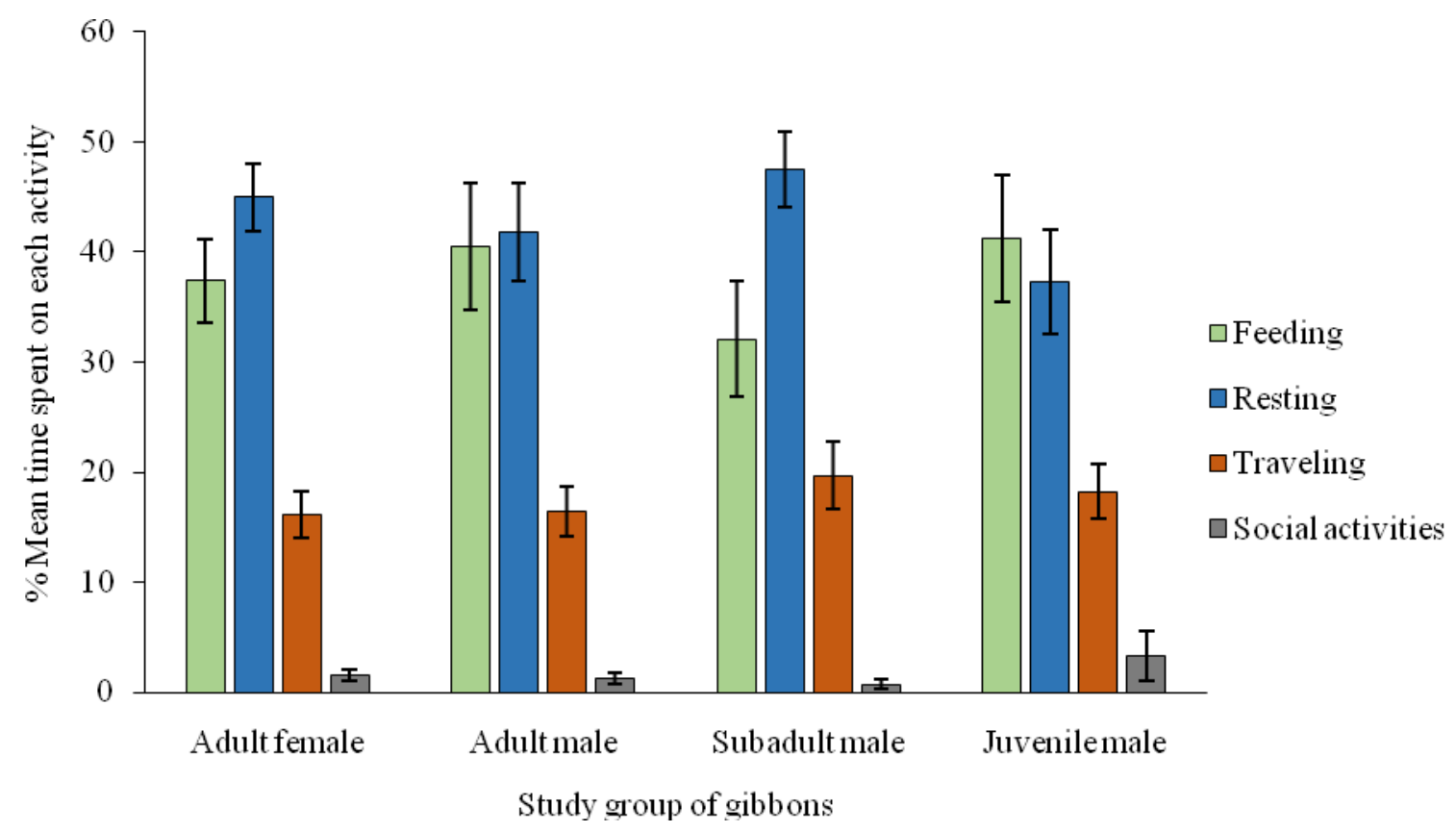

Figure 2.3: The average percentage of time that each individual gibbon spent on each activity, (feeding, resting, travelling and socializing) ( \pm Standard error).

Table 2.1: Results of a Kruskal-Wallis $H$ test comparing the mean percentage of time that individual gibbonss spent feeding, resting, travelling and socializing.

\begin{tabular}{lrrr}
\hline Behaviours & $\boldsymbol{N}($ days $)$ & Chi-square & $\boldsymbol{P}$-value \\
\hline Feeding & 10 & 1.92 & 0.58 \\
Resting & 10 & 3.25 & 0.35 \\
Travelling & 10 & 0.67 & 0.87 \\
Socializing & 10 & 3.49 & 0.32 \\
\hline
\end{tabular}


While all group members engaged in activities for similar proportions of time, there were significant differences in the amount of time the entire group engaged in different activities (feeding, resting, travelling and socializing) (all $P=0.0001$, Table 2.2, Figure 2.3). Moreover, there were statistically significant differences between times that all individual gibbons spent time on most activities (Mann-Whitey Utests:all $P \leq 0.01$, Figure 2.3). However, the percentage of time that all individual gibbons spent feeding and resting were not significantly different (Mann-Whitey $U$ tests:all $P \geq 0.07$, Figure 2.3 ). For more detail about each pairwise activity comparisons and significant values see Appendix 4, Table1.

The gibbons either hid, rested or moved out of observation when there was excessive noise (two cases of chainsaw and one case of tractor), especially when the noise of chainsaws from illegal loggings was close to the observation areas. Several cases of illegal loggings were observed around the VSSPCA (Appendix 2, Figure 1a and b). Moreover, although the gibbons in group A were habituated to humans, the gibbons avoided dogs and were suddenly out of observation when they saw domestic dogs with local researchers (one case).

Table 2.2: Results for Kruskal-Wallis $H$ test comparing the mean percentage of time spent feeding, resting, travelling and socializing among $N$. annamensis.

\begin{tabular}{lrrr}
\hline Gibbons & $\boldsymbol{N}($ days $)$ & $\boldsymbol{C h i}$-square & $\boldsymbol{P}$-value \\
\hline Adult female & 10 & 32.41 & 0.0001 \\
Adult male & 10 & 30.11 & 0.0001 \\
Sub-adult male & 10 & 28.91 & 0.0001 \\
Juvenile male & 10 & 26.02 & 0.0001 \\
\hline Overall gibbons & 40 & 120.20 & 0.0001 \\
\hline
\end{tabular}

When comparing activity by month, the gibbons in group A spent a similar amount of time feeding (38.80\%) and resting (44.49\%) in January, more than travelling (14.34\%) and socializing $(2.37 \%)$. In contrast, the time spent feeding increased to $49.06 \%$ in February, while resting dropped to $37.06 \%$. In March, the time spent feeding declined to $28 \%$, whereas resting and travelling increased to $49.55 \%$ and $21.44 \%$ respectively. The gibbons spent the least amount of time in social activities in all three months (Figure 2.4). 


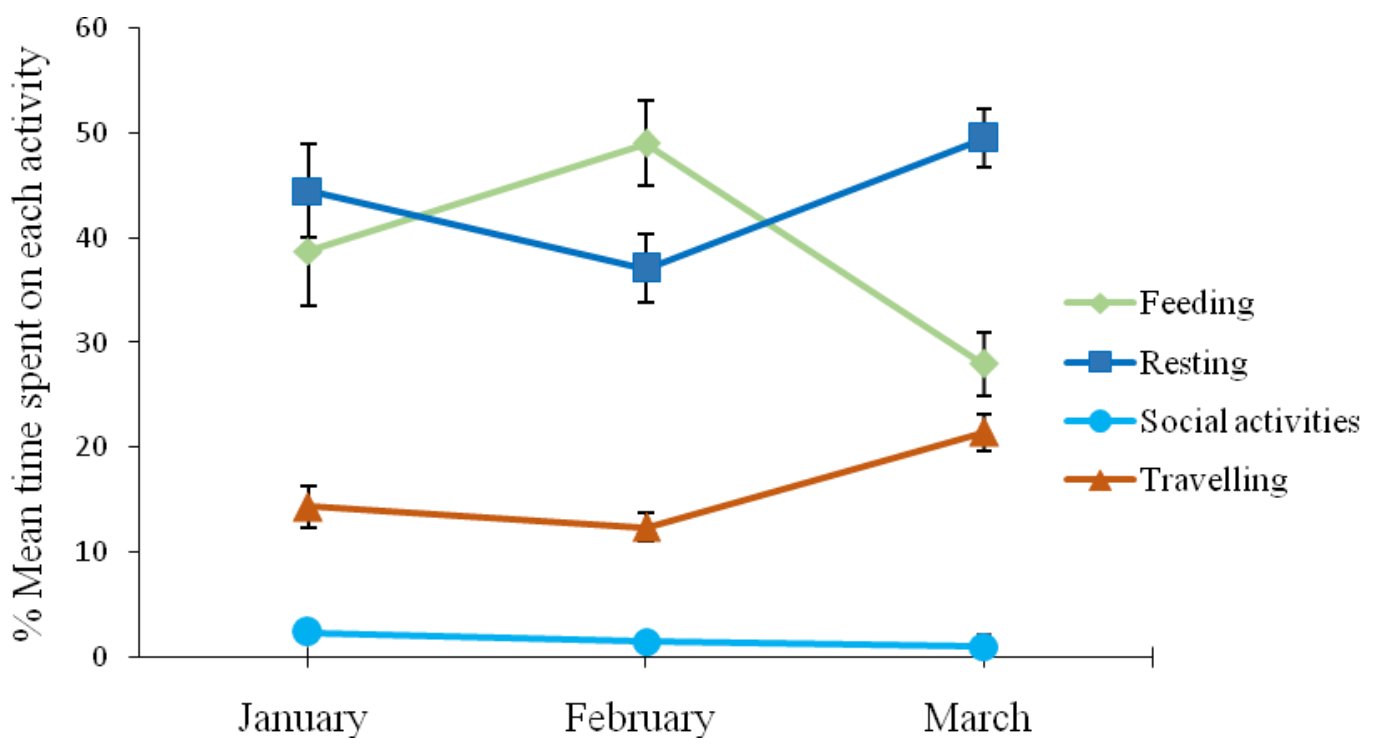

Figure 2.4: The average percentage of time that gibbons in group A spent on each activity budget from January to March 2015 ( \pm standard error).

\subsubsection{Food plant selection}

In total, the gibbons fed on 37 different plant species from more than 17 families, and these plant species were distributed evenly inside their home range (Figure 2.5) of which 18 species were trees (48.65\%), 17 species were lianas (45.94\%) and two species were epiphytes $(5.41 \%$ ) (Table 2.3$)$. Twenty-one species were fed on for less than $1 \%$ of the feeding time, however the top 16 species (feeding time more than $1 \%$ in the diet) made up $88.83 \%$ of the overall diet (Table 2.3 ). The gibbons were occasionally observed feeding on insects, spiders and larvae, although the species were not identified (Appendix 2, Figure 2). The gibbons were also observed feeding on honey bees and bee larvae. 
Table 2.3: Plant species selected by group A of $N$. annamensis, including the time they spent feeding each species and the tissue consumed from January until early April 2015 in northern Cambodia. Percentage here represents the amount of time that the gibbons spent feeding all food plant species. The species are ranked according to the time spent feeding those species (highest to lowest) with the line draw under the top 16 species. Months here refer to the periods that the gibbons selected the food items.

\begin{tabular}{|c|c|c|c|c|c|c|}
\hline Family & Species & Time (\%) & Rank & Form & Plant tissue & Months \\
\hline Aquifoliaceae & Ilex umbellulata & 22.13 & 1 & $\mathrm{~T}$ & $\mathrm{~F} / \mathrm{Fr}$ & Feb/Mar \\
\hline Moraceae & Ficus. sp & 14.56 & 2 & $\mathrm{~L}$ & Fr & $\mathrm{Jan} / \mathrm{Feb} / \mathrm{Mar}$ \\
\hline Fagaceae & Lithocarpus elegans & 9.50 & 3 & $\mathrm{~T}$ & YL & $\mathrm{Jan} / \mathrm{Feb} / \mathrm{Mar}$ \\
\hline Guttiferae & Garcinia oliveri & 6.91 & 4 & $\mathrm{~T}$ & $\mathrm{YL} / \mathrm{F}$ & $\mathrm{Jan} / \mathrm{Feb} / \mathrm{Mar}$ \\
\hline Apocynaceae & Willughbeia edulis & 6.62 & 5 & $\mathrm{~L}$ & $\mathrm{Fr} / \mathrm{YL}$ & Feb/Mar/Apr \\
\hline Dipterocarpaceae & Dipterocarpus alatus & 5.89 & 6 & $\mathrm{~T}$ & $\mathrm{~F}$ & Feb/Mar \\
\hline Gnetaceae & Gnetum macrostachyum & 3.68 & 7 & $\mathrm{~L}$ & Fr & $\mathrm{Jan} / \mathrm{Feb} / \mathrm{Mar}$ \\
\hline Leguminosae & Dialium cochinchinensis & 3.20 & 8 & $\mathrm{~T}$ & YL & Feb/Mar \\
\hline Sapotaceae & Madhuca elliptica & 3.12 & 9 & $\mathrm{~T}$ & Fr & Mar/Apr \\
\hline Anacardiaceae & Mangifera duperreana & 2.78 & 10 & $\mathrm{~T}$ & YL & Feb \\
\hline Unknown & Unknown-1 & 2.16 & 11 & $\mathrm{~T}$ & YL & $\mathrm{Jan} / \mathrm{Feb}$ \\
\hline Unknown & Kbal Thum & 2.01 & 12 & $\mathrm{~T}$ & Fr & Feb/Mar \\
\hline Unknown Liana & Vor Krovanh (LN) & 1.71 & 13 & $\mathrm{~L}$ & YL & $\mathrm{Feb} / \mathrm{Mar}$ \\
\hline Unknown & Unknown-2 & 1.69 & 14 & $\mathrm{~T}$ & YL & Jan \\
\hline Unknown Liana & Chrey Slekthum (LN) & 1.64 & 15 & $\mathrm{~L}$ & ML & Feb \\
\hline Apocynaceae & Dischidia. $s p$ & 1.23 & 16 & $\mathrm{E}$ & ML & Jan \\
\hline Unknown Liana & Vor Antong (LN) & 0.93 & 17 & $\mathrm{~L}$ & YL & Jan/Feb \\
\hline Unknown Liana & Vor Tang Ant (LN) & 0.79 & 18 & $\mathrm{~L}$ & YL & $\mathrm{Jan} / \mathrm{Feb}$ \\
\hline Unknown & Unknown-4 & 0.46 & 19 & $\mathrm{~T}$ & YL & $\mathrm{Jan} / \mathrm{Feb}$ \\
\hline Ochnaceae & Ochna atropurpurea & 0.35 & 20 & $\mathrm{~T}$ & $\mathrm{~F} / \mathrm{YL}$ & Feb/Mar \\
\hline Dipterocarpaceae & Anisoptera costata & 0.34 & 21 & $\mathrm{~T}$ & YL & Jan \\
\hline Unknown & Unknown-3 & 0.28 & 22 & $\mathrm{~T}$ & YL & $\mathrm{Jan} / \mathrm{Feb}$ \\
\hline Moraceae & Ficus racemosa & 0.24 & 23 & $\mathrm{~T}$ & Fr & Mar \\
\hline Meliaceae & Aglaia grandis & 0.24 & 24 & $\mathrm{~T}$ & Fr & Jan \\
\hline Unknown & Unknown-5 & 0.12 & 25 & $\mathrm{~T}$ & YL & Jan \\
\hline Myrtaceae & Syzygium. sp & 0.06 & 26 & $\mathrm{~T}$ & YL & Jan \\
\hline Unknown & Other Unknown Species* & 5.74 & $27-37$ & $\mathrm{~L}$ & YL & Jan/Feb/Mar \\
\hline Arthropods & Spiders/Insects/Larvae & 0.56 & & $\mathrm{~A}$ & & Jan/Feb/Mar \\
\hline Water & Drinking water & 1.06 & & $\mathrm{~W}$ & & Mar \\
\hline
\end{tabular}

Key: $\mathrm{A}=$ animal, $\mathrm{T}=$ tree, $\mathrm{L}=$ liana, $\mathrm{E}=$ epiphyte, $\mathrm{YL}=$ young leaves, $\mathrm{ML}=$ mature leaves, $\mathrm{F}=$ flowers, $\mathrm{Fr}=$ fruit, and $\mathrm{W}=$ water, $\mathrm{LN}=$ local name. Other unknown species ${ }^{*}=$ Unidentified food plant species (11 species). 


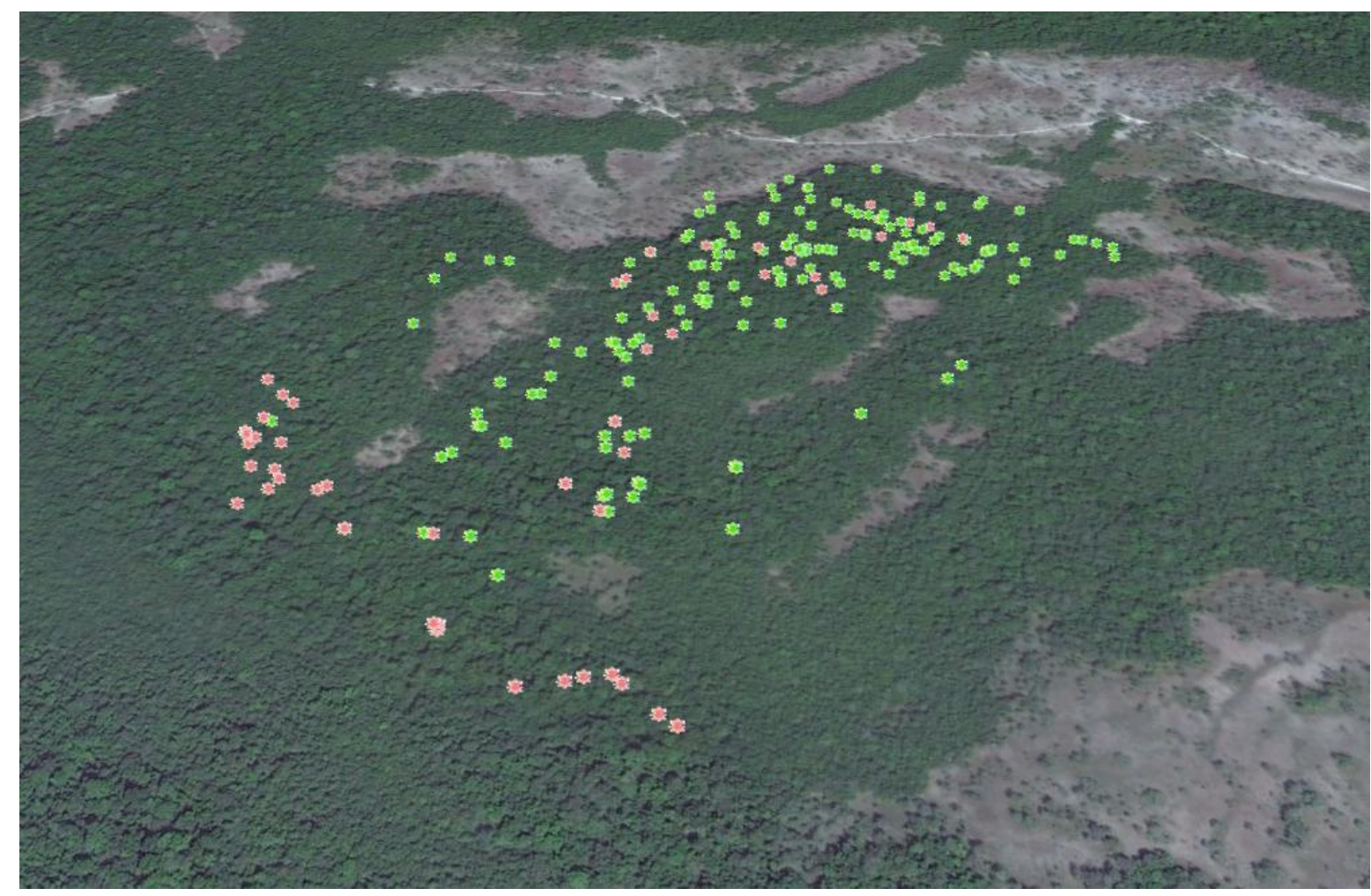

Figure 2.5: Distribution of food plant tree and liana species selected by the group of Nomascus annamensis at VSSPCA, northern Cambodia. The green stars refer to the top 10 feeding plant species, while the pink stars refer to the rest of feeding plant species. These data are based on the GPS locations of each species recorded during observation periods. The dark-green is evergreen and semi-evergreen forest, while grey-brown sports are deciduous forests.

Image credit: Google Earth, created by Kuthet Sok

\subsubsection{Diet budgets}

All group members of $N$. annamensis had similar diets with no statistically significant differences in time spent feeding on each food types among group members (Kruskal-Wallis $H$ test: all $P \geq 0.53$, Table 2.4, Figure 2.6). When all 37 plant species consumed by gibbons in group A were considered, fruit was the most preferred food in each gibbon's diet, making up 60.36\%, followed by young leaves $(22.60 \%)$, flowers $(13.74 \%)$, and mature leaves $(3.30 \%)$. The gibbons mostly consumed only the flesh of the fruit, and generally spat out the seeds (Appendix 2, Figure 4), although some small fruits were swallowed with seeds. For example, the gibbons usually consumed only flesh from W. edulis and M. elliptica, while I. umbellulata and G. macrostachyum were swallowed with their seeds. Of the fruit selected, the gibbons mainly chose ripe fruit 
$(87 \%)$ over unripe $(11 \%)$ and mature fruit $(2 \%)$. The common unripe fruits consumed was: I. umbellulata (Appendix 2, Figure 5), while mature fruit was A. grandis (Appendix 2, Figure 6). The two adults were observed consuming mature leaves of an unknown liana species and one species of epiphyte (small leaves) $(4.33-4.46 \%)$. The other two individuals (sub-adult and juvenile male) consumed mature leaves only very rarely (0.1$0.74 \%$ ). One species of epiphyte was chewed and sucked, and then spat out, providing only liquid nutritional values (Appendix 2, Figure 7).

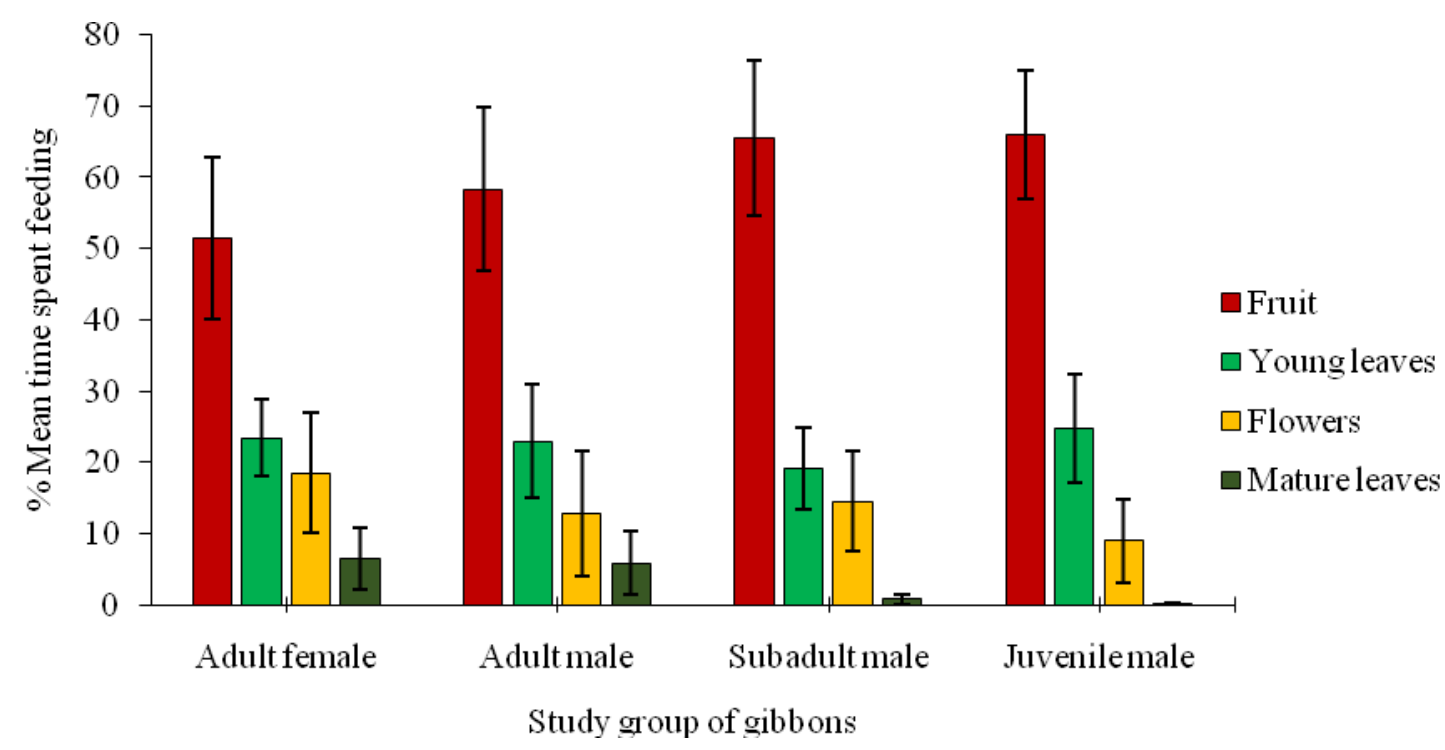

Figure 2.6: The average percentage of time that each gibbon spent consuming fruit, young leaves, flowers and mature leaves from all 37 sources of food items ( \pm standard error).

Table 2.4: Results of a Kruskal-Wallis $H$ test comparing the mean percentage time that each gibbon spent feeding different food types (fruit, young leaves, flowers, and mature leaves)

\begin{tabular}{lrrr}
\hline Plant tissues & $\boldsymbol{N}$ (days) & Chi-square & $\boldsymbol{P}$-value \\
\hline Fruit & 10 & 1.37 & 0.71 \\
Young leaves & 10 & 0.63 & 0.88 \\
Flowers & 10 & 0.94 & 0.81 \\
Mature leaves & 10 & 2.20 & 0.53 \\
\hline
\end{tabular}

Generally, the gibbons, both individually and as a group, spent significantly different amounts of time feeding on each plant tissue (fruit, young leaves, flowers, and mature leaves) (Kruskal-Wallis $H$ test: individually: $P \leq 0.01$; group: $P=0.0001$, Table 2.5, 
Figure 2.6). All group members of gibbons spent significant more time feeding on fruit than young leaves, flowers, and mature leaves (Mann-Whitney $U$ tests: all $P \leq 0.01$, Figure 2.6). Moreover, both the sub-adult male $(U=16.5, P=0.01)$ and the juvenile male $(U=11, P=0.003)$ spent significantly more time feeding on young leaves than mature leaves, while both the adult female $(U=19.5, P=0.02)$ and the adult male $(U=19, P=$ 0.02) spent similar amount of time feeding on young leaves and mature leaves. No significant differences were found in feeding time for young leaves, flowers and mature leaves for all gibbons (Mann-Whitney $U$ tests: all $P \geq 0.04$ ). For more detail of each pairwise comparison and significant values see Appendix 4, Table 2.

Table 2.5: Results of a Kruskal-Wallis $H$ test comparing the mean percentage time spent feeding different food types (fruit, young leaves, flowers and mature leaves) by each individual gibbon in group A.

\begin{tabular}{lrrr}
\hline Gibbons & $\boldsymbol{N}$ (days) & Chi-square & $\boldsymbol{P}$-value \\
\hline Adult female & 10 & 11.13 & 0.01 \\
Adult male & 10 & 13.82 & 0.003 \\
Sub-adult male & 10 & 19.60 & 0.0001 \\
Juvenile male & 10 & 26.23 & 0.0001 \\
\hline Overall gibbons & 40 & 72.96 & 0.0001 \\
\hline
\end{tabular}

The gibbons spent similar time feeding on young leaves $(33.45 \%)$, flowers (28.40\%), and fruit (27.51\%) in January, while mature leaves were the least consumed food $(10.64 \%)$. In contrast, the time spent feeding on fruit increased to $46.25 \%$ in February and $82.80 \%$ in March, while the time spent feeding on young leaves and flowers declined from $26.59 \%$ to $16.17 \%$ and $25.13 \%$ to $1.04 \%$, respectively. The gibbons continued to spend less time feedingon mature leaves in February (2.03\%) and did not feed on mature leaves at all in March (Figure 2.7). 


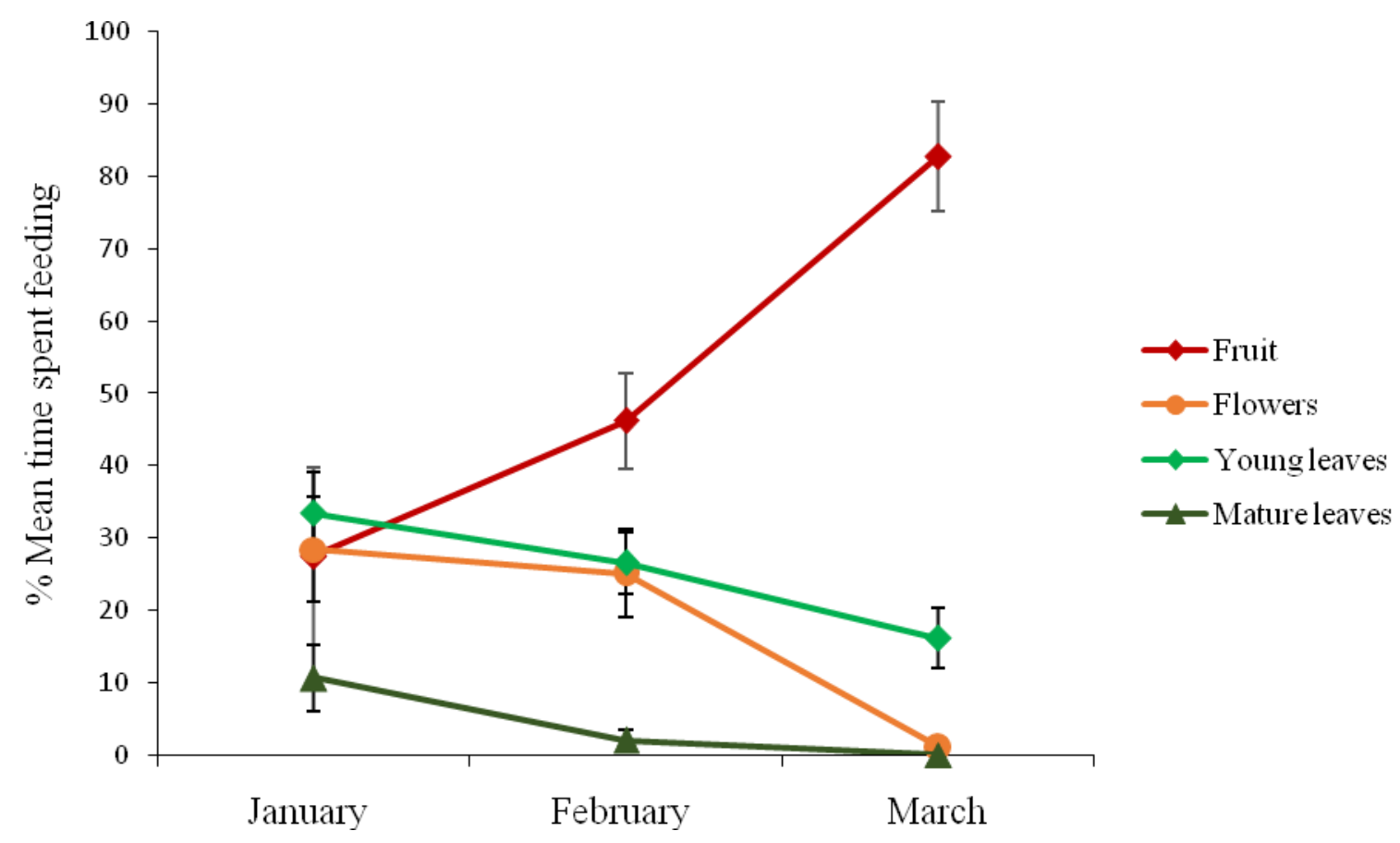

Figure 2.7: The average percentage time that the group of Nomascus annamensis spent consuming fruit, young leaves, flowers and mature leaves from January to March 2015 ( \pm standard error).

\subsubsection{Food availability}

\subsubsection{Phenology}

The percentage coverage of plant tissues during the study period was determined from fixed transects set within the home range of gibbons in group A. The fruit coverage was very low in January (1.21\%) and highest in March (4.23\%). This is due to the fact that in January, only about 3\% of plants bore fruit, whereas $8 \%$ were fruiting in February and $10 \%$ in March. Among the top 10 feeding species, Ficus. sp and G. macrostachyum bore fruit for the entire period of data collection (January - March), while I. umbellulata, M. elliptica, and W. edulis began bearing fruit in February. The coverage of flowers and young leaves were also low (0.66 - 2.91\% and $11.53-13.11 \%$, respectively), while the bulk of the plant material was mature leaves (82.17 - 83.21\%) (Figure 2.8). 


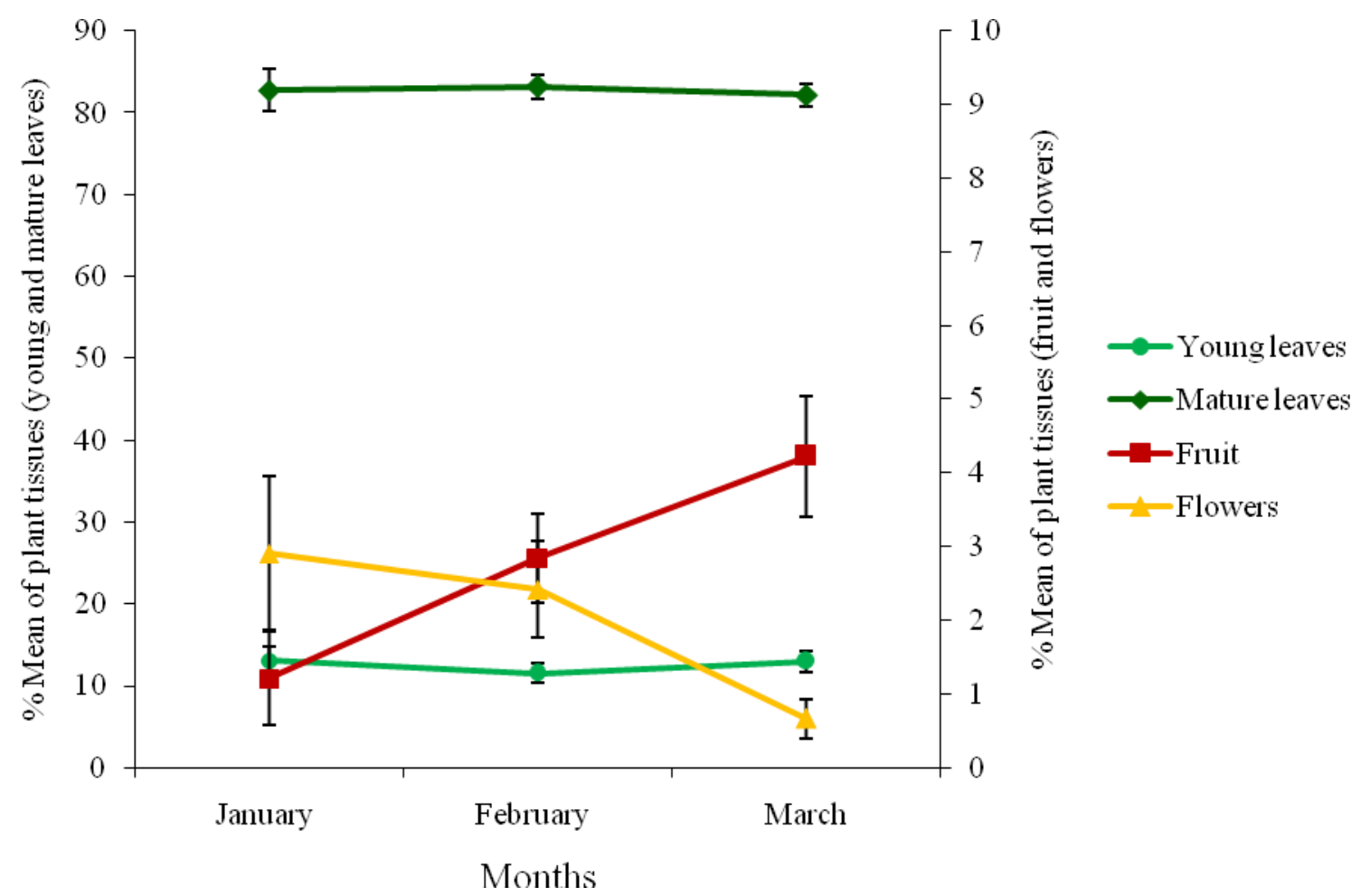

Figure 2.8: The coverage percentage of fruit, flowers, young leaves, and mature leaves between January and March 2015 in Veun Sai-Siem Pang Conservation Area (VSSPCA), northern Cambodia. Fruit and flower are represented on the right axis, while the left axis shows young and mature leaves. This data was obtained from fixed phenology transect lines within the home range of gibbons in group A ( \pm standard error).

\subsubsection{Vegetation plots}

In total, 969 individual trees and lianas were recorded inside the 20 vegetation plots, comprising more than 74 different species (including some unidentified species), of which $80 \%$ were trees, and $20 \%$ were lianas. Of these, 16 were food species of the gibbons - with 11 being food trees and 5 being food lianas. This represents a total food plant density of $77 \%$ and a basal area of $34.55 \mathrm{~m}^{2}$. plot $^{-1}$ for food species within the sampled area (trees $34.22 \mathrm{~m}^{2}$.plot ${ }^{-1}$ and lianas $0.34 \mathrm{~m}^{2} \cdot$ plot $^{-1}$ ) (Table 2.6). The number of food plant species in the plots (16 species) differed from the food plants noted during observation (46 species) because some plant species were not found inside the sampled plots. Based on these plots, Lithocarpus eleganswas the third most abundant species in the gibbon's home range (Table 2.6), and this species was also the third highest source of food for group A (Table 2.6). Nephelium mutabile and Nang Kmov (local name) were even more abundant than L. elegans (Table 2.6), but these trees did not bear fruit or produce flowers during the 
study periods. Thus, although these two dominant tree species are known to the local guides as common sources of food (particularly for fruit), the gibbons were not observed consuming any plant parts from them during the study periods. Similarly, other tree and liana species are sources of food according to local knowledge, but the gibbons did not consume any parts of these species during this study (Table 2.6, last column). Most plant species consumed by the gibbons were rare in the home range of this gibbon study group, with the two most commonly eaten species, I. umbellulata and Ficus. sp comprising only $0.82 \%$ and $0.41 \%$ of the total canopy in the plots, respectively (Table 2.6). 
Table 2.6: The relative density and average basal area of trees and lianas as determined from the 20 vegetation plots inside the home range of gibbon group A. Species in bold are the top 10 species used for food by the study group of N. annamensis from January until early April 2015 in northern Cambodia, and the rank in their diet (Table 2.2) is given in brackets. Tree and liana species that were consumed during the study period are listed under the food column. Other tree and liana species that are known from local knowledge to be food species are also indicated.

\begin{tabular}{|c|c|c|c|c|c|c|}
\hline Species/local name & Life form & Rank & Relative density & Average of basal area $\left(\mathrm{m}^{2}\right)$ & Food & Food (local knowledge) \\
\hline Nephelium mutabile & $\mathrm{T}$ & 1 & 0.180 & 55.55 & No & Yes \\
\hline Nang Kmov (LN) & $\mathrm{T}$ & 2 & 0.144 & 35.83 & No & Yes \\
\hline Lithocarpus elegans (3) & $\mathrm{T}$ & 3 & 0.137 & 67.57 & Yes & Yes \\
\hline Syzygium. sp & $\mathrm{T}$ & 4 & 0.065 & 55.04 & Yes & Yes \\
\hline Unknown-sp & $\mathrm{T}$ & 5 & 0.063 & 31.96 & No & Yes \\
\hline Sterculia lychnophora & $\mathrm{T}$ & 6 & 0.033 & 8.99 & No & Yes \\
\hline Aglaia odorata & $\mathrm{T}$ & 7 & 0.027 & 4.91 & No & No \\
\hline Willughbeia edulis (5) & $\mathrm{L}$ & 8 & 0.025 & 1.98 & Yes & Yes \\
\hline Aihoun $(L N)$ & $\mathrm{T}$ & 9 & 0.017 & 4.21 & No & No \\
\hline Dom Sambok Krohom ( $L N)$ & $\mathrm{T}$ & 10 & 0.016 & 4.25 & No & Yes \\
\hline Madhuca elliptica (9) & $\mathrm{T}$ & 11 & 0.014 & 8.63 & Yes & Yes \\
\hline Bouea oppositifolia & $\mathrm{T}$ & 12 & 0.013 & 8.88 & No & Yes \\
\hline Gnetum macrostachyum (7) & $\mathrm{T}$ & 13 & 0.012 & 0.81 & Yes & Yes \\
\hline Kbal Thum $(L N)$ & $\mathrm{T}$ & 14 & 0.012 & 41.51 & Yes & Yes \\
\hline Irvingia malayana & $\mathrm{T}$ & 15 & 0.010 & 69.55 & No & Yes \\
\hline Tang Ant $(L N)$ & $\mathrm{L}$ & 16 & 0.010 & 0.74 & Yes & Yes \\
\hline Anisoptera costata & $\mathrm{T}$ & 17 & 0.009 & 13.14 & No & Yes \\
\hline Cinnamomum cambodian & $\mathrm{T}$ & 18 & 0.009 & 1.80 & No & Yes \\
\hline $\operatorname{Dom} \operatorname{Atchor}(L N)$ & $\mathrm{T}$ & 19 & 0.009 & 2.73 & No & No \\
\hline Shorea thorelii & $\mathrm{T}$ & 20 & 0.009 & 12.48 & No & No \\
\hline Tong Nam $(L N)$ & $\mathrm{T}$ & 21 & 0.009 & 2.07 & No & Yes \\
\hline Ilex umbellulata (1) & $\mathrm{T}$ & 22 & 0.008 & 4.71 & Yes & Yes \\
\hline Klang Kan Trong $(L N)$ & $\mathrm{T}$ & 23 & 0.008 & 6.61 & No & No \\
\hline Nephelium hypoleucm & $\mathrm{T}$ & 24 & 0.008 & 2.29 & No & Yes \\
\hline Diospyros nitida & $\mathrm{T}$ & 25 & 0.007 & 1.48 & No & No \\
\hline Albizia myriophylla & $\mathrm{T}$ & 26 & 0.006 & 2.93 & No & No \\
\hline Albizia. sp & $\mathrm{T}$ & 27 & 0.006 & 4.01 & No & No \\
\hline Antong $(L N)$ & $\mathrm{L}$ & 28 & 0.006 & 0.25 & Yes & Yes \\
\hline Dipterocarpus alatus (6) & $\mathrm{T}$ & 29 & 0.006 & 35.37 & Yes & Yes \\
\hline
\end{tabular}




\begin{tabular}{|c|c|c|c|c|c|c|}
\hline Species/local name & Life form & Rank & Relative density & Average of basal area $\left(\mathrm{cm}^{2}\right)$ & Food & Food (local knowledge) \\
\hline Dom Mek Tech $(L N)$ & $\mathrm{T}$ & 30 & 0.006 & 2.31 & No & Yes \\
\hline Garcinia oliveri (4) & $\mathrm{T}$ & 31 & 0.006 & 3.40 & Yes & Yes \\
\hline Parinari annamensis & $\mathrm{T}$ & 32 & 0.006 & 4.47 & No & Yes \\
\hline Ochna atropurpurea & $\mathrm{T}$ & 33 & 0.005 & 0.68 & Yes & Yes \\
\hline Calophyllum calaba & $\mathrm{T}$ & 34 & 0.004 & 1.86 & No & Yes \\
\hline Ficus. sp (2) & $\mathrm{L}$ & 35 & 0.004 & 2.20 & Yes & Yes \\
\hline Khov Keb $(L N)$ & $\mathrm{T}$ & 36 & 0.004 & 0.50 & No & Yes \\
\hline Mak Dekkouy (LN) & $\mathrm{T}$ & 37 & 0.004 & 0.77 & No & Yes \\
\hline Mangifera duperreana (10) & $\mathrm{T}$ & 38 & 0.004 & 3.06 & Yes & Yes \\
\hline $\operatorname{Smach}(L N)$ & $\mathrm{T}$ & 39 & 0.004 & 0.89 & No & Yes \\
\hline Vor Sleng $(L N)$ & $\mathrm{L}$ & 40 & 0.004 & 0.69 & No & Yes \\
\hline Dialium cochinchinensis (8) & $\mathrm{T}$ & 41 & 0.003 & 2.12 & Yes & Yes \\
\hline Dom Slek Toch $(L N)$ & $\mathrm{T}$ & 42 & 0.003 & 0.55 & No & No \\
\hline Douk Kouy $(L N)$ & $\mathrm{T}$ & 43 & 0.003 & 1.16 & No & Yes \\
\hline Krovanh $(L N)$ & $\mathrm{L}$ & 44 & 0.003 & 0.14 & Yes & Yes \\
\hline Sidong $(L N)$ & $\mathrm{T}$ & 45 & 0.003 & 1.68 & No & No \\
\hline Sindora cochinchinensis & $\mathrm{T}$ & 46 & 0.003 & 6.15 & No & Yes \\
\hline Aglaia leptantha & $\mathrm{T}$ & 47 & 0.002 & 0.47 & No & Yes \\
\hline Antidesma cochinchinensis & $\mathrm{T}$ & 48 & 0.002 & 0.31 & No & Yes \\
\hline Chhor tree $(L N)$ & $\mathrm{T}$ & 49 & 0.002 & 6.68 & No & No \\
\hline Dom man chor $(L N)$ & $\mathrm{T}$ & 50 & 0.002 & 0.21 & No & No \\
\hline Dom Sambok Kras ( $L N)$ & $\mathrm{T}$ & 51 & 0.002 & 0.77 & No & No \\
\hline Hopea. sp & $\mathrm{T}$ & 52 & 0.002 & 6.80 & No & No \\
\hline Microcos paniculata & $\mathrm{T}$ & 53 & 0.002 & 1.46 & No & Yes \\
\hline $\operatorname{Mok}(L N)$ & $\mathrm{T}$ & 54 & 0.002 & 13.24 & No & No \\
\hline Mout $(L N)$ & $\mathrm{T}$ & 55 & 0.002 & 0.46 & No & No \\
\hline Vor Sor $(L N)$ & $\mathrm{L}$ & 56 & 0.002 & 0.17 & No & Yes \\
\hline Carallia brachiata & $\mathrm{T}$ & 57 & 0.001 & 1.06 & No & Yes \\
\hline Chan Kikai $(L N)$ & $\mathrm{T}$ & 58 & 0.001 & 0.12 & No & No \\
\hline Cheng Tea $(L N)$ & $\mathrm{T}$ & 59 & 0.001 & 2.28 & No & No \\
\hline Dom Koung $(L N)$ & $\mathrm{T}$ & 60 & 0.001 & 0.11 & No & No \\
\hline Dom Sambok Sdeang $(L N)$ & $\mathrm{T}$ & 61 & 0.001 & 0.18 & No & No \\
\hline Dom Sambok sor $(L N)$ & $\mathrm{T}$ & 62 & 0.001 & 0.31 & No & No \\
\hline
\end{tabular}




\begin{tabular}{|c|c|c|c|c|c|c|}
\hline Species/local name & Life form & Rank & Relative density & Average of basal area $\left(\mathrm{cm}^{2}\right)$ & Food & Food (local knowledge) \\
\hline Dom Sambok Sroy $(L N)$ & $\mathrm{T}$ & 63 & 0.001 & 0.16 & No & No \\
\hline Dom Slek Kras $(L N)$ & $\mathrm{T}$ & 64 & 0.001 & 0.21 & No & No \\
\hline $\operatorname{Ham} \operatorname{Oav}(L N)$ & $\mathrm{T}$ & 65 & 0.001 & 3.75 & No & No \\
\hline Kam Pul Bay $(L N)$ & $\mathrm{T}$ & 66 & 0.001 & 0.26 & No & No \\
\hline Khai Phai $(L N)$ & $\mathrm{T}$ & 67 & 0.001 & 0.59 & No & No \\
\hline $\mathrm{Ki} \mathrm{Nu}(L N)$ & $\mathrm{T}$ & 68 & 0.001 & 0.15 & No & No \\
\hline Nephelium. sp & $\mathrm{T}$ & 69 & 0.001 & 0.19 & No & Yes \\
\hline Plea Keave $(L N)$ & $\mathrm{T}$ & 70 & 0.001 & 0.12 & No & Yes \\
\hline Rang Phnom $(L N)$ & $\mathrm{T}$ & 71 & 0.001 & 0.12 & No & Yes \\
\hline Romdoul (LN) & $\mathrm{T}$ & 72 & 0.001 & 0.14 & No & Yes \\
\hline Sayak $(L N)$ & $\mathrm{T}$ & 73 & 0.001 & 0.22 & No & Yes \\
\hline Shorea cochinchinensis & $\mathrm{T}$ & 74 & 0.001 & 0.99 & No & No \\
\hline
\end{tabular}

$\mathrm{LN}=$ local name, $\mathrm{RD}=$ relative density, $\mathrm{T}=$ tree, $\mathrm{L}=$ liana 


\subsubsection{Relationship between food availability and food consumption}

The total FAI fr from the top 10 species increased 10 -fold from 0.21 in January to 2.29 in March (Table 2.7). Although $\mathrm{FAI}_{\mathrm{fr}}$ increased, no statistically significant relationship was found between feeding time and $\mathrm{FAI}_{\mathrm{fr}}\left(\mathrm{r}_{\mathrm{s}}=0.09, P=0.76, N=12\right.$, Figure 2.9a). This may be due to the fact that the relative densities of fruit bearing trees that gibbons selected were very low inside their home range. However, those trees produced an abundance of fruit during the study period, and this led the group to increase feeding on fruit of those specific species. For example, the FAI $\mathrm{fr}_{\mathrm{r}}$ for Ficus. sp did not change over the three month period, but the amount of time feeding on this item did with the most time ingesting Ficus. $s p$ fruit occurring in February. However, the relative density of Ficus. $s p$ was only $0.004\left(0.4 \%\right.$ of the total plant density). The total of $\mathrm{FAI}_{\mathrm{yl}}$ from the top 10 species increased slightly from 3.44 in January to 5.32 in February, but declined to 4.25 in March (Table 2.7). As a result, there was no statistically significant relationship between feeding time and $\mathrm{FAI}_{\mathrm{yl}}\left(\mathrm{r}_{\mathrm{s}}=0.30, P=0.36, N=9\right.$, Figure 2.9b). The total FAI $\mathrm{f}_{\mathrm{fl}}$ from the top 10 species increased from 0.39 in January to 0.72 in February. Although it declined to 0.38 in March (Table 2.7), there was a significant relationship between feeding time and $\mathrm{FAI}_{\mathrm{fl}}\left(\mathrm{r}_{\mathrm{s}}=\right.$ 0.82, $P=0.04, N=6$, Figure 2.9c). D. alatus and G. oliveri were important sources of flowers, especially in February when flowers became more available, and the gibbons spent more time feeding on these tree species (Table 2.7). 
Table 2.7: Food availability index (FAI) for each of the top 10 species found in quadrats for January, February and March 2015. For FAI columns and rows, "0" values indicate those plants that did not bear fruit, flowers or leaves. Values in bold refer to those plant species that were eaten by gibbons. Values not bold show plants that produced edible tissues that gibbons were not observed feedingon them.

\begin{tabular}{|c|c|c|c|c|c|c|}
\hline Species & Months & $\begin{array}{r}\text { Timespent } \\
\text { feeding }(\%) \\
\text { onall plant } \\
\text { tissues }\end{array}$ & $\mathrm{FAI}(\mathrm{fr})$ & FAI(fl) & FAI(yl) & $\mathrm{FI}(\mathrm{ml})$ \\
\hline Ficus. $s p$ & Jan & 24.25 & 0.14 & 0.00 & 0.03 & 0.24 \\
\hline Garcinia oliveri & Jan & 16.83 & 0.00 & 0.22 & 0.09 & 0.25 \\
\hline Gnetum macrostachyum & Jan & 1.10 & 0.08 & 0.00 & 0.00 & 1.16 \\
\hline Ilex umbellulata & Jan & 0.77 & 0.00 & 0.17 & 0.14 & 0.51 \\
\hline Willughbeia edulis & Jan & 0.58 & 0.00 & 0.00 & 0.31 & 2.16 \\
\hline Lithocarpus elegans & Jan & 0.22 & 0.00 & 0.00 & 2.66 & 11.02 \\
\hline Dialium cochinchinensis & Jan & 0.00 & 0.00 & 0.00 & 0.10 & 0.21 \\
\hline Madhuca elliptica & Jan & 0.00 & 0.00 & 0.00 & 0.00 & 1.44 \\
\hline Mangifera duperreana & Jan & 0.00 & 0.00 & 0.00 & 0.04 & 0.37 \\
\hline Dipterocarpus alatus & Jan & 0.00 & 0.00 & 0.00 & 0.00 & 0.62 \\
\hline Total (eaten + not eaten) & & 43.75 & 0.21 & 0.39 & 3.44 & 17.98 \\
\hline Ficus. sp & Feb & 19.55 & 0.14 & 0.00 & 0.10 & 0.17 \\
\hline Lithocarpus elegans & Feb & 14.56 & 0.00 & 0.00 & 3.80 & 9.88 \\
\hline Dipterocarpus alatus & Feb & 12.94 & 0.00 & 0.31 & 0.15 & 0.15 \\
\hline Ilex umbellulata & Feb & 10.26 & 0.25 & 0.11 & 0.07 & 0.39 \\
\hline Garcinia oliveri & Feb & 7.76 & 0.00 & 0.25 & 0.09 & 0.28 \\
\hline Gnetum macrostachyum & Feb & 6.78 & 0.54 & 0.00 & 0.31 & 0.39 \\
\hline Mangifera duperreana & Feb & 6.50 & 0.00 & 0.00 & 0.17 & 0.24 \\
\hline Dialium cochinchinensis & Feb & 1.92 & 0.00 & 0.00 & 0.13 & 0.18 \\
\hline Willughbeia edulis & Feb & 1.78 & 0.62 & 0.00 & 0.46 & 1.39 \\
\hline Madhuca elliptica & Feb & 0.95 & 0.20 & 0.06 & 0.03 & 1.16 \\
\hline Total (eaten + not eaten) & & 83.00 & 1.74 & 0.72 & 5.32 & 14.23 \\
\hline Ilex umbellulata & Mar & 46.37 & 0.34 & 0.00 & 0.03 & 0.45 \\
\hline Willughbeia edulis & Mar & 18.43 & 0.93 & 0.00 & 0.00 & 1.54 \\
\hline Madhuca elliptica & Mar & 9.78 & 0.42 & 0.03 & 0.15 & 0.84 \\
\hline Lithocarpus elegans & Mar & 9.14 & 0.00 & 0.00 & 3.52 & 10.16 \\
\hline Dialium cochinchinensis & Mar & 5.87 & 0.00 & 0.00 & 0.10 & 0.21 \\
\hline Ficus. sp & Mar & 3.30 & 0.14 & 0.00 & 0.00 & 0.27 \\
\hline Gnetum macrostachyum & Mar & 1.38 & 0.46 & 0.00 & 0.15 & 0.62 \\
\hline Dipterocarpus alatus & Mar & 0.86 & 0.00 & 0.23 & 0.15 & 0.23 \\
\hline Garcinia oliveri & Mar & 0.55 & 0.00 & 0.12 & 0.12 & 0.37 \\
\hline Mangifera duperreana & Mar & 0.00 & 0.00 & 0.00 & 0.00 & 0.41 \\
\hline Total (eaten + not eaten) & & 95.68 & 2.29 & 0.38 & 4.24 & 15.10 \\
\hline Total (Jan + Feb + Mar) & & & 4.24 & 1.49 & 13.00 & 47.31 \\
\hline
\end{tabular}




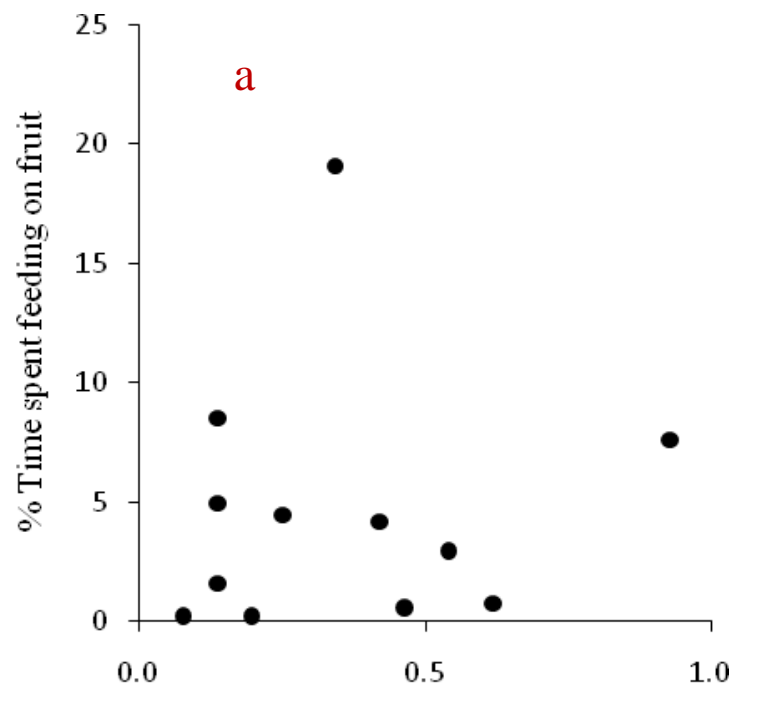

Food availability index (fruit)

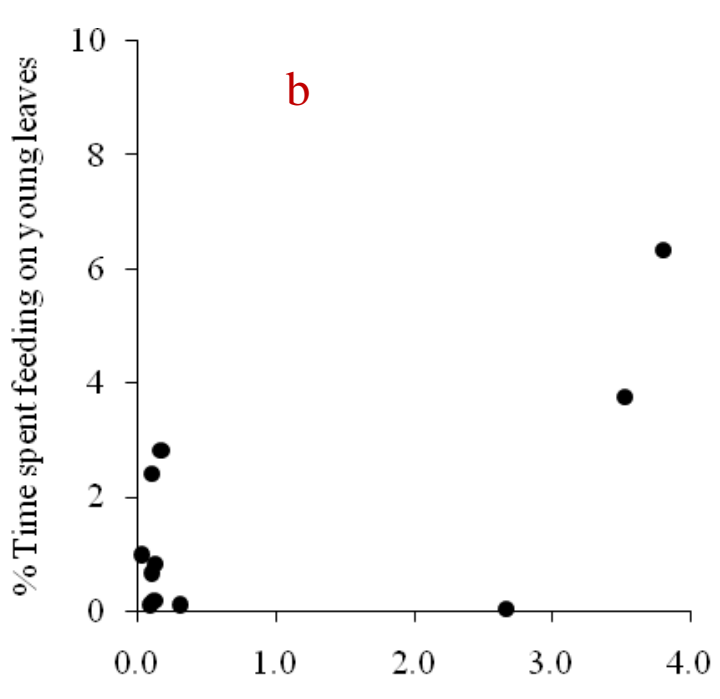

Food avaliability index (young leaves)

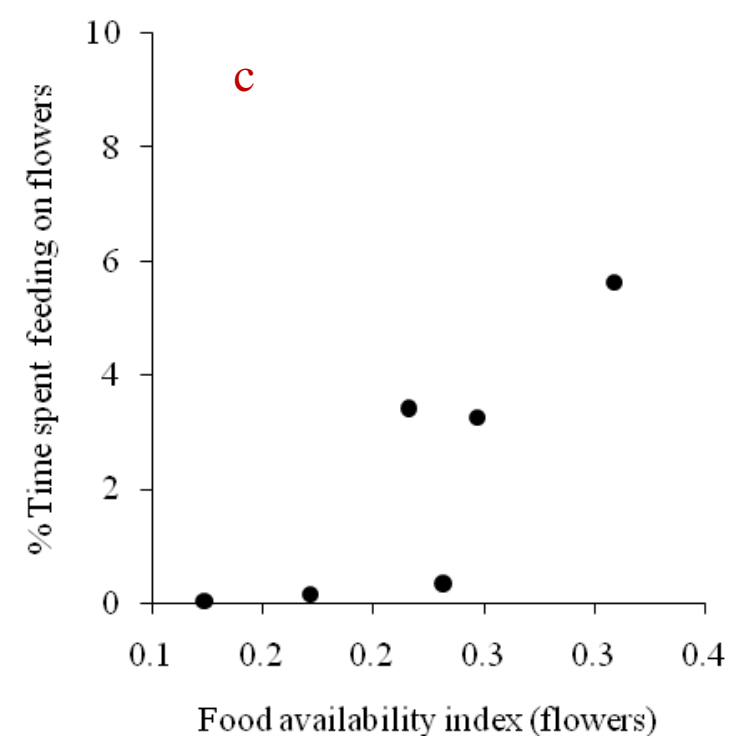

Figure 2.9: Scatter plots showing the relationship between (a) feeding time and $\mathrm{FAI}_{(\mathrm{fr})}$, (b) feeding time and $\mathrm{FIA}_{(\mathrm{yl})}$, (c) feeding on time and $\mathrm{FAI}_{(\mathrm{fl})}$ from the top 10 species (the data was accumulated from the three-month study period, January, February and March 2015). 


\subsection{Discussion}

\subsubsection{Activity budgets}

Activity budgets were similar between all members of the study group of northern yellow-cheeked crested gibbons ( $N$. annamensis). This pattern is similar to other studies where individual primates in the same group spend similar amounts of time on each activity (Isbell \& Young 1993; Fan et al. 2008; Frechette et al. in prep). This synchronous behaviour is relatively common when animals live in a group (Engel \& Lamprecht 1997). This behaviour is also found in other gibbon studies, where when one member starts, others usually also join in (Islam \& Feeroz 1992). The gibbons in group A spent the most activity time resting, followed by feeding and travelling. Socializing took up a comparatively minor part of the activity budget. This is similar to eastern hoolock gibbons (Hoolock leuconedys) that spend more time resting than other parts of their activity budgets (Fan et al. 2013). However, it contradicts another study where it was found that hoolock gibbons (Hoolock hoolock) spend most of their daily time feeding, particularly between October and April (Islam \& Feeroz 1992). Although the present study did not analyse the various factors that influence this behaviour, other studies on gibbons and monkeys reveal that weather conditions including rainfall, temperature, and food availability may influence behaviour and may therefore be playing a role here (Islam \& Feeroz 1992; Watanuki \& Nakayama 1993; Fan et al. 2013).

During the study periods, selective illegal logging was occasionally observed, particularly in March, due to the lack of law enforcement during that time. Logging may modify the ecology and behaviours of some primate species due to the reducing food availability (Johns 1986; Hardus et al. 2012). After logging, orang-utans, spend more time travelling and searching for food (Hardus et al. 2012). Noise pollution, such as that produced by logging activities, also impacts animal behaviour (Hanson et al. 1976; Brumm 2004; Siemers \& Schaub 2011). For example, while common marmosets (Callithrix jacchus) generally select habitats with high food availability (Pontes \& Soares 2005), noise pollution, can lead to them avoiding such areas and instead selecting habitat with low levels of noise, even if there is low food availability in these areas (Duarte et al. 2011). Gibbons are territorial animals (Marshall \& Marshall 1976), so their strategies of avoiding noise pollution may be different from other primates. The gibbons in group A were frequently out of observation or hiding when chainsaws were heard near the observation areas, compared to times when only researchers were present and the environment was quiet. They also 
increased their inactive time when logging was more frequent (in March). This suggests that noise pollution from logging activities may modify the behaviour of $N$. annamensis, although future study is needed to clarify that how this behaviour will change when they are exposed to noise (logging or increased number of people).

\subsubsection{Food plant selection}

Although the two dominant plant species, N. mutabile and Nang Kmov (local name) are categorised by the local guides as gibbon feeding trees, they were not used as food sources during the study periods. The genus Nephelium normally bears fruit in late April and early May, and its fruit is also consumed by white-handed gibbons $(H$. lar) in Thailand (Whitington \& Treesucon 1991). Although the gibbons selected 37 different plant species for their food sources, only 16 species (feeding more than $1 \%$ ) were the most selected. However, the relative density of these most preferred food species (top 10 species) were very low inside the home range of this group of gibbons, particularly I. umbellulata and Ficus. sp, at $0.82 \%$ and $0.41 \%$, respectively. This indicates that this group of $N$. annamensis actively selects rare over common plant species, at least at some points in the year. Since selective loggings and shifting cultivations are common near the study area, by cutting down those uncommon species would pose a serious threat to $N$. annamensis.

\subsubsection{Diet budgets}

Fruit makes up the majority of $N$. annamensis' diet. The gibbons mostly consumed only the flesh of the fruit, and generally spat seeds out, although some small fruits were swallowed with seeds. Other studies have also found that fruit is the main diet for most species in the Hylobatidae family (McConkey et al. 2002; Fan et al. 2013; Ni et al. 2014). However, in the harsh environment, some species of gibbons, N. c. jingdongensis, spend more time feeding on young leaves than fruit (Fan et al. 2009). Although fruit is important for $N$. annamensis, unripe fruit were usually avoided in the present study. The gibbons were not observed feeding on the unripe fruit from some species, including W. edulis and M. elliptica, and were rarely observed feeding on unripe fruit of I. umbellulata, G. macrostachyum, Ficus. sp, and Ficus racemosa. Similarly, white-handed gibbons (H. lar) consume only a small quantity of unripe fruit (Whitington \& Treesucon 1991). This may be due to the fact that unripe fruits contain less sugar and lipids (Felton et al. 2009c), but higher concentration of toxins and other secondary compounds than ripe fruit (Wrangham \& Waterman 1983). 
Young leaves and flowers were also important plant tissues in the diet of this group of $N$. annamensis. The gibbons preferred the young leaves from L. elegans and the flowers from D. alatus over those of other plant species. Both young leaves and flowers from G. oliveri were also consumed by this study group. Mature leaves and insects including honey bee and bee larvae comprised the lowest proportion of the gibbons' diets. These feeding behaviours are also found in other gibbon species (Whitington \& Treesucon 1991; McConkey et al. 2002; Fan et al. 2009; Borah et al. 2014). Together, these observations indicate that fruit is the preferred plant tissue in the diet of $N$. annamensis, and this is likely due to the fact that fruit has higher level of sugar and lipids than other plant parts (Rothman et al. 2006; Felton et al. 2009c). However, as with other gibbons, this gibbon species needs to consume alternative food sources in order to meet nutritional requirement including young leaves, which generally contain high concentration of protein (Rothman et al. 2006). Further details of the nutritional compositions of food consumed by $N$. annamensis see Chapter 3 .

\subsubsection{Food availability}

Although $N$. annamensis spent most of the time feeding on fruit when it became available, there was no statistically significant relationship between feeding time and the availability of fruit $\left(\mathrm{FAI}_{\mathrm{fr}}\right)$ inside the home range of this group of gibbons. This is due to the fact that only a small number of plants bore fruit, especially in January. Furthermore, the relative densities of trees and lianas that bore fruit were very low. For example, eight of the 10 most common food plants represented only $\sim 7 \%$ of the total plant species, and only $3 \%$ of plants bore fruit in January, although the number increased to $10 \%$ in March (Figure 2.8). However, the small density of those plants produce a large abundance of fruit, which meant that the gibbons increased feeding time on fruit, but only in on small numbers of plant species.

There was also no significant relationship between feeding time and the availability of young leaves $\left(\mathrm{FAI}_{\mathrm{yl}}\right)$. The absence of this relationship may be due to the fact that young leaves were an alternative food source for $N$. annamensis, as found in other studies (Fan et al. 2013; Ni et al. 2014). Most gibbons feed on fruit as the main diet, but may shift to young leaves or flowers during periods when fruit availability is low (McConkey et al. 2002; Fan et al. 2009; Mitrajit et al. 2014). The N. annamensis study group here spent more time feeding on young leaves in January, but this declined when fruit became available in March (Figure 2.7). However, there was a significant relationship between feeding time and availability of 
flowers $\left(\mathrm{FAI}_{\mathrm{fl}}\right)$. That is to say that time spent feeding increased when the species became more available in the habitat. The production of flowers in Cambodian forests mostly peak in February until April (Rawson 2009). Although flowers are a third choice for N. annamensis, there may be important nutrition values that this gibbon species need to include in their diets. Generally, individual flowers provide very low nutritional values, but flowers may serve as good sources of sugar, water content (Garber 1988) and minerals (Hladik 1977; Rop et al. 2012).

The present study clearly indicates that those small numbers of trees that bore fruit play an important role for gibbons' food sources during the study periods. The reason why the gibbons mainly select these 16 plant species for food sources is likely to be that they both produced a large quantity. This suggests that without special protection on those particular feeding plants, especially the 10 feeding plant species, there may be a negative effect on the population size of this gibbon species. The reduction of food availability may affect the lifespan and reproductive success of this species as it does for other primates (Thompson \& Wrangham 2008; Mattison et al. 2012). Because of the removal of trees in Uganda, the population size of the olive baboon (Papio anubis) and common chimpanzee (Pan troglodytes) were lower in logged forested areas than non-logged forested areas (Plumptre \& Reynolds 1994). Juvenile and infant primates in selectively logged regions generally have higher mortality rates than those in non-logging habitats (Chapman et al. 2000). This may due to the fact that those primates consumed food with lower nutritional values due to the deduction of food availability, leading to the overall consumption of lower quality and lower milk production by lactating females (Altmann et al. 1977). 


\subsection{Summary}

All $N$. annamensis individuals in the study group spent similar amounts of time on each activity in their activity budget, and fed on similar plant tissues. They spent most of the time resting compared to other activities, including feeding, travelling and socializing. Although the gibbons spent more time feeding on flowers when they became available, no relationships were found between feeding time and availability of fruit or young leaves. Fruit is a stable' diet of this gibbon species, but they also consumed young leaves, flowers, mature leaves, and insects as alternative food sources. Although N. annamensis selected 37 plant species as food sources, 16 of these plant species contributed a major role in their diets. Of these 16 important food plant species, only a few of them bore a large amount of fruit during the study period in particular, I. umbellulata, Ficus. sp, and W. edulis. These species were particularly important food sources for $N$. annamensis; however, their relative density was very low inside the home range of this group of gibbons.

These results clearly indicate that this gibbon species selected rare over common plant species for food. These findings contribute to long-term conservation programs for this species in the wild, by suggesting key food species (I. umbellulata, Ficus. sp, L. elegans, G. oliveri and W. edulis) which should be additionally protected. The availability of preferred food species must be maintained, lest a reduction in food availability reduce population sizes of primates (Plumptre \& Reynolds 1994; Chapman et al. 2000; Thompson \& Wrangham 2008; Duarte et al. 2011). Other factors that may have influenced the behavioural ecology of this species were logging and noise pollution. Although data is currently insufficient to show whether noise pollution from chainsaws influences the behavioural ecology of $N$. annamensis, future studies are needed, as it does affect other primate species (Pontes \& Soares 2005; Hardus et al. 2012) and may appears to impact the behaviour of N. annamensis. 


\section{Chapter 3}

\section{Nutritional composition of northern yellow-cheeked crested gibbons (Nomascus annamensis) diets in northern Cambodia}

\subsection{Introduction}

Food is the most important resource for all living organisms (Leibold \& Wilbur 1992; Mead et al. 1999; Grandison et al. 2009), as it can affect health, lifespan, social relationships, fitness and reproduction (Fernandes et al. 1976; Koenig et al. 1997; Givens \& Shingfield 2004; Grandison et al. 2009; Harris et al. 2010; Trepanowski et al. 2011). In order to optimise the benefits of food items, animals must make a choice about which foods to include in their diets (Felton et al. 2009c; Matsuda et al. 2013). Optimal foraging theory states that animals will maximize nutritional intake while minimising searching time in order to conserve energy (MacArthur \& Pianka 1966; Cowles et al. 1988; Demott 1989; Belovsky 1997). Following this theory, it would be expected that to maximize nutritional intake, most animals would select high quality food sources (those with easily digestible nutrients) over those of lower quality (that are harder to digest) (Milton 1979; Cowles et al. 1988; Moser et al. 2006). In addition, most animals should search for food in areas of high food availability (Vedder 1984; Moser et al. 2006), and increase resting time when food is less available (Watanuki \& Nakayama 1993; Korstjens et al. 2010). These ideas have led to research on food selection (MacArthur \& Pianka 1966; Mckey et al. 1981; Kool 1992; Belovsky 1997; Chapman \& Chapman 2002), and the role of plant chemistry in food selection by animals (Speiser \& Rowell-Rahier 1991; Coley \& Barone 1996; Rothman et al. 2006; Felton et al. 2009a; Behie \& Pavelka 2012a).

Research on primates has found that many primate species prioritise plant foods with high concentrations of protein (Milton 1979; Rothman et al. 2008b; Felton et al. 2009a; Felton et al. 2009b; Felton et al. 2009c; Rothman et al. 2011; Hanya \& Bernard 2015). This is due to the fact that protein is a crucial nutrient for reproduction, growth, and survival (Mattson Jr 1980; Yiming 2006; Felton et al. 2009a; Felton et al. 2009b). However, different species of primates rely on different sources for protein. For example, most gibbons (Hylobatidae) normally gain protein from protein-rich insects rather than plant tissues (Chivers 1998; Borah et al. 2014), whereas the Old World colobines consume young leaves as their main source of protein (Kool 1992; Chivers 1998; Chapman \& Chapman 2002). Even 
for species that ingest primarily low protein fruit, some groups have been found to maintain a consistent daily protein intake, while allowing the relative intake of other nutrients including lipids and carbohydrates (sugar and starch) to fluctuate (Felton et al. 2009c), showing the importance of protein selection for all species regardless of diet type.

Plant tissues with a high fibre content and/or high levels of secondary compounds tend to be less selected or avoided by most primate species (Davies et al. 1988; Yiming 2006; Hanya \& Bernard 2015). This is perhaps to be expected, considering that food items with high concentrations of secondary metabolites are difficult to digest, lack nutritional value, and can contain toxins (Glander 1982; Davies et al. 1988; Chapman \& Chapman 2002; Acamovic \& Brooker 2005; Simmen et al. 2013). For example, unripe fruits are usually avoided by white-handed gibbons (Hylobates lar) (Whitington \& Treesucon 1991). This may be because unripe fruit not only contain less sugar and lipids (Felton et al. 2009c), but also have higher concentrations of toxins and other secondary compounds than ripe fruit (Wrangham \& Waterman 1983). Similarly, mature leaves are normally avoided by most primates (Kool 1992; Felton et al. 2009c). However, in contrast to usual primate foodselection behaviour, black howler monkeys (Alouatta pigra) preferentially select mature leaves over young leaves following a hurricane in 2001, due to the higher concentration of simple sugars (Behie \& Pavelka 2012a). These variable findings suggest that the composition of primate diets are complicated and highly dependent on species and the environments in which they are found (Chapman \& Chapman 2002; Strier 2007; Smith et al. 2013).

Nutritional geometry has recently been proposed as a framework to simplify the complexity of primate nutritional ecology (Simpson \& Raubenheimer 1995; Raubenheimer 2011). A nutritional geometrical framework (GF) is used to show those nutrients that are prioritized by animals, and those that are allowed to fluctuate (Simpson \& Raubenheimer 1993; Raubenheimer \& Simpson 1997). This model has been tested in some primate species including mountain gorillas (Gorilla beringei) (Rothman et al. 2011) and Peruvian spider monkeys (Ateles chamek) (Felton et al. 2009c). While this method provides a more accurate picture of food selection in wild primates, it does require detailed measurements of the amount of each food item consumed, which often precludes its use (Raubenheimer et al. 2015). The right-angled mixture triangle (RMT) is a simpler method that uses the variation in dietary nutrients as a proportion rather than overall amount in a single graph (Figure 3.1) (Raubenheimer 2011; Raubenheimer et al. 2015). The RMT model provides data on an animal's food selection, mixture of food items, and nutritional requirements (Raubenheimer 
2011), enabling simple and effective comparisons between species or populations, and annual intakes of nutritional components consumed primates, including protein, lipid, and fibre (Raubenheimer et al. 2015). Consequently, the RMT model is a useful and appropriate tool when comparing food selection and nutritional requirements, and this model has been tested in some primate species, including chacma baboon (Papio hamadryas ursinus) (Johnson et al. 2013), common chimpanzees (Pan troglodytes), blue monkeys (Cercopithecus mitis), redtailed monkeys (Lophocebus albigena), grey-cheeked mangabey (Lophocebus albigena) and mountain gorillas (G. beringei) (Raubenheimer et al. 2015).

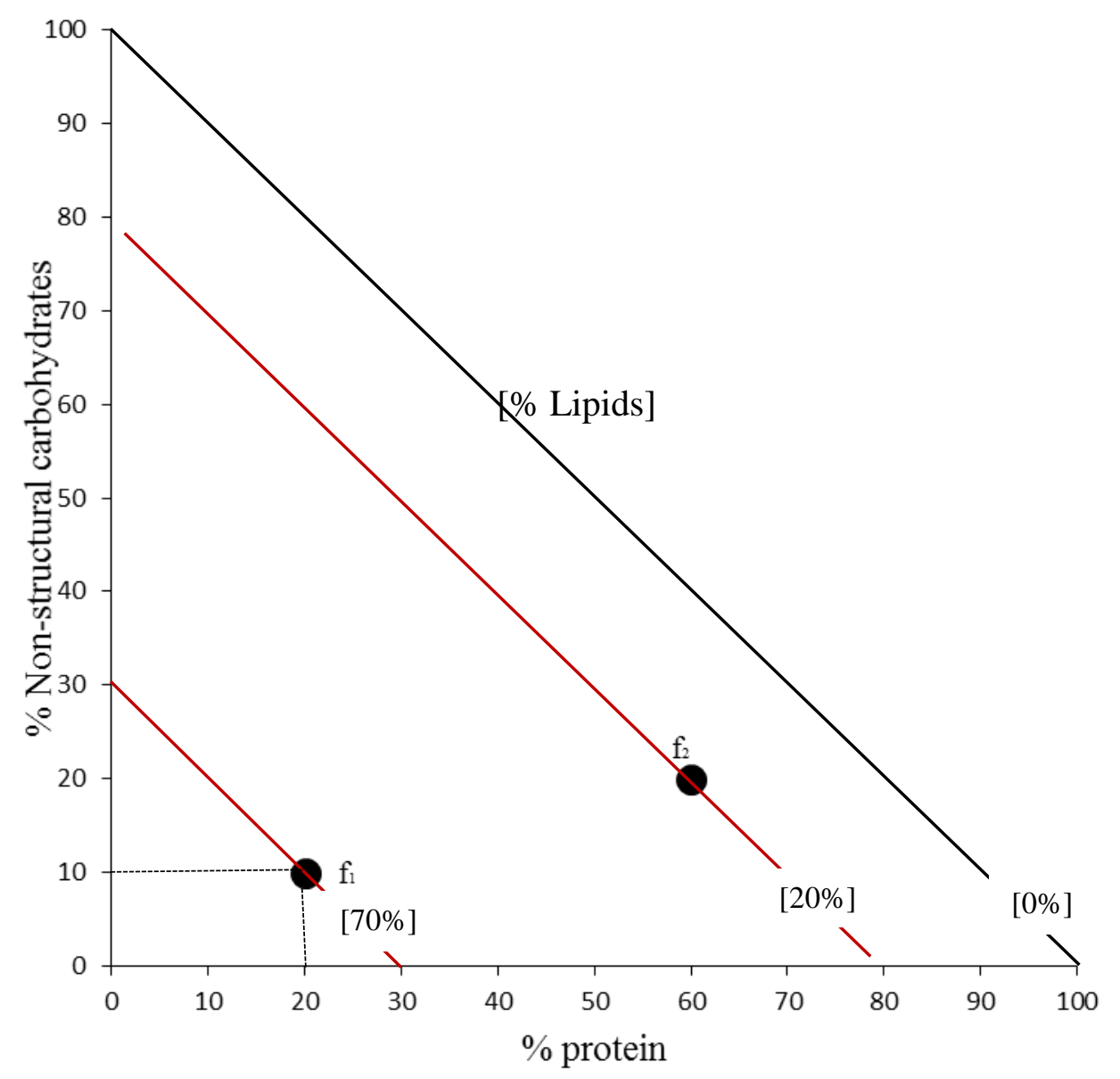

Figure 3.1: An example of right-angled mixture triangle (RMT) showing the combination of protein $(\mathrm{P})$, total non-structural carbohydrates (TNC) and lipids ( $\mathrm{L}$ ) of two food items $\left(\mathrm{f}_{1}\right.$ and $\left.\mathrm{f}_{2}\right)$. P and TNC are plotted on the $X$ and $Y$ axes, respectively. The lipid (L) content is determined by the equation $\mathrm{L}=$ $100-(\mathrm{TNC}+\mathrm{P})$, assuming the total value of $\mathrm{P}, \mathrm{TNC}$, and $\mathrm{L}$ are $100 \%$. The values of $\mathrm{L}$ are illustrated by a series of diagonal lines. Each point $\left(\mathrm{f}_{1}\right.$ and $\left.\mathrm{f}_{2}\right)$ represents the percentage of $\mathrm{P}, \mathrm{TNC}$, and $\mathrm{L}$ in each food item. For example, $\mathrm{f}_{1}$ contains $20 \% \mathrm{P}$ and $10 \% \mathrm{TNC}$, so the value of $\mathrm{L}$ is $100-(20+10)=70 \%$. So, to gain more lipids, animals need to eat $\mathrm{f}_{1}$, or any food item that fits on the $70 \% \mathrm{~L}$ diagonal line. Food item $\mathrm{f}_{2}$, is on the $20 \%$ lipid line with $60 \% \mathrm{P}$ and $20 \% \mathrm{TNC}$.

Source: Modified from Raubenheimeret al. (2015) 
Despite the recent use of GF and RMTs in primate studies, current knowledge of the drivers of food selection in these animals remains limited (Rothman et al. 2006; Rothman et al. 2008b; Felton et al. 2009a; Felton et al. 2009c; Behie \& Pavelka 2012b; Simmen et al. 2013), with relatively nothing known regarding crested gibbons (Nomascus. spp). Crested gibbons are among the most endangered primates in the world (Geissmann 2007). Populations of these species have declined significantly due to habitat destruction and hunting (Cheyne et al. 2008; Gray et al. 2010; Rawson 2010b). Most species of crested gibbons are listed as Endangered or Critically Endangered by the IUCN Red List and all are in CITES Appendix I (Geissmann 2007; Rawson 2010b). The northern yellow-cheeked crested gibbon (Nomascus annamensis) is a newly described species (Thinh et al. 2010) and even though the status of this species has not yet been updated, it is likely to be listed as Endangered by IUCN Red List as it faces similar threats to other gibbons (Thinh et al. 2010).

Fruit is the main diet of $N$. annamensis, supplemented with young leaves, flowers, mature leaves and insects (Frechette et al. in prep; Chapter 2) However, the nutritional composition of these food items is as yet unknown. This knowledge would allow an understanding of the nutritional requirements of this endangered species. This understanding would also help policy makers to preserve key food resources for wild populations. Monitoring key plant species would then help maintain wild gibbon populations by protecting crucial resources for the survival of these animals. In focussing on food selection by $N$. annamensis and detailing the nutritional composition and value of food items ingested by this species, this study will contribute to long-term primate conservation programs, not only in Cambodia, but in other countries where this gibbon species is found. As such, this chapter focuses on the drivers of food selection in N. annamensis in northern Cambodia, and aims to answer two basic questions: (1) What are the nutritional compositions of food items selected by this gibbon species? (2) Using the RMT model (Raubenheimer et al. 2015), what food items and nutritional compositions are targeted by this group of $N$. annamensis? 


\subsection{Methods}

See Chapter 2 sections 2.2.1, 2.2.2, and 2.2.3 for details of the study site, study group of $N$. annamensis, and behavioural data collection, respectively.

\subsubsection{Plant sample collection}

Where possible, samples of food items (plant tissues) were obtained from trees and lianas on the same day as gibbons were observed feeding on them. If samples could not be obtained immediately, the plant was tagged with a coloured tag, its GPS location noted, and it was climbed the next day, with assistance from local villagers when required (Figure 3.2). Samples were collected from as close a location as possible within the tree or liana to where the gibbon had been seen feeding. Fruit samples were collected at a similar level of ripeness to those consumed, and leaves and flowers (Figure 3.3a) of a similar age were selected. If the observed feeding area was too high for samples to be safely collected, plant samples were collected from trees or lianas of the same species nearby or inside the home range of the study group.

Once back at base camp, each sample was weighed on a balance until the final mass was $100 \pm 0.1 \mathrm{~g}$. Before weighing, food items were processed as the gibbons processed them. For example, seeds were removed from any fruit samples if the gibbons did not eat the seeds (Figure 3.3b). Samples were air-dried in direct sunlight (between 7 and 15 days or until the dry weight was constant), and then re-weighed to give an initial dry weight. Samples were then sealed in plastic bags and stored out of sunlight. One bag of silica gel was put in each bag of plant sample to absorb any moisture and avoid decomposition. Samples were then exported for analysis at the Nutritional Ecology Lab at Hunter College, the City University of New York (CUNY), USA where they were stored at room temperature until analysis. 

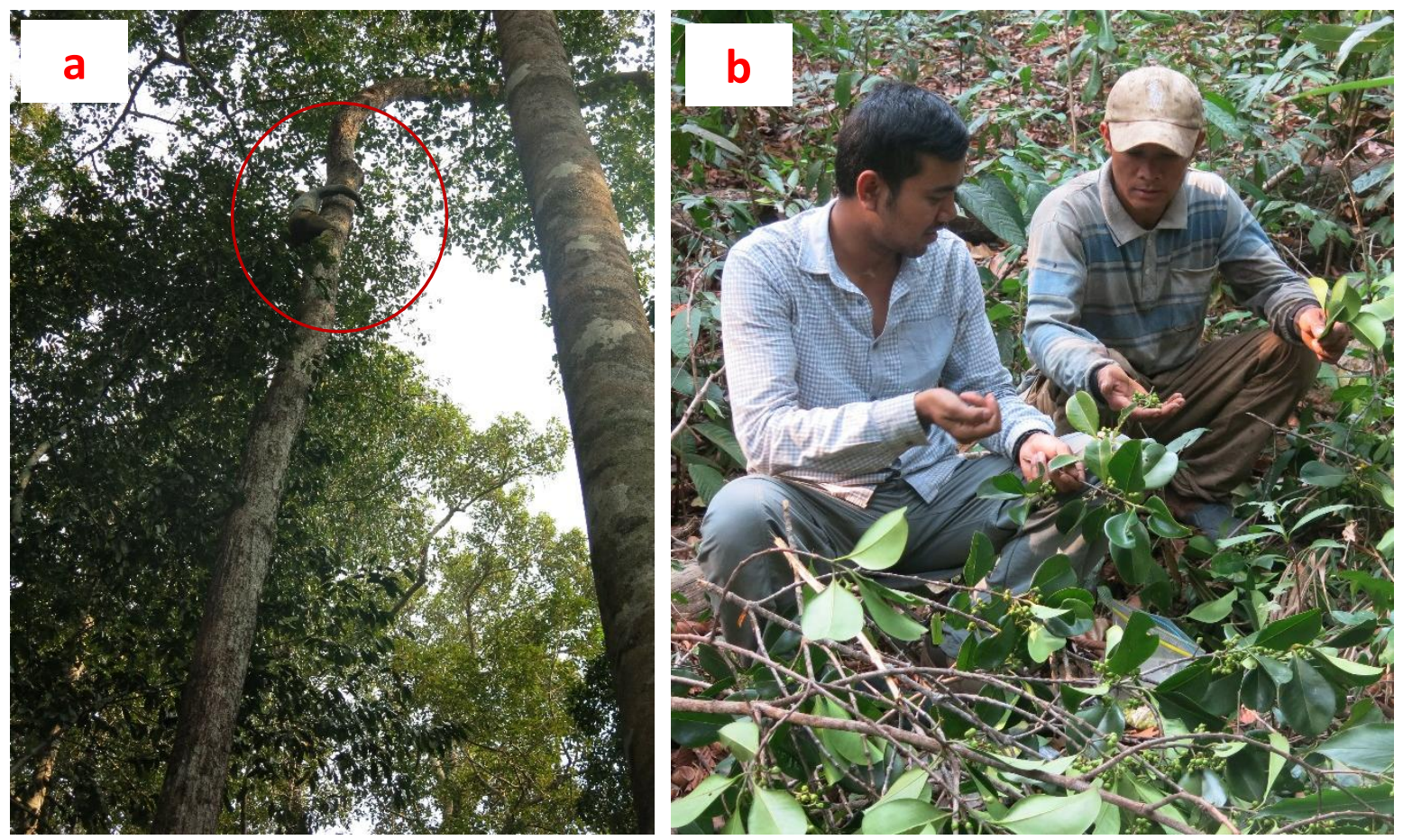

Figure 3.2: Plant sample collection. Most samples were collected by climbing. (a) Local assistant climbing I. umbellulata to collect fruit samples; (b) selecting fruit samples after collection. The ripe fruit from this species are red, yellow, and slightly yellow, while the unripe fruits are green and dark green.

Photo: Nave Hon and Noy Gnet.
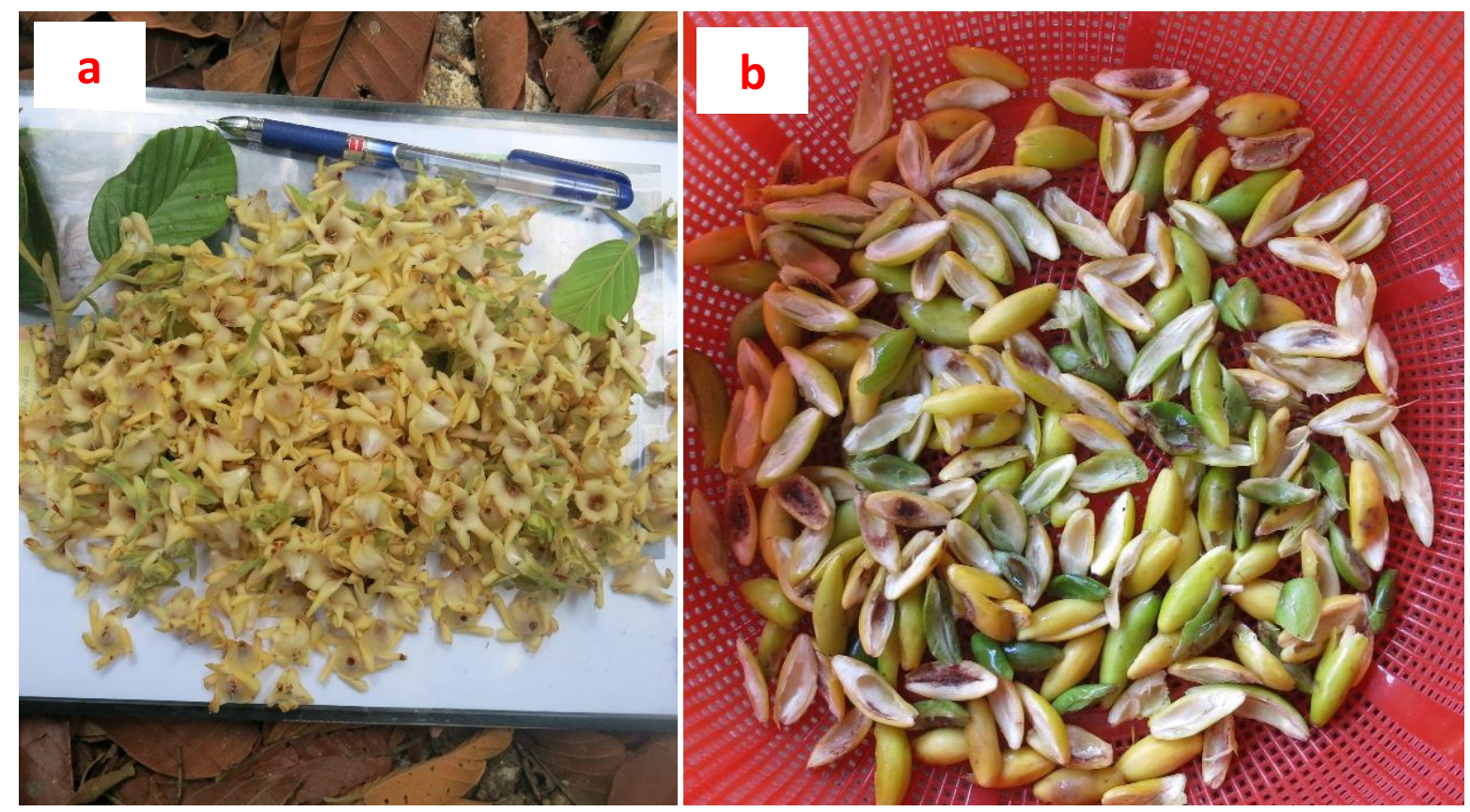

Figure 3.3: Plant sample preparation. Flowers of D. alatus were (a) collected at the field site, and (b) seeds of M. elliptica were removed, in preparation for drying in direct sunlight. The ripe fruit from this species are yellow or slightly green and yellow, while the unripe fruits are green and dark green.

Photo: Naven Hon 


\subsubsection{Nutritional analyses}

The nutritional analyses of all plant samples were undertaken at the Nutritional Ecology Lab at Hunter College with the assistance of Dr Jessica Rothman's team. Seventyfour plant samples (plant tissues) from 20 plant species were selected for analysis. The samples were comprised of 66 trees, six lianas, and two epiphytes and included fruit $(N=39)$, young leaves $(N=15)$, flowers $(N=14)$, and mature leaves $(N=6)$. All plant samples were ground in a Wiley Mill ${ }^{\circledR}$ (Arthur H. Tjomas Co., Philadelphia, PA), and passed through a 1mm screen (Rothman et al. 2006). The samples were analysed for protein (P), lipids (L), total non-structural carbohydrate (TNC), neutral detergent fibre (NDF), acid detergent fibre (ADF), acid detergent lignin (ADL), and the presence and absence of condensed tannins in dry matter (DM). Before analysis, samples were oven-dried at $105^{\circ} \mathrm{C}$ to obtain the absolute DM of the samples.

The moisture content was determined from the fresh weight (FW) and dry weight (DW) of the sample. Protein was calculated through combustion analysis using Leco Tru Spec nitrogen (N) analyser by calculating N x 6.25 to get protein (Licitra et al. 1996; Rothman et al. 2008a), and followed the protocol of Licitra et al. (1999). A method of analysing lipids was adapted from ANKOM Technology, and followed the protocol of Rothman et al. (2012). The cellulose and hemicellulose of the plant samples were measured via NDF, ADF, and ADL (Van Soest et al. 1991; Rothman et al. 2006). NDF includes both $\mathrm{ADF}$ and lignin, and it contains cellulose, hemicellulose and lignin, while ADF contains cellulose and lignin (Van Soest et al. 1991; Rothman et al. 2006; Rothman et al. 2012). The amount of ADL is estimated by removing cellulose and residual ash (Rothman et al. 2006). Finally, TNC was calculated by subtracting all other nutrients including crude protein, NDF, ash, and lipids from all plant samples (Rothman et al. 2012). Condensed tannins were estimated using an acid-butanol assay (Porter et al. 1985). A qualitative system was used to report the presence and absence of condensed tannins by measuring the absorbance values at $0.10-0.50(+), 0.50-1.00$ or above $(++), 1.00$, while values lower than 0.10 were marked as absent (Rothman et al. 2006).

\subsubsection{Statistical analyses}

The data were non-normal distributed, so Kruskal-Wallis tests were used to compare between groups (more than 2 groups), while Mann-Whitney $U$ tests were used to conduct 
pairwise tests. The percentage of nutrients $(\mathrm{P}, \mathrm{L}$, and TNC) and the concentration of different types of fibres (NDF, ADF, and ADL) of each plant tissue (fruit, flowers, young leaves and mature leaves) were compared using Kruskal-Wallis tests. Mann-Whitney $U$ tests were used to compare moisture, $\mathrm{P}, \mathrm{L}, \mathrm{TNC}, \mathrm{NDF}, \mathrm{ADF}$, and $\mathrm{ADL}$ in each plant tissue.

A right-angled mixture triangle (RMT) (Raubenheimer et al. 2015) was then constructed to show the relative contribution of $\mathrm{P}, \mathrm{TNC}$ and $\mathrm{L}$ in each food item in a single plot. Sixty-nine samples from 19 plant species were used for this model, including fruit $(N=$ $34)$, flowers $(N=14)$, young leaves $(N=15)$ and mature leaves $(N=6)$. Another five fruit samples were excluded from the analyses because some nutritional data was not available. The Kruskal-Wallis tests were used to compare the overall nutritional compositions (P, TNC and $\mathrm{L}$ ) in the 74 food samples [Food item $\mathrm{f}_{10}$ (Kbal Thum) was excluded in the analyses because protein data was unavailable]. Mann-Whitney $U$ tests were used to compare differences in P, L, and TNC in all 74 food samples.

All statistical analyses were performed in SPSS version 22, and in most cases $\alpha=$ 0.05. In pairwise tests (Mann-Whitney $U$ tests), a Bonferroni correction $(0.05 / \mathrm{N}$, i.e., $\alpha=$ 0.0125) was used to adjust for multiple tests (Rice 1989). 


\subsection{Results}

\subsubsection{Nutritional composition of Nomascus annamensis diets}

The nutritional composition of each plant tissue sample consumed by the study group of $N$. annamensis is summarised in Table 3.1. Seventy-four plant samples from the 20 plant species consumed by this group of gibbons were collected for nutritional analyses including P, L, TNC, fibres (ADL, ADF, and NDF) and condensed tannins (Table 3.2).

Table 3.1: Mean amount of nutrients (\% dry matter) in plant tissues consumed by one habituated group of northern yellow-cheeked crested gibbons (N. annamensis) from January - April 2015 at Veun Sai-Siem Pang Conservation Area (VSSPCA), Cambodia.

\begin{tabular}{llrr|llrr}
\hline Plant tissues & $\boldsymbol{N}$ & Mean (\%) & SD & Plant tissues & $\boldsymbol{N}$ & Mean (\%) & SD \\
\hline Fruit & & & & Young leaves & & & \\
\hline Moisture & 39 & 69.52 & 11.92 & Moisture & 15 & 80.34 & 4.06 \\
\hline Protein & 34 & 8.76 & 3.79 & Protein & 15 & 22.45 & 6.93 \\
TNC & 34 & 40.24 & 13.54 & TNC & 15 & 26.66 & 11.11 \\
Lipids & 34 & 5.64 & 4.57 & Lipids & 15 & 2.48 & 2.27 \\
Ash & 34 & 5.86 & 3.62 & Ash & 15 & 6.78 & 4.54 \\
NDF & 34 & 39.50 & 12.56 & NDF & 15 & 41.63 & 8.96 \\
\hline ADF & 34 & 31.32 & 11.24 & ADF & 15 & 28.34 & 12.35 \\
ADL & 34 & 18.74 & 6.88 & ADL & 15 & 25.73 & 10.19 \\
\hline Flowers & & & & Mature leaves & & & \\
\hline Moisture & 14 & 79.46 & 2.97 & Moisture & 6 & 88.93 & 4.16 \\
\hline Protein & 14 & 9.39 & 2.87 & Protein & 6 & 6.22 & 3.56 \\
TNC & 14 & 38.54 & 10.76 & TNC & 6 & 31.30 & 7.19 \\
Lipids & 14 & 5.98 & 3.89 & Lipids & 6 & 5.00 & 3.44 \\
Ash & 14 & 4.50 & 1.75 & Ash & 6 & 13.42 & 4.19 \\
NDF & 14 & 41.59 & 8.69 & NDF & 6 & 44.06 & 7.92 \\
\hline ADF & 14 & 30.81 & 12.56 & ADF & 6 & 37.86 & 14.86 \\
ADL & 14 & 28.61 & 7.85 & ADL & 6 & 18.48 & 4.74 \\
\hline SD: Stan
\end{tabular}

SD: Standard deviation, TNC: total non-structural carbohydrates, ADL: acid detergent lignin, ADF: acid detergent fibre, NDF: neutral detergent fibre. In the fruit section, the samples sizes for moisture* was $N=39$, because the data for one sample was not available. The sample sizes for other nutritional compositions of fruit was $N=34$, becausenutritional data for six samples were not available. 
Table 3.2: Mean nutritional compositions (\% dry matter) from the 20 plant species (trees and lianas) consumed by the northern yellow-cheeked crested gibbons (N. annamensis) from January - April 2015 at VSSPCA, Cambodia.

\begin{tabular}{|c|c|c|c|c|c|c|c|c|c|c|c|c|c|}
\hline Food & Species & $N$ & $\begin{array}{l}\text { Life } \\
\text { form }\end{array}$ & Part & $\% \mathrm{H}_{2} \mathrm{O}$ & $\%$ Protein & \%Lipids & $\% \mathrm{TNC}$ & Ash\% & $\% \mathrm{NDF}$ & $\% \mathrm{ADF}$ & $\% \mathrm{ADL}$ & Tannins \\
\hline f1 & Aglaia grandis & 1 & Tree & Fr & 82.53 & 6.26 & 4.10 & 59.24 & 8.38 & 22.02 & 19.21 & 14.95 & 0 \\
\hline $\mathrm{f} 2$ & Dialium cochinchinensis & 4 & Tree & YL & 77.67 & 20.06 & 1.87 & 31.68 & 2.76 & 43.63 & 22.42 & 27.85 & + \\
\hline f3 & Dipterocarpus alatus & 7 & Tree & $\mathrm{Fl}$ & 79.42 & 7.20 & 3.02 & 43.72 & 4.07 & 41.99 & 35.97 & 28.91 & $\mathbf{0}$ \\
\hline f4 & Dischidia ruscifolia & 2 & Epiphyte & ML & 91.54 & 3.45 & 3.04 & 29.50 & 16.20 & 47.82 & 44.95 & 19.99 & 0 \\
\hline f5 & Dischidia. $S p$ & 2 & Epiphyte & ML & 91.65 & 4.46 & 3.28 & 27.10 & 15.10 & 50.07 & 48.41 & 17.00 & 0 \\
\hline f6 & Ficus. Sp (2) & 10 & Liana & Fr & 60.29 & 5.23 & 2.40 & 33.09 & 7.03 & 52.25 & 38.93 & 27.74 & $\mathbf{0}$ \\
\hline f7 & Garcinia oliveri & 2 & Tree & YL & 88.02 & 16.07 & 2.99 & 40.14 & 5.90 & 34.90 & 18.97 & 18.51 & 0 \\
\hline f8 & Gnetum macrostachyum & 5 & Liana & $\mathrm{Fr}$ & 49.65 & 12.75 & 1.87 & 38.36 & 1.87 & 45.15 & 24.03 & 20.98 & 0 \\
\hline f9 & Ilex umbellulata (1) & 1 & Tree & $\mathrm{Fl}$ & 71.64 & 7.68 & 5.49 & 47.79 & 6.85 & 32.18 & 11.53 & 23.66 & ++ \\
\hline f9 & Ilex umbellulata (1) & 12 & Tree & Fr & 74.81 & 11.67 & 9.20 & 41.09 & 7.13 & 30.91 & 19.80 & 18.65 & + \\
\hline $\mathrm{f} 10$ & Kbal Thum $(L N)$ & 2 & Tree & Fr & 74.62 & ND & 22.21 & ND & 5.80 & 44.41 & 24.14 & 11.74 & 0 \\
\hline f11 & Lithocarpus elegans (3) & 2 & Tree & YL & 83.25 & 32.99 & 1.90 & 27.95 & 7.96 & 29.20 & 15.77 & 15.35 & 0 \\
\hline f12 & Madhuca elliptica ${ }^{* *}$ & 4 & Tree & $\mathrm{Fr}$ & 75.97 & 5.03 & 5.52 & 58.11 & 4.61 & 36.69 & 36.48 & 26.75 & 0 \\
\hline $\mathrm{f} 13$ & Mangifera duperreana & 2 & Tree & YL & 75.05 & 23.91 & 1.80 & 9.00 & 9.79 & 55.49 & 45.64 & 44.99 & $\mathbf{0}$ \\
\hline f14 & Ochna atropurpurea & 1 & Tree & $\mathrm{Fl}$ & 78.75 & 14.76 & 2.55 & 32.48 & 3.78 & 46.43 & 24.30 & 38.26 & 0 \\
\hline f15 & Syzygium. Sp & 1 & Tree & YL & 79.48 & 10.40 & 1.80 & 41.89 & 5.67 & 40.24 & 37.31 & 26.91 & + \\
\hline f16 & Unknown Liana & 1 & Liana & YL & 80.04 & 30.92 & 2.67 & 8.42 & 19.9 & 38.06 & 26.64 & 12.64 & 0 \\
\hline $\mathrm{f} 17$ & Vor Chrey Slektom $(L N)$ & 2 & Liana & ML & 83.60 & 10.77 & 8.69 & 37.30 & 8.97 & 34.28 & 20.21 & 18.46 & + \\
\hline $\mathrm{f} 18$ & Vor Krovanh $(L N)$ & 1 & Liana & YL & 80.48 & 30.54 & 10.26 & 20.87 & 5.47 & 32.86 & 29.82 & 25.73 & 0 \\
\hline f19 & Vor Tangant $(L N)$ & 1 & Liana & YL & 82.88 & 15.09 & 1.05 & 22.68 & 5.37 & 55.80 & 47.02 & 26.55 & 0 \\
\hline $\mathrm{f} 20$ & Willughbeia edulis (5) & 5 & Liana & $\mathrm{Fr}$ & 83.36 & 3.97 & 6.65 & 64.24 & 2.03 & 26.86 & 22.43 & 18.54 & + \\
\hline
\end{tabular}

Key: YL: young leaves, ML: mature leaves, Fl: flowers, Fr: fruit, LN: local name, TNC: total non-structural carbohydrate, ADL: acid detergent lignin, ADF: acid detergent fibre, NDF: neutral detergent fibre, ND: no data. Condensed tannins absorbance values represent absorbance units of 0.10-0.50 (+), 0.50-1.00 $(++)$ in a $12.5 \mathrm{mg} / \mathrm{ml}$ solution (dry weight) of plant sample. The number in brackets in the species column is the ranking of the top 5 plant species, order from 1 to 5 , from the highest percentage of time spent feeding on a species (1) to the highest (5). 


\subsubsection{Moisture}

Overall, moisture content was significantly different between all plant tissues (Kruskal-Wallis test: $H=31.34, P=0.0001$; Figure 3.4), fruit and flowers (Mann-Whitey tests: $U=114, P=0.001)$, fruit and young leaves $(U=107, P=0.0001)$, fruit and mature leaves $(U=3, P=0.0001)$, flowers and mature leaves $(U=1, P=0.001)$, and young leaves and mature leaves $(U=5, P=0.002)$. Only flowers and young leaves were similar $(U=101$, $P=0.86)$. Fruit had the lowest moisture content $(69.52 \%)$, while mature leaves contained more water $(88.93 \%)$ than young leaves $(80.34 \%)$, and flowers $(79.46 \%)$ (Figure 3.4). N. annamensis drank water from cavities within tree trunks (Appendix 2, Figure 3), and were never seen drinking water from the ground.

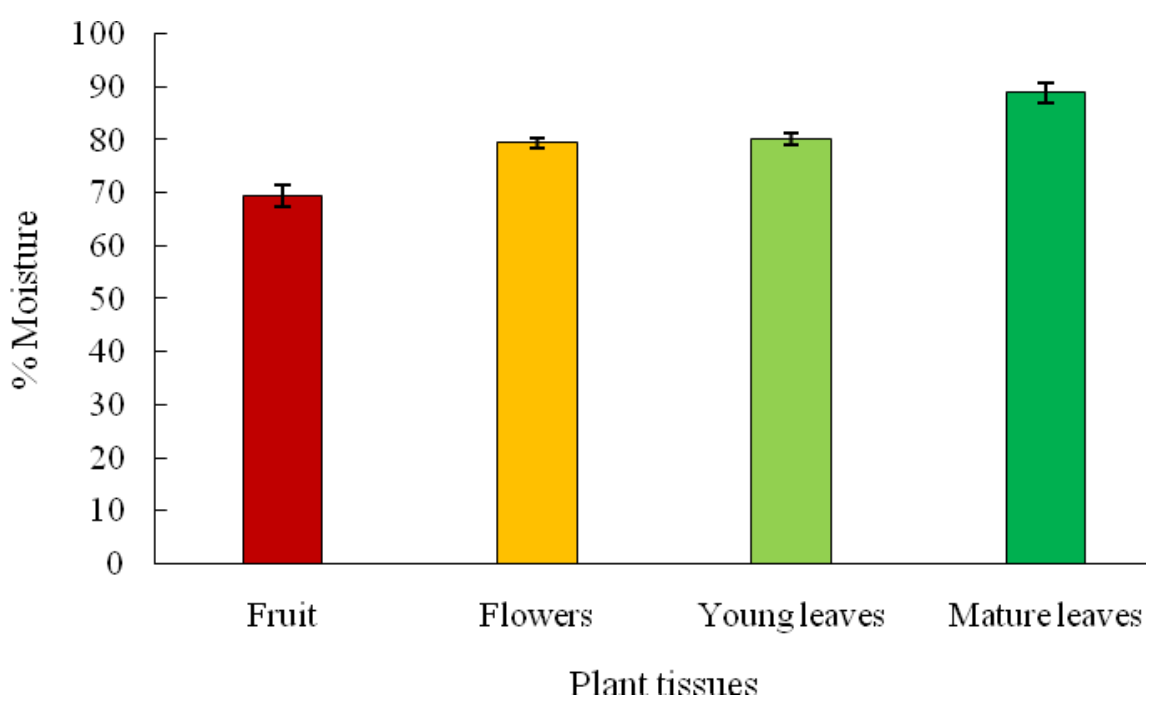

Figure 3.4: The average percentage of moisture contents in food items (fruit, flowers, young leaves and mature leaves) eaten by the study group of $N$. annamensis ( \pm standard error). 


\subsubsection{Protein}

Generally, the concentration of protein was significantly different among each plant tissue type (Kruskal-Wallis test: $H=33.61, P=0.0001$; Figure 3.5). Young leaves contained more protein than fruit (Mann-Whitney test: $U=14, P=0.0001)$, flowers $(U=2, P=$ $0.0001)$ and mature leaves $(U=2, P=0.002)$, while the protein content of other plant tissues were not statistically different from each other (all: $P \geq 0.10$ ). Young leaves had the highest level of protein $(22.45 \%)$, followed by flowers (9.39\%), fruit (8.52\%), and mature leaves $(6.22 \%)$ (Figure 3.5).

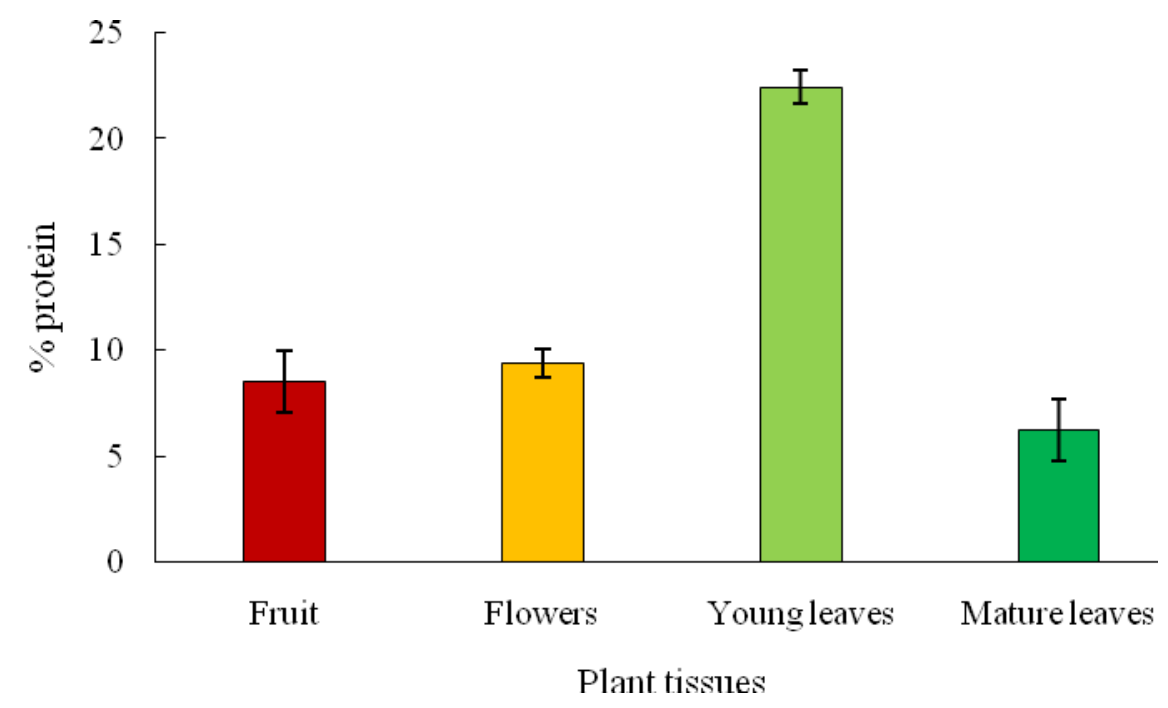

Figure 3.5: The average percentage of protein levelsof food items (fruit, flowers, young leaves and mature leaves) eaten by the study group of $N$. annamensis ( \pm standard error).

\subsubsection{Lipids}

Overall, the amount of lipids was significantly different for all plant tissues (KruskalWallis test: $H=31.34, P=0.005$; Figure 3.6). Young leaves had significantly lower lipid levels than fruit (Mann-Whitey tests: $U=140, P=0.002)$ and flowers $(U=24, P=0.0001)$, while the lipid contents of other food items were similar: fruit and flowers $(U=244, P=$ $0.47)$, fruit and mature leaves $(U=109, P=0.72)$, flowers and mature leaves $(U=36, P=$ $0.62)$ and young and mature leaves $(U=23, P=0.08)$. Fruit had the highest level of lipids (6.70\%), while flowers and mature leaves contained $5.98 \%$ and $4 \%$, respectively, and young leaves $(2.48 \%)$ had the lowest (Figure 3.6). 


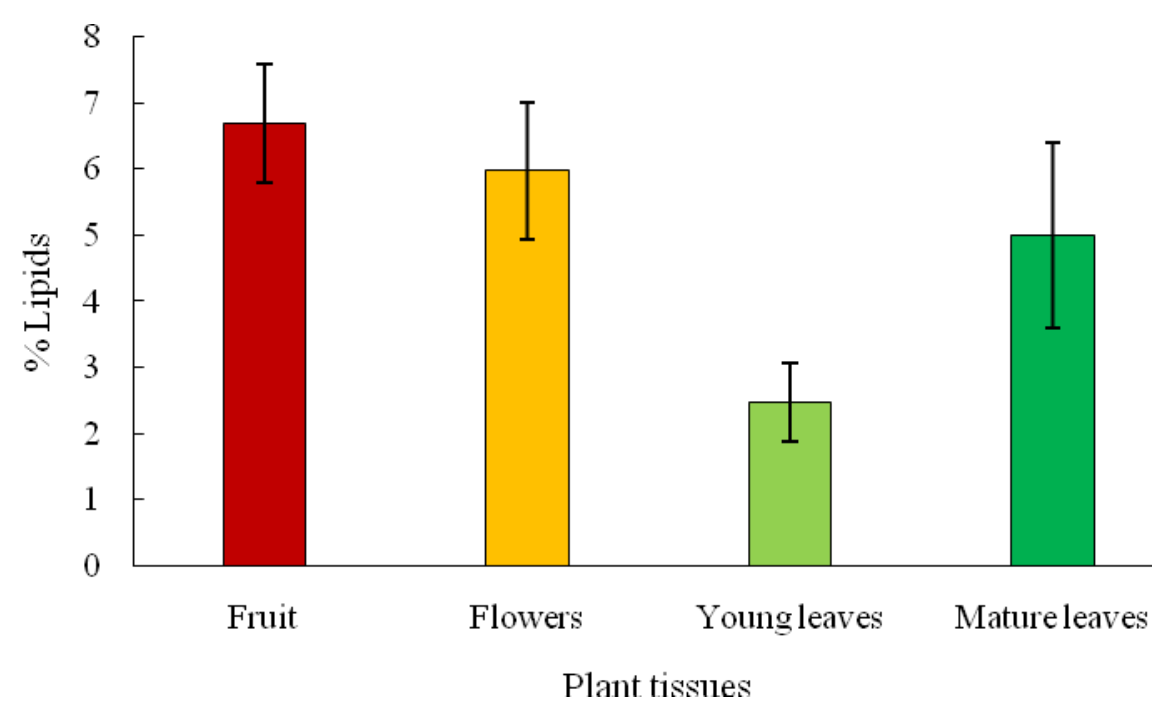

Figure 3.6: The average percentage of lipid levelsof food items (fruit, flowers, young leaves and mature leaves) eaten by gibbons in the study group of $N$. annamensis ( \pm standard error)

\subsubsection{Total non-structuralcarbohydrates (TNC)}

Generally, the level of TNC was significantly different among all plant tissues (Kruskal-Wallis test: $H=15.3, P=0.002$; Figure 3.7). Upon pairwise analysis, significant differences were found between the TNC content of fruit and young leaves (Mann-Whitey tests: $U=91, P=0.0001)$ and flowers and young leaves $(U=49, P=0.01)$. All other pairwise comparisons yielded no statistically significant results (all: $P \geq 0.04$ ). Fruit had the highest concentration of TNC (42.59\%), while flowers, mature leaves and young leaves contained $38.54 \%, 31.00 \%$, and $26.66 \%$, respectively (Figure 3.7 ). 


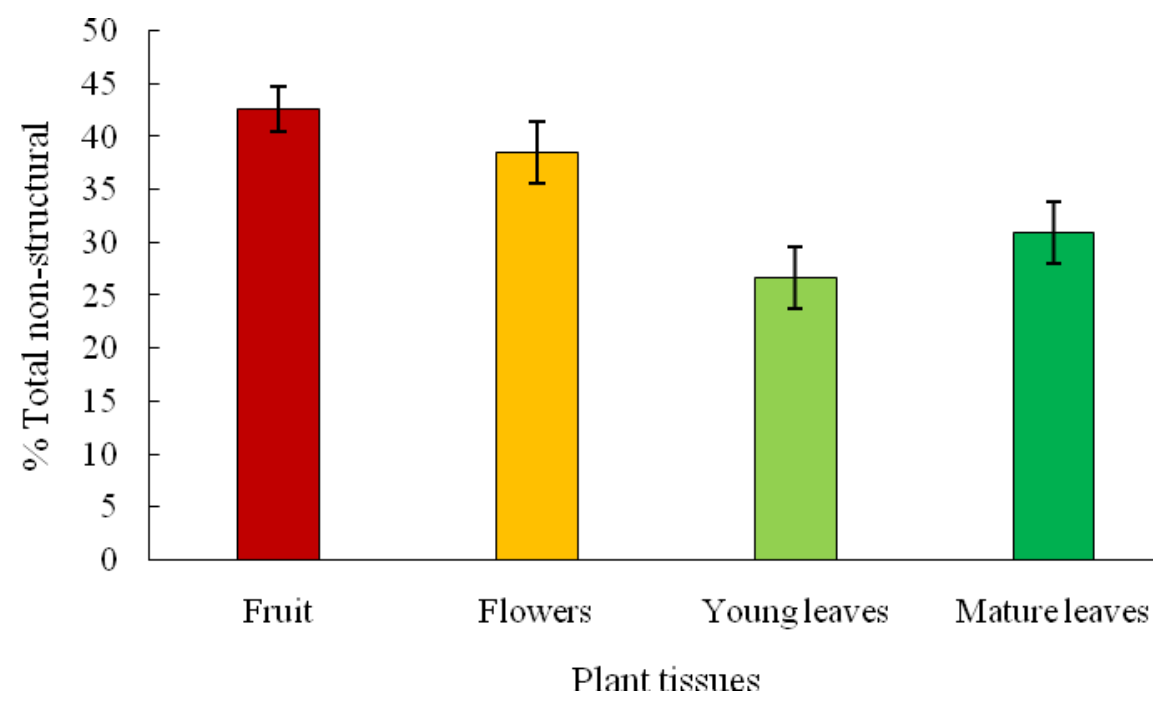

Figure 3.7: The average percentage of total non-structural carbohydrates of food items (fruit, flowers, young leaves and mature leaves) eaten by the study group of $N$. annamensis ( \pm standard error).

\subsubsection{Fibre}

Overall, there was no difference in the amount of NDF (Kruskal-Wallis test: $H=1.42$, $P=0.69)$, ADF $(H=3.46, P=0.32)$, or $\operatorname{ADL}(H=6.83, P=0.07)$ among all plant tissues consumed by this group of gibbons (Figure 3.8). All pairwise comparisons revealed no significant differences between plant tissue types (Table 3.3 and Figure 3.8).

Table 3.3: Result of Mann-Whitney $U$ tests for pairwise comparison of NDF, ADF and ADL in plant tissues consumed by the northern yellow-cheeked crested gibbons in group A.

\begin{tabular}{lrrrrrr}
\hline Plant tissues & NDF & \multicolumn{3}{c}{ ADF } & \multicolumn{2}{c}{ ADL } \\
& $U$ & $P$ & $U$ & $P$ & $U$ & $P$ \\
\hline Fruit and flowers & 248 & 0.7 & 207 & 0.2 & 155 & 0.02 \\
Fruit and young leaves & 253 & 0.5 & 246 & 0.4 & 246 & 0.4 \\
Fruit and mature leaves & 93 & 0.5 & 57 & 0.05 & 84 & 0.3 \\
Flowers and young leaves & 85 & 0.4 & 78 & 0.2 & 84 & 0.4 \\
Flowers and Mature leaves & 27 & 0.2 & 22 & 0.1 & 16 & 0.03 \\
Young leaves and mature leaves & 36 & 0.5 & 30 & 0.2 & 30 & 0.2 \\
\hline
\end{tabular}




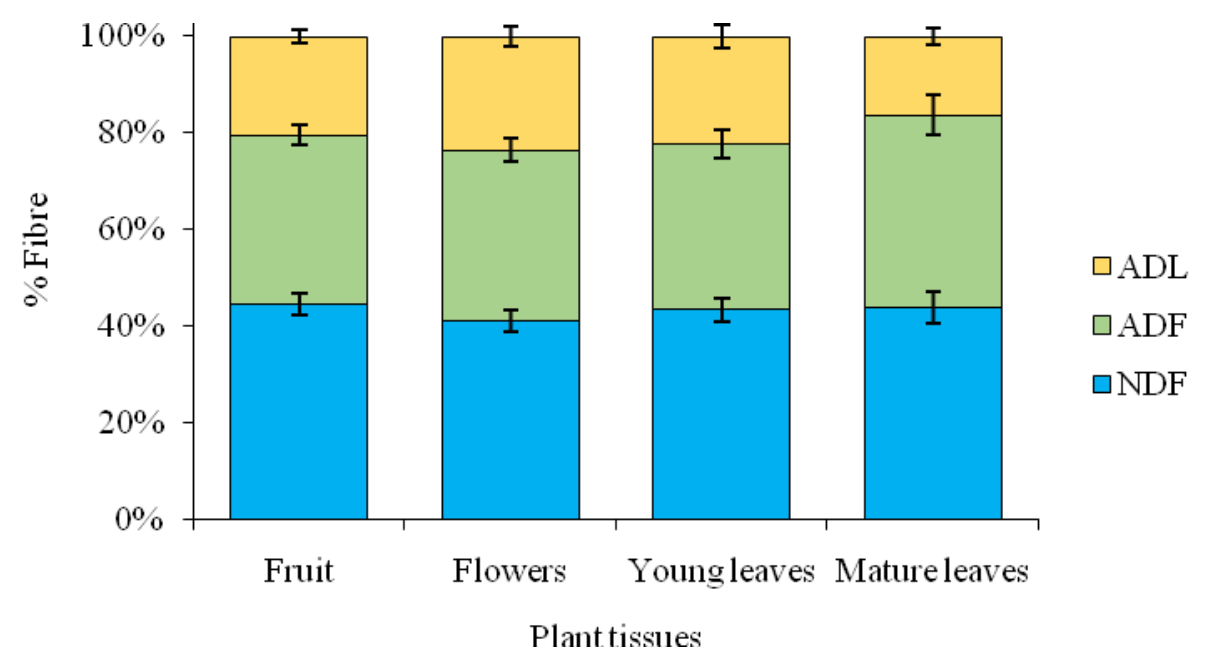

Figure 3.8: The average percentage fibre content of acid detergent lignin (ADL), acid detergent fibre $(\mathrm{ADF})$, and neutral detergent fibre (NDF) of food items (fruit, flowers, young leaves and mature leaves) eaten by the study group of $N$. annamensis ( \pm standard error).

\subsubsection{Condensed tannins}

Thirty-two percent of all plant tissues selected by this gibbon group contained condensed tannins. Flowers contained more often condensed tannins than other plant tissues. While some plant tissues contained condensed tannins and others did not, overall there were no significant differences between plant tissues (Kruskal-Wallis test: $H=0.32, P=0.95$ ). Similarly, pairwise comparisons of each plant tissue showed no significant differences (all: $P$ $\geq 0.56$ ). Forty-three percent of flowers consumed by N. annamensis contained condensed tannins, while $33 \%$ of mature leaves, $30 \%$ of fruits, and $27 \%$ of young leaves contained tannins (Table 3.2).

\subsubsection{Balance of nutrients in foods eaten by Nomasus annamensis}

There were statistically significant differences in the relative content of TNC, P, and L in food items selected by $N$. annamensis (Kruskal-Wallis test: $H=146, P=0.0001$ ). Pairwise tests showed that the group of $N$. annamensis studied here consumed food items with significantly more TNC than protein (Mann-Whitey tests: $U=173.5, P=0.0001$ ) and lipids $(U=7, P=0.0001)$. Similarly, they consumed food items with significantly more protein concentration than lipids $(U=740, P=0.0001)$. Those food items were among the top plant species selected by N. annamensis particularly high in TNC (Figure 3.9, Table 3.1). For example, two frequently ingested food items had the highest concentration of TNC relative to $\mathrm{P}$ and L: M. elliptica (f $\mathrm{f}_{12}$, fruit, TNC: $89.32 \%, \mathrm{P}: 7.71 \%, \mathrm{~L}: 2.97 \%$ ); and W. edulis, 
$\mathrm{f}_{20}$, fruit,TNC: $87.09 \%$, P: $5.38 \%$, L: $7.53 \%$ ). Some food items were notable for a comparatively low levels of TNC and L but high P levels; an unknown liana ( $f_{16}$, young leaves, P: $73.61 \%$, TNC: $20.04 \%$, L: $6.35 \%$ ) and $M$. duperreana $\left(\mathrm{f}_{13}\right.$, young leaves, P: 69.13\%, TNC: $25.80 \%$, L: $5.07 \%$ ). All food items analysed were low in L relative to TNC and P (Figure 3.9).

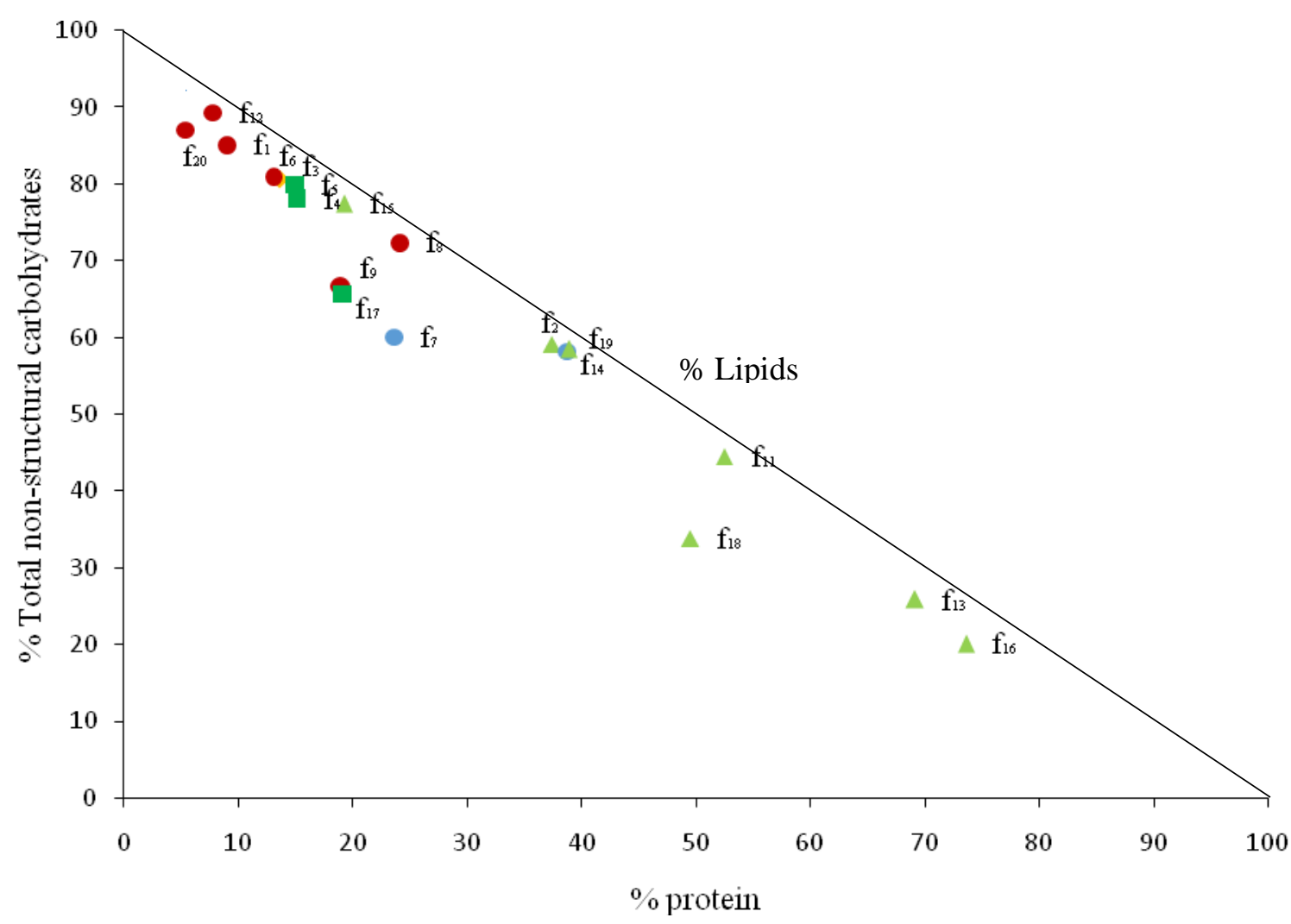

Figure 3.9: Right-angled mixture triangle (RMT) showing the relative contribution of total nonstructural carbohydrates (TNC), protein (P) and lipids (L) of food items from particular plant species consumed by the northern yellow-cheeked crested gibbon ( $N$. annamensis) at Veun Sai-Siem Pang Conservation Area (VSSPCA), northern Cambodia. P and TNC are plotted on the $X$ and $Y$ axes respectively, while $L$ is depicted on the diagonal. Each point $\left(f_{1} \ldots f_{20}\right)$ representsthe average energy mixture provided by the food item from that plant species, e.g, $\mathrm{f}_{20}$ is a fruit (W. edulis) that supplies $87.14 \%$ energy from TNC, $5.85 \%$ from protein and $7 \%$ from lipids. The red circles are fruit, lightgreen triangles are young leaves, dark-green squares are mature leaves, orange diamonds are flowers, and blue circles are species where both flowers and young leaves were consumed.

Note: Food code from $\mathrm{f}_{1}$ until $\mathrm{f}_{20}$ see the first column of Table 3.2. 


\subsection{Discussion}

\subsubsection{Nutritional composition of plant tissues}

Each type of plant tissue consumed by $N$. annamensis had different nutritional compositions. Fruit, the principal food source for these gibbons (60.36\% in diet, Chapter 2), had the highest levels of TNC and lipids. Mature leaves had the highest moisture content, while young leaves had the highest concentration of protein, and flowers contained more often condensed tannins than other plant tissues. All plant tissues consumed by this group of gibbons had similar amounts of NDF, ADF, and ADL.

The group of $N$. annamensis were never seen drinking water from sources on the ground. During the period of this study (dry season), they were only observed drinking water from the cavities within tree trunks. However, considering the high moisture content of mature leaves found in this study, mature leaves may be acting as another water source for this group during the dry season. A similar result was found in mountain gorillas (G. beringei), that consume pith, which has low nutritional value but is high in moisture (Rothman et al. 2006), when water availability is low. While mature leaves are generally avoided by primates due to their high fibre content and the associated difficulty in digestion (Milton 1979; Davies et al. 1988; Kool 1992), this did not seem to be an obstacle here; mature leaves selected by $N$. annamensis had surprisingly similar fibre levels to other ingested food items. Coupled with their high moisture content, they may be valuable to these gibbons' diets during the dry season.

It is likely that this group of gibbons gain most of their protein by consuming young leaves (Figure 3.5) as do most primates living in natural habitats (Milton 1979; Milton 1999; Rothman et al. 2006; Irwin et al. 2014). This contradicts other gibbon studies that report that insects serve as protein sources (Chivers 1998; O'Malley \& Power 2012; Borah et al. 2014; Rothman et al. 2014). While young leaves may also contain other nutritional compounds including lipids and primates generally consume young leaves primarily to meet their protein requirements (Milton 1979; Oftedal et al. 1991; Felton et al. 2009a; Felton et al. 2009b; Rothman et al. 2011). In this study, young leaves contained significantly more protein than other ingested plant items, suggesting that $N$. annamensis individuals also consume young leaves to meet their protein requirements. However, future studies are need to estimate the nutritional contribution of insects to the diet of $N$. annamensis. 
Fruit was a major source of carbohydrates for N. annamensis. Fruit is a dominant food source in the diet of most gibbon species (McConkey et al. 2002; Fan et al. 2009; Fan et al.2013; Ni et al. 2014), likely due to the fact that fruits contain more readily available energy than other plant tissues (Barton \& Whiten 1994; Rothman et al. 2006; Felton et al. 2009c). However, they cannot rely entirely on fruit alone (Chivers 1998), as fruit contains insufficient protein (Rothman et al. 2006; Rothman et al. 2011; Behie \& Pavelka 2012a), which is necessary for survival and reproductive success (Mattson 1980; Felton et al. 2009a; Grandison et al. 2009). This suggests that young leaves are being added to the diet here to meet protein requirements. This is important for captive animals where it should be ensured that protein sources are added to a fruit based diet.

Dietary fibres are composed of hemicellulose, cellulose, and lignin and are not easily digested by primates with simple stomachs such as gibbons (Cork \& Foley 1991; Rothman et al. 2006), and consequently fibre is generally considered negative nutrients (Van Soest 1978; Shah et al. 1982). In order to digest fibres, animals must depend on gut micro-organisms to utilize dietary fibres for the production of fatty acids and microbial protein (Cork \& Foley 1991; Clements et al. 2009). Although most studies find that mature leaves consumed by primates have higher fibre contents than other plant tissues (Oates et al. 1980; Felton et al. 2009c; Behie \& Pavelka 2012a), this study found that the mature leaves from three plant species, two epiphytes (D. ruscifolia and Dischidia. sp) and an liana (Vor Chrey Slektom), had similar amount of fibre to other plant tissues. In addition, the amount of fibre in all food items was similar. This unusual result may be due to $N$. annamensis in this group consuming the entire fruit of some species including both seeds and their skins, especially G. macrostachyum, which are more fibrous than the pulp, bulking up the fibre content of the fruit samples.

Although about $30 \%$ of food consumed by $N$. annamensis contained condensed tannins, most primates avoid food with high concentration of such secondary compounds (Glander 1982; Barton \& Whiten 1994). Plants that contain high concentrations of condensed tannins are typically difficult to digest, lack nutritional value, and may contain toxins (Milton 1979; Oates et al. 1980; Acamovic \& Brooker 2005). However, condensed tannins provide nutritional benefits as they bind proteins and polysaccharides (Carrai et al. 2003), but also can negatively affect the digestibility of these molecules (Glander 1982; Kool 1992). The flowers $(43 \%)$ consumed by $N$. annamensis in the present study contained more often condensed tannins than other plant tissues. These flowers were high in fibre, but also 
contained protein, which may have provided benefits greater than the costs of the tannins. Although not tested here, flowers may also be a source of minerals for the gibbons as they have been found to contribute relatively high levels of calcium and phosphorous to diets of chimpanzees (Hladik 1977).

\subsubsection{Balance of nutrients in foods eaten by Nomascus annamensis}

The RMT (Figure 3.9) shows that this group of gibbons predominantly consumed food items with a high concentrations of TNC. However, these individuals also consumed other plant tissues to gain protein and lipids. This contradicts other studies, where proteinrich foods are the main target for primates (Milton 1979; Rothman et al. 2006; Felton et al. 2009a). This prioritization of protein in the diet can be seen at a daily level, with some primate species maintaining a daily intake of protein while allowing carbohydrate and lipid intake to fluctuate (Felton et al. 2009b; Johnson et al. 2013). However, this study indicates that this group of $N$. annamensis consumed more food with a high concentration of TNC, while only a few food items were higher in protein, and lipids was lower in all plant tissues.

Flowering, and the availability of fruit and young leaves, changes seasonally in Southeast Asian tropical forests (Hamilton \& Galdikas 1994; Wendeln et al. 2000; McConkey et al. 2002; Hanya \& Bernard 2012), and some gibbon species shift their diet from fruit to young leaves according to season and the availability of food sources (McConkey et al. 2002; Fan et al. 2009; Fan et al. 2013). Although gibbons are considered fruit specialists, black crested gibbons (Nomascus concolor) consume more young leaves than fruit in harsh environments (Ganasia et al. 2008; Fan et al. 2009). Likewise, fruit forms a considerable part of gorillas (Gorilla. spp) diets (Doran-Sheehy et al. 2009). However, the mountain gorillas ( $G$. beringei) consume more young leaves to increase protein intake, possibly to compensate for carbohydrate-rich fruit (Rothman et al. 2011). The present study found $N$. annamensis eat a diet high in carbohydrate-rich fruit, but they may later switch to consume more young leaves or insects to meet protein requirements at different times of year (Frechette et al. in prep).

The RMT model also shows that some key food species play very important roles in providing good sources of both TNC and protein for $N$. annamensis. Fruit from the tree M. elliptica and the liana W. edulis (Appendix 2, Figure 8) were the two richest sources of TNC, while young leaves from two tree species $M$. duperreana (Appendix 2, Figure 8) and L. elegans were among the few species providing a rich source of protein (Figure 3.9). 
Although most plant species contained low proportions of lipids, some species were the main sources of lipids, including young leaves of tree G. oliveri and liana Vor Krovanh. Figs (Ficus. $s p$ ) were also one of the most important plant species for $N$. annamensis due to their high carbohydrate levels, though their comparatively low levels of protein and lipids may necessitate the consumption of other types of fruit and young leaves. Figs are an important, nutritionally balanced food source for spider monkeys (Ateles chamek) due to their available lipids and proteins (Felton et al. 2009b). The fruit of some species may have a high concentration of required nutrients, while others have low concentrations, or have evolved secondary compounds to avoid consumption by herbivores (Ryan 1989; Speiser \& RowellRahier 1991). Consequently, not all plant species available are consumed by animals; for example, the black crested gibbon (Nomascus concolor) selects only 77 plant species as food sources from their entire territory, and spend the majority of time feeding on only 10 plant species (Fan et al. 2009), similarly to that was found here (Chapter 2). This study clearly indicates that plant species selected by the study group of $N$. annamensis play varying and important nutritional roles to maintain the population of this study group.

The nutritional chemistry of plant tissues is spatially and temporally variable (Rothman et al. 2006). Several factors are expected to influence the nutritional compositions of each plant tissue, including the maturity of the plant tissues, weather, season, temperature, soil type, and exposure to sunlight (Baranga 1983; Chapman et al. 2003; Rothman et al. 2006). Plant samples were collected for this study in the dry season. As a result, a future study is needed on the nutritional composition of plant tissues consumed by this group in the rainy season. The results show all plant tissues had different nutritional values, with fruit a good source for TNC, while young and mature leaves were a good source of protein and moisture, respectively. To balance nutritional requirements, the group of $N$. annamensis needs to consume varieties of plant tissues from different plant species. Consequently, some plant species that this group of gibbons selected for food play very important roles in maintaining the nutrient intake required by this species, and they need special protection for the long-term conservation for N. annamensis. 


\subsection{Summary}

The present study demonstrates that all plant tissues consumed by $N$. annamensis had different nutritional values, suggesting animals are nutrient balancing. Mature leaves had the highest moisture content, while young leaves had significantly high values of protein, and fruit contained high levels of TNC. All food items consumed by this group of gibbons had similar amounts of fibre (NDF, ADF, and ADL), whereas flowers had a higher frequency of condensed tannins than other consumed plant tissues. Generally, food items selected by this gibbon species were high in TNC, with only a few high in protein, and all items had low levels of lipids.

The results from this research contribute to long-term conservation programs for this gibbon species. When developing feeding plans for this species in captivity, fruit and young leaves should be included, with an emphasis on fruit-rich carbohydrates. Key plant species selected by this group of gibbons, in particular I. umbellulata, Ficus. sp, L. elegans, G. oliveri and $W$. edulis, must be protected as they provide good nutritional input, and appear to be the main plant species that this group of gibbons rely on in their small territory in the dry season.

Considering this study was conducted in the dry season, food selection by this group in the rainy season should be considered in order to compare food types selected throughout the year, and to show if their nutritional requirements vary between seasons. Insects are good sources of protein in other gibbon species, and great apes like mountain gorillas (Chivers 1998; Borah et al. 2014; Rothman et al. 2014), and considering N. annamensis were observed to occasionally eat insects in the present study, future studies on insects selected by this species are needed to elucidate what nutritional value these insects provide. 


\section{Chapter 4}

\section{General conclusions and implications for conservation}

\subsection{Summary of research findings}

Optimal foraging theory states that animals should balance energy output and intake so that energy intake is maximised in relation to the costs of finding and ingesting food (MacArthur \& Pianka 1966; Cowles et al. 1988; Belovsky 1997). Animals, including primates, must make a choice about what types of food items to include in their diets, as different foods can affect lifespan, health, social relationships, fitness and reproduction and have various costs associated with them (Fernandes et al. 1976; Koenig et al. 1997; Givens \& Shingfield 2004; Felton et al. 2009a; Grandison et al. 2009; Harris et al. 2010; Trepanowski et al. 2011). Tropical plants provide a wide range of potential food sources, but not all plant species and tissues are selected by animals (Westoby 1974; Oates et al. 1980). Some plant species have evolved both physical and chemical defences, and as a result some animals avoid consuming these plant species (Wittstock et al. 2004; Rosenthal \& Berenbaum 2012).

Gibbons are the smallest apes in the world (Mootnick \& Fan 2011; Carbone et al. 2014), and populations have declined significantly worldwide due to habitat destruction and hunting pressure (Cheyne et al. 2008). Gibbons are usually frugivores (Lappan \& Whittaker 2009), but their diet is supplemented by young leaves, flowers, mature leaves, and insects (McConkey et al. 2002; Fan et al. 2009; Fan et al. 2013). Most gibbons are listed as Critically Endangered and Endangered by IUCN Red List, and several species are likely go extinct without conservation effort (Gray et al. 2010). The northern yellow-cheeked crested gibbon (Nomascus annamensis) is a recently described species (Thinh et al. 2010), and less is known about this species than other gibbons. To assist the development of a long-term conservation program for this gibbon species, this study addressed five research questions. The findings of these are summarised below.

Overall, the members of the study group of $N$. annamensis spent the majority of their time resting, followed by feeding, travelling and socializing. All group members (adult male, adult female, sub-adult male and juvenile male) spent similar amounts of time in each of these activity categories. This shows that social animals like this group of $N$. annamensis may have similar activity budgets. 
The study group of $N$. annamensis selected 37 plant species for their food sources, although only 16 of these were consumed for the majority of time. The relative density of these plant species was very low inside the home range of this group, with the 10 most selected plant species representing less than $7 \%$ of the total density of tree and liana species in the area. This indicates that $N$. annamensis specifically selects comparatively rare species as food over more common plant species, suggesting that something other than availability is dictating their choices.

Like other gibbons, fruit was the main food for this group, supplemented by young leaves, flowers, mature leaves, and occasionally insects. The gibbons in this group spent more time feeding on flowers when they became available, however, there was no relationship between the availability of fruit or young leaves and the amount of time $N$. annamensis individuals spent feeding on them, suggesting flowers may be a preferred food item at this time of year. The lack of relationship between the availability of fruit and feeding time may be because densities of plant species selected by $N$. annamensis were very low inside the home range of this animal, although some plants produced a large quantity of fruit. In addition, young leaves may be used mainly as an alternative food source, where a preferred item is low in abundance. The study group of $N$. annamensis were not observed feeding on mature leaves from the top 10 plant species.

Mature leaves had the highest concentration of moisture, followed by young leaves and flowers, while fruit had the lowest, and this may be because the fruits selected by northern yellow-cheeked crested gibbons were less pulpy and tougher than the fruits other gibbons may choose (McConkey et al. 2002). Young leaves contained more than double the protein of flowers, fruit and mature leaves, suggesting they are eaten to meet the protein demands of this group. Most plant tissues had a low level of lipids, but fruit contained more lipids than other plant tissues, due to the seeds that were ingested with some fruit species. The level of total non-structural carbohydrate (TNC) was highest in fruit, likely due to the high sugar content. All plant tissues had similar fibre contents including, NDF, ADF and ADL. While this is an unusual result, it may be due to the ingestion of seeds and tough skin with fruits that increased their fibre content to a similar level to that of leaves. About one third of all plant tissues consumed by $N$. annamensis contained some condensed tannins, and flowers had the higher frequency of condensed tannins. All these findings clearly demonstrate that plant tissues selected by this group of $N$. annamensis had different nutritional values. The gibbons fed on fruit for TNC and lipids, while young leaves were consumed for protein, 
mature leaves for moisture, and flowersprovided TNC and other nutrients, although they contained more condensed tannins than other plant tissues.

The right-angle mixture triangle (RMT) model indicated that this group of gibbons consumed food items with more TNC than protein, and most food items were low in lipids. This reflects the fact that this group of $N$. annamensis spent more time feeding on fruit than other plant tissues, and those fruits were rich in TNC. This model also showed that plant species selected by this group of $N$. annamensis provided different nutritional benefits. Some plant species provided a majority of fruit resources that were high in TNC, and some plants provided a majority of young leaves that were good sources of protein, while others provided both flowers and young leaves that were good sources of both TNC and protein. All plant tissues selected by N. annamensis were low inlipids. 


\subsection{General discussion}

The study of the behavioural ecology of animals helps conservationists predict factors that may influence their behaviours (Sutherland 1998). This is important because some behaviours may negatively impact survival rates (Siemers \& Schaub 2011; Hardus et al. 2012). The present study showed that the study group of $N$. annamensis spent most of the time resting, and the remaining time feeding, travelling, and socializing, in that order. In normal conditions, hoolock gibbons (Hoolock hoolock) spend more time feeding than other activities (Islam \& Feeroz 1992). However, in cold habitats (an average temperature of $<10$ ${ }^{\circ} \mathrm{C}$ ), eastern hoolock gibbons (Hoolock leuconedys) spend more time resting than other behaviours, which indicates that gibbons may need to conserve energy when at high latitudes and in cold habitats (Fan et al. 2013). This may also be affected by rainfall, which requires additional thermoregulation (Watanuki \& Nakayama 1993; Fan et al. 2013). While February has one of the coldest minimum temperatures in Cambodia, the minimum temperature at the study site during the dry season (November to April) was $15.5^{\circ} \mathrm{C}$ (Nelson 2014), which is not dramatically different to the wet season. There was also no rainfall during the study period. This indicates that thermoregulatory factors are unlikely to have influenced the behaviour of this gibbon group over the course of this study.

Noise can alter animal behaviours (Brumm 2004; Lengagne 2008). Noise can affect mate attraction, reproductive success (Halfwerk et al. 2011) and territory defence (Slabbekoorn \& Ripmeester 2008). Noise associated with logging can impact the behaviour and activity budgets of primate species (Pontes \& Soares 2005; Hardus et al. 2012), and in this study inactive activity increased in March when chainsaw use was at its highest in the study areas (pers. observation), indicating that chainsaws may be impacting energy and activity budgets in this group. This finding, however, is preliminary, and future studies are needed to determine whether resting is the normal dominant behaviour for this group of gibbons, or if there are any other factors that influence these behaviours, such as anthropogenic noise pollution and selective logging.

Food sources that are reliable and of sufficient quantity and quality are hugely important for all organisms on the planet (Leibold \& Wilbur 1992; Mead et al. 1999; Grandison et al. 2009). As a result, to have successful long-term conservation programs and captive breeding programs, it is important to know which types of foods and what nutritional 
compositions are selected by animals in the wild to maintain survival and reproduction (Kleiman et al. 1986). Most gibbon populations have declined considerably due to habitat destruction and hunting (Geissmann 2007; Cheyne et al. 2008; Gray et al. 2010). Little is known about the feeding ecology of gibbons in general, and even less is known about crested gibbons, which leads to difficulty in conservation. Based on the results from this study, captive $N$. annamensis should be provided not only with fruit, but also with young leaves, and priority should be given to the 16 species consumed most often by the group in this study (Table 2.3), although additional research is needed to see what food species are eaten by other groups of $N$. annamensis.

It is vital to protect habitat and food plants for the long-term conservation of most primate species (Medley 1993; Gates 1996). Gibbons live in small groups (Fan et al. 2010), with small territories (Chivers \& MacKinnon 1977). They completely rely on resources available in their relatively restricted home range for survival (Marshall \& Marshall 1976). Moreover, not all plant species in their territory are edible, or appropriate food sources (Fan et al. 2009; Fan et al. 2013). Any logging which damages feeding plants would negatively impact both the lifespan and reproductive success of $N$. annamensis, as with other primate species (Plumptre \& Reynolds 1994; Chapman et al. 2000; Thompson \& Wrangham 2008; Mattison et al. 2012), and should be avoided. N. mutabile and Neang Kmov were the most common tree species inside the home range of this group of $N$. annamensis. $N$. mutabile bear fruit in late April that are consumed by white-handed gibbons (H. lar) in Thailand (Whiten et al. 1991) and both N. mutabile and Neang Kmov were also confirmed by local guides as gibbon feeding on plant species. However, during the study period, the study group of $N$. annamensis were not observed feeding any plant tissues from those plant species. Furthermore, the relative density of the 10 most selected plant species in the home range of the study group was very low, indicating their disproportionate importance for $N$. annamensis. For example, the relative density of Ficus. sp, which was one of the most important food species, was just $0.41 \%$, but it bore fruit from January until early April providing a constant fruit source in these months. These data clearly indicate that the gibbons selected rare over common plant species, and this suggests that protection of these food species is even more crucial. Moreover, if logging reduces the abundance of feeding plant species, this group of $N$. annamensis will need to travel long distances to find appropriate food sources during the dry season. 
The majority of plant species selected by $N$. annamensis were high in TNC, with some species high in protein, but all plant tissues were low in lipids. For instance, the tree M. elliptica and the liana W. edulis, which were the top two food plant species, provided good sources of TNC, while the tree M. duperreana, another important food species, provided a good source of protein. Consequently, plant species selected by this group of gibbons have significantly different yet equally necessary nutritional values, and special protection and increasing density of those plant species would contribute positively to long-term conservation for this gibbon species.

Five main models have been proposed for primate nutritional goals, including (i) maximising protein, (ii) maximizing energy, (iii) limiting fibre content, (iv) avoiding secondary compounds, and (v) balancing nutritional values (Schoener 1971; Freeland \& Janzen 1974; Milton 1979; Mattson 1980; Raubenheimer \& Simpson 2004; Felton et al. 2009a). This study found that food items consumed by $N$. annamensis had high concentrations of TNC, while only a few items were high in protein. This contradicts a study in similarly frugivorous spider monkeys (Ateles chamek) that prioritized protein in their daily intake, and allowed carbohydrate and lipids intake to fluctuate (Felton et al. 2009b). Similarly, mountain gorillas (Gorilla beringei) consumed more food (young leaves) with high concentrations of protein when they became available (Rothman et al. 2011). Other studies indicate gibbons gain more protein content from insects rather than plant tissues (Chivers 1998; Borah et al. 2014; Ni et al. 2014). As the present study did not measure the amount of food ingested daily, there is no evidence at present to reject or support whether that $N$. annamensis prioritizes protein and allows levels of other nutrients to fluctuate. However, the results from the present study do shed light on the diet of this species. N. annamensis consumed more food items with high concentrations of TNC, and few foods chosen were high in protein. This prioritisation of TNC makes sense, considering the fact that TNC is commonly found in fleshy fruit, and is a good source for energy (Barton \& Whiten 1994). A long-term study on food selection by $N$. annamensis as well as a specific study on the nutritional value of insects consumed by this species should be undertaken to further elucidate the feeding habits of this species.

The studied group of $N$. annamensis spent most of the time feeding on fruit, which provide good sources for carbohydrate that contribute more than $40 \%$ of the metabolizable energy in primates' diets (NRC 2003). In addition, they also spent time feeding on young leaves, which are also good sources for protein. These information indicate that this group of 
$N$. annamensis selected high quality food sources over lower quality food items, and of the five nutritional models described above, this food selection may best support the energy maximization theory (Schoener 1971).

Plant cell walls generally cannot be brokendown by animals with simple stomachs (Milton 1999), and this may explain why some primates select food items with low concentrations of fibre (Davies et al. 1988; Barton \& Whiten 1994; Hanya \& Bernard 2015). The results of the present study indicate that similar levels of all fibres (NDF, ADF, and ADL) were found in the different plant tissues consumed by this group of gibbons. As a consequence, the current results suggest that $N$. annamensis does not limit its fibre intake. This result differed from other studies in that fruit generally contains lower fibre content than leaves (Oates et al. 1980; Felton et al. 2009c; Behie \& Pavelka 2012a). This may due to the fact that the ingestion of seeds and tough skin with fruits increased their fibre concentration. However, future studies on the nutritional composition of unselected food items should be conducted in order to understand whether those non-food plants have higher concentrations of fibre than selected foods.

Some plants have evolved a wide range of secondary metabolites to avoid consumption by herbivores (Wittstock et al. 2004; Rosenthal \& Berenbaum 2012). Plants containing secondary compounds are often bitter and even toxic (Acamovic \& Brooker 2005), so most primates avoid food items with high concentrations of these compounds (Glander 1982; Barton \& Whiten 1994). This study measured only one type of secondary compound, condensed tannins, in each plant sample, and the result indicates that more than $30 \%$ of plant tissues consumed by $N$. annamensis contained condensed tannins, particularly flowers. Condensed tannins consumed by animals may have both negative and positive effects (Rothman et al. 2006). Food items containing this compound may have reduced nutritional quality, decreased digestibility, and reduced palatability (Reed 1995), but tannins also contribute to protection from intestinal parasites, pathogenic bacteria and fungi (Chung et al. 1998; Min \& Hart 2003). Primates may even deliberately consume foods containing condensed tannins for self-medication (Barton \& Whiten 1994; Carrai et al. 2003). As food items consumed by $N$. annamensis still contained condensed tannins, this study has no evidence that gibbons avoid foods containing these secondary compounds. More studies are need to link the consumption of secondary compounds to parasite infections, and compare these compounds between food and non-food items. 
To ensure continued survival and reproductive success, animals need to balance nutritional intakes from the food that they eat (Whiten et al. 1991; Raubenheimer \& Simpson 1997). Although some primate species prefer young leaves (Barton \& Whiten 1994; Carrai et al. 2003), which have high levels of protein (Felton et al. 2009c; Rothman et al. 2011; Hanya $\&$ Bernard 2015), they may need to consume fruit, seeds or insects to balance their nutritional requirements (Whiten et al. 1991; Borah et al. 2014; Rothman et al. 2014; Hanya \& Bernard 2015). The present study demonstrates that $N$. annamensis individuals did not change the time they spent time feeding food items depending on either their availability or their nutritional composition. The group of $N$. annamensis spent more time feeding on flowers when they became available. This may be because flowers contained significant levels of nutrients and minerals (Rop et al. 2012) that are required by N. annamensis.

The knowledge from this thesis may help a long-term conservation of $N$. annamensis. This study suggests that key food plant species, I. umbellulata, Ficus. sp, L. elegans, G. oliveri, W. edulis, and M. elliptica should receive additional protection. Total nonstructural carbohydrates are generally gained from fresh fruit, and they are an important dietary component for this species of gibbon. Young leaves provide good sources for protein. Therefore this thesis has assisted both wild and captive conservation programs for northern yellow-cheeked crested gibbons as well as augmenting behavioural ecological knowledge for this recently discovered species. 


\subsection{Implications for conservation}

Although the northern yellow-cheeked crested gibbon ( $N$. annamensis) has not yet been listed in the IUCN Red List, it is likely to be listed as Endangered as it faces similar threats to other gibbons (Thinh et al. 2010). This species plays a crucial role in seed dispersal (Frechette 2014), which maintains forest structure. Reducing the population of this gibbon species may therefore alter forest ecosystems (Nuñez-Iturri \& Howe 2007). Consequently, scientific knowledge is urgently needed for a long-term conservation program of this gibbon species to be successful.

\subsubsection{Food plant selection}

While most of the plant species selected for food by $N$. annamensis in this study are currently not targeted for commercial timber collection in the VSSPCA, two of the top 10 food species, D. alatus and D. cochinchinensis, are targeted for logging (pers. comm. from local villagers). The Dipterocarpaceae are both ecologically and commercially valuable (Appanah \& Turnbull 1998; Bunyavejchewin et al. 2003), and their wood dominates international tropical timber markets (Whitmore \& Burnham 1975). The combination of high demand for house construction (Schmidt \& Nguyen 2005) and unsustainable timber collection practices have now rendered most dipterocarps under threat (Appanah \& Turnbull 1998). Although other plant species selected by $N$. annamensis are not commonly collected for construction, local people collect some species including G. oliveri, M. elliptica and W. edulisfor daily consumption (pers. comm. from local villagers). For example, local communities in Ratanakiri province collect stems of W. edulisfor traditional medicine, and their fruits for sale and household consumption (Laval et al. 2011). There is no actual inventory of plant species in the VSSPCA area yet, however, the relative densities of those selected plants are very low inside the home range of the study group of $N$. annamensis. This indicates that special protection is needed to ensure that these important food plant species are sufficiently protected to sustain the survival of this group of gibbons. 


\subsubsection{Illegal logging and hunting pressure in the VSSPCA}

In the last decade, the VSSPCA has been protected by the cooperation of the Forestry Administration, the Cambodian government, and the non-profit organization Conservation International. Consequently, although valuable trees have been cut down from other locations, this area still contains relatively large numbers of most commercially logged plant species (pers. observation). Unfortunately, large plants in the VSSPCA are now being targeted for timber collection (pers. comm. from local villagers). Should larger trees decline in number as a result of this logging, there is a risk that smaller trees will then be targeted as they become economically viable (Sasaki 2006), with associated declines in habitat quality and food availability for $N$. annamensis. During the study period, illegal logging was occasionally observed inside the home range of the study group, and frequency was observed around VSSPCA. While these logged trees were not gibbon food plant species, these activities may negatively impact the behaviour of $N$. annamensis. In addition, previous work has found that $N$. annamensis rely on large and tall trees for calling and sleeping, and if logging target those tree species, the gibbon group may suffer (Nelson 2014). Other studies indicate that some gibbons are being targeted for poaching (Geissmann 2007; Phoonjampa \& Brockelman 2008; Malone et al. 2014), although gibbons at the VSSPCA have a low rate of hunting, and just recently the hunting of a gibbon has been confirmed (pers. comm. from villagers). In addition, local people hunt other primates and animals for food and traditional medicines (Hill 2011). Lorises are the most common hunted primates for traditional medicine (Pollard et al. 2007; Starr et al. 2010; Hill 2011), while gibbons are likely live-caught and kept as pets (Johnson et al. 2005; Pollard et al. 2007). Considerably, hunting may not the main threat to gibbons at the study site; instead, illegal logging and deforestation are of considerable concern for the conservation of this species and its habitat.

\subsubsection{Possibility of captive breeding}

Captive breeding of animals has become a popular method for conservation, particularly for endangered species (Philippart 1995; McPhee 2004). After being bred in zoos, animals are trained to find food, then released or reintroduced into their natural habitats (Beck et al. 1994). This method has prevented the extinction of some species (Ebenhard 1995; Fraser 2008). The endangered white-handed gibbon ( $H$. lar) became locally extinct in Phuket Island, Thailand, but eight families (30 individuals) have been introduced to the island 
(Osterberg et al. 2014). After 10 years, over half of the reintroduced populations have survived (Osterberg et al. 2015).

Captive breeding, when combined with reintroductions, is an important tool for conserving threatened populations. However, in order to maintain successful captive breeding programs, the correct food must be provided to captive individuals. Ascertaining the correct type, amount, and nutritional composition of food is a priority, especially for species that have never been captive before. Currently, knowledge of ideal food and nutritional regimes for captive gibbons is limited, and even more so for crested gibbons (NRC 2003). During the study period, a baby N. annamensis was rescued (Appendix 3, Figure 1) and sent to the Phnom Tamao Wildlife Recuse Centre (Appendix 3, Figure 2). This incident provides further motivation to develop a feeding regime for this species from observations gathered over the course of the current study. If there are any chances for captive breeding of N. annamensis, this study suggests that food items provided to this species should include a majority of fruit, supplemented with young leaves from M. duperreana, L. elegans, and Vor Krovanh. Although this study would suggest insects are also another alternative food items for this gibbon species, future study is needed to clarify which insect species are targeted and what nutritional values they contain. 


\subsection{Conclusions}

Individuals in the study group of $N$. annamensis (group A) each spent similar amounts of time on each activity. All group members spent most of the time resting, with the remainder of the activity budget spent on feeding, travelling, and socializing, in that order. $N$. annamensis individuals observed in the present study selected almost 40 trees and lianas for their food sources, but predominately fed on only 16 species. The relative density of most of these preferentially selected species was very low, although some of those plants produced a large quantity of fruit, and as $N$. annamensis is predominately frugivorous, such fruitbearing plants could be expected to contribute significantly to its sources of food.

Fruit was the main diet for this gibbon species, with alternative food items including young leaves, flowers, mature leaves, and insects. The gibbons spent more time feeding on flowers when they became available, indicating a switch in diet and an active preference for flowers. However, no relationships were found between feeding times and the availability of fruit or young leaves. Fruit consumed by $N$. annamensis had high concentrations of TNC and lipids, while young leaves had high level of protein, and mature leaves had a high water content. Condensed tannins were more present in flowers consumed by this gibbon species than in fruit, mature leaves or young leaves. All plant tissues had similar amount of fibre (NDF, ADF, and ADL). A RMT reveals that most food items selected by this group of gibbons had high levels of TNC, while a few plant species had high concentrations of protein, and all food items were low in lipids.

The findings of this thesis contribute to long-term conservation programs for northern yellow-cheeked crested gibbons ( $N$. annamensis) both in the wild and captivity. The key plant species selected by the study group of $N$. annamensis, in particularly I. umbellulata, Ficus. sp, L. elegans, G. oliveri, M. duperreana and W. edulis, should have additional protection. Selective logging of food plant species should be avoided because reduced food availability is likely to affect the population size of primates (Plumptre \& Reynolds 1994; Chapman et al. 2000; Thompson \& Wrangham 2008; Duarte et al. 2011). Introduction programs for $N$. annamensis should ensure that these plant species grow in the rehabilitation site. Knowledge of food items that should be provided for captive breeding for $N$. annamensis is sparse, however, this study suggests that food should include fruit and young leaves because fruit provide good sources for TNC, and young leaves provide protein. 


\subsection{Limitations}

Safety is the main concern when collecting data at the field, so experienced local assistants were needed for this study. Daily data collection was impractical and therefore focal observations were performed two to five days per week. Also, on occasion, the gibbon group could not be found. The level of plant diversity in VSSPCA is very high and it was difficult to identify all species. In some cases even local names for some species were not known and these were labelled as unknown.

It would have been preferable for the phenological data to be collected inside the 20 vegetation plots, not along the transect lines as the trees and lianas inside the 20 vegetation plots are more evenly distributed than the trees and lianas along the transect lines. However, time constraints at the beginning of the data collection period meant that phenological data was collected from the transect lines, which had been set up inside the home range of the gibbon study group by the team from Forestry Administration and Conservation International.

Not all food items that this group of gibbons consumed were collected for nutritional analysis. This was due to the difficulty of collecting plant samples from large and tall trees. Moreover, other trees produced a small amount of young leaves or flowers, and there were not enough remaining for sample collection. The study period was only three months (January to early April 2015), so I cannot generalize that plant species selected by this group of gibbons are the only important feeding plant species year-round. Ideally, the study should continue for at least one year, but this is clearly beyond the scope of this thesis. 


\subsection{Future directions}

This thesis investigated food selection by a group of $N$. annamensis in northern Cambodia, and the aim of this thesis was to contribute to a long-term conservation program for this particular species. Throughout the course of this research, new interesting research questions have been suggested. The answers to these questions will be important for the longterm conservation for this gibbon species and will extend the findings of this study.

It is likely that logging inside the home range of this group of gibbons may influence the behavioural ecology of this species, as it does for other primates (Pontes \& Soares 2005; Hardus et al. 2012). Future studies should examine the impact of illegal logging and how it overlaps with food plants as well as determining whether noise pollution from chainsaws influences activity budgets of $N$. annamensis. More importantly, this group of gibbons has been habituated to humans, with the main goal of attracting tourists to visit the site. Increased numbers of tourists influence animal ecological behaviours, leading to stress (Wells 2005; Behie et al. 2010), and may expose them to human diseases (Woodford et al. 2002; Malone et al. 2010). Future studies should compare the level of stress and contamination of human diseases between a group of gibbons visited by tourists and a non-visited group. Such of the study (the level of stress) is set to commence in 2016 (Behie pers. comm.).

This study indicated that most food items consumed by this gibbon species were high in $\mathrm{TNC}$, so it did not show that primates maximize protein intake as for other primates (Felton et al. 2009b; Johnson et al. 2013). However, since some gibbons and other apes may gain protein by consuming insects rather plant tissues (Chivers 1998; Borah et al. 2014; Rothman et al. 2014), future studies should consider collecting and identifying insects consumed by this gibbon species for nutritional analyses. The results from this type of study would improve our understanding of the food requirements for this gibbon species in captive breeding.

Due to limited time of the research, this study was conducted only on one group of gibbons, and compared diet selection only between group members, and was only conducted in the dry season. However, food and nutritional selection by primates may be different among groups, age, and sex classes (Rothman et al. 2008b). Future studies should compare food selection in a larger sample of groups over a whole year to see how these current results compare. 
To give a good recommendation for gibbons in captive breeding, knowing food items and their nutritional values may not enough. Most living organisms including animals and plants require minerals as structural components of organs and tissues (NRC 2003). Future studies should not only collect plants for analysing nutritional compositions, but minerals should be considered. 


\section{Bibliography}

Acamovic T. \& Brooker J. (2005) Biochemistry of plant secondary metabolites and their effects in animals. Proceedings of the Nutrition Society 64, 403-12.

ADB (2014) Cambodia: Country poverty analysis 2014, Asian Development Bank (ADB).

Altmann J. \& Alberts S.C. (2005) Growth rates in a wild primate population: Ecological influences and maternal effects. Behavioral Ecology and Sociobiology 57, 490-501.

Altmann J., Altmann S.A., Hausfater G. \& McCuskey S.A. (1977) Life history of yellow baboons: physical development, reproductive parameters, and infant mortality. Primates 18, 315-30.

Alves R.R.N., Rosa I.L., Albuquerque U.P. \& Cunningham A.B. (2013) Medicine from the wild: an overview of the use and trade of animal products in traditional medicines. In: Animals in Traditional Folk Medicine (pp. 25-42. Springer.

Appanah S. \& Turnbull J.M. (1998) A Review of Dipterocarps: Taxonomy, Ecology, and Silviculture. Centre for International Forestry Research, Bogor, Indonesia

Avtar R., Sawada H., Takeuchi W. \& Singh G. (2012) Characterization of forests and deforestation in Cambodia using ALOS/PALSAR observation. Geocarto International 27, 119-37.

Baird I.G. \& Dearden P. (2003) Biodiversity conservation and resource tenure regimes: a case study from northeast Cambodia. Environmental Management 32, 541-50.

Baranga D. (1983) Changes in chemical composition of food parts in the diet of colobus monkeys. Ecology, 668-73.

Barney K. (2005) Customs, Concessionaires and Conflict: Tracking Cambodia's Forest Commodity Chains and Export Links to China.

Barton R.A. \& Whiten A. (1994) Reducing complex diets to simple rules: food selection by olive baboons. Behavioral Ecology and Sociobiology 35, 283-93.

Beck B.B., Rapaport L.G., Price M.S. \& Wilson A.C. (1994) Reintroduction of captive-born animals. In: Creative conservation (pp. 265-86. Springer).

Behie A.M. \& Pavelka M.S. (2012a) Food selection in the black howler monkey following habitat disturbance: implications for the importance of mature leaves. Journal of Tropical Ecology28, 153-60.

Behie A.M. \& Pavelka M.S. (2012b) The role of minerals in food selection in a black howler monkey (Alouatta pigra) population in Belize following a major hurricane. American Journal of Primatology 74, 1054-63. 
Behie A.M., Pavelka M.S. \& Chapman C.A. (2010) Sources of variation in fecal cortisol levels in howler monkeys in Belize. American Journal of Primatology 72, 600-06.

Belovsky G.E. (1984) Herbivore optimal foraging: a comparative test of three models. American Naturalist, 97-115.

Belovsky G.E. (1997) Optimal foraging and community structure: the allometry of herbivore food selection and competition. Evolutionary Ecology 11, 641-72.

Bender D.J., Contreras T.A. \& Fahrig L. (1998) Habitat loss and population decline: a metaanalysis of the patch size effect. Ecology 79, 517-33.

Biere A., Marak H.B. \& van Damme J.M. (2004) Plant chemical defense against herbivores and pathogens: generalized defense or trade-offs? Oecologia 140, 430-41.

BirdLifeInternational (2015) Species factsheet: Thaumatibis gigantea. BirdLife International.

Boesch C., Bi Z.B.G., Anderson D. \& Stahl D. (2006) Food choice in Tai chimpanzees: are cultural differences present? Cambridge Studies in Biological and Evolutionary Anthropology 48, 183.

Boonratana R., Das J., Yongcheng L., Htun S. \& Timmins R. (2008) Mocaa leoninia. The IUCN Red List of Threatened Species. Version 2015. 2.

Borah M., Devi A. \& Kumar A. (2014) Feeding on non-plant food items by Western hoolock gibbon (Hoolock hoolock). Current Science 107, 1657-60.

Brockelman W., Geissmann T., Timmins T. \& Traeholt C. (2008) Hylobates pileatus. The IUCN Red List of Threatened Species. Version 2015.2.

Brook B.W., Sodhi N.S. \& Ng P.K. (2003) Catastrophic extinctions follow deforestation in Singapore. Nature 424, 420-6.

Brooks T.M., Mittermeier R.A., Mittermeier C.G., Da Fonseca G.A., Rylands A.B., Konstant W.R., Flick P., Pilgrim J., Oldfield S. \& Magin G. (2002) Habitat loss and extinction in the hotspots of biodiversity. Conservation Biology 16, 909-23.

Brumm H. (2004) The impact of environmental noise on song amplitude in a territorial bird. Journal of Animal Ecology 73, 434-40.

Buckley C., Nekaris K. \& Husson S.J. (2006) Survey of Hylobates agilis albibarbis in a logged peat-swamp forest: Sabangau catchment, Central Kalimantan. Primates 47, 327-35.

Bunyavejchewin S., LaFrankie J.V., Baker P.J., Kanzaki M., Ashton P.S. \& Yamakura T. (2003) Spatial distribution patterns of the dominant canopy dipterocarp species in a seasonal dry evergreen forest in western Thailand. Forest Ecology and Management 175, 87-101. 
Carbone L., Harris R.A., Gnerre S., Veeramah K.R., Lorente-Galdos B., Huddleston J., Meyer T.J., Herrero J., Roos C. \& Aken B. (2014) Gibbon genome and the fast karyotype evolution of small apes. Nature 513, 195-201.

Carrai V., Borgognini-Tarli S.M., Huffman M.A. \& Bardi M. (2003) Increase in tannin consumption by sifaka (Propithecus verreauxi verreauxi) females during the birth season: a case for self-medication in prosimians? Primates 44, 61-6.

Ceballos G. \& Ehrlich P.R. (2002) Mammal population losses and the extinction crisis. Science 296, 904-7.

Ceballos G., Ehrlich P.R., Soberón J., Salazar I. \& Fay J.P. (2005) Global mammal conservation: what must we manage? Science 309, 603-7.

Chapman C.A. (1989) Primate seed dispersal: the fate of dispersed seeds. Biotropica, 148-54.

Chapman C.A., Balcomb S.R., Gillespie T.R., Skorupa J.P. \& Struhsaker T.T. (2000) Long-Term Effects of Logging on African Primate Communities: a 28-Year Comparison From Kibale National Park, Uganda. Conservation Biology14, 207-17.

Chapman C.A. \& Chapman L.J. (2002) Foraging challenges of red colobus monkeys: influence of nutrients and secondary compounds. Comparative Biochemistry and Physiology Part A: Molecular \& Integrative Physiology 133, 861-75.

Chapman C.A., Chapman L.J., Rode K.D., Hauck E.M. \& McDowell L.R. (2003) Variation in the nutritional value of primate foods: among trees, time periods, and areas. International Journal of Primatology 24, 317-33.

Chapman C.A. \& Onderdonk D.A. (1998) Forests without primates: primate/plant codependency. American Journal of Primatology 45, 127-41.

Chapman C.A., Wasserman M.D., Gillespie T.R., Speirs M.L., Lawes M.J., Saj T.L. \& Ziegler T.E. (2006) Do food availability, parasitism, and stress have synergistic effects on red colobus populations living in forest fragments? American Journal of Physical Anthropology 131, 525-34.

Chatterjee H.J. (2009) Evolutionary relationships among the gibbons: a biogeographic perspective. In: The Gibbons (pp. 13-36. Springer.

Chetry D., Chetry R., Das A., Loma C. \& Panor J. (2008) New distribution records for Hoolock leuconedys in India. Primate Conservation 23, 125-8.

Cheyne S.M., Thompson C.J., Phillips A.C., Hill R.M. \& Limin S.H. (2008) Density and population estimate of gibbons (Hylobates albibarbis) in the Sabangau catchment, Central Kalimantan, Indonesia. Primates 49, 50-6.

Chivers D.J. (1998) Measuring food intake in wild animals: primates. Proceedings of the Nutrition Society 57, 321-32. 
Chivers D.J. \& MacKinnon J. (1977) On the behaviour of siamang after playback of their calls. Primates 18, 943-8.

Chung K.-T., Wong T.Y., Wei C.-I., Huang Y.-W. \& Lin Y. (1998) Tannins and human health: a review. Critical reviews in food science and nutrition 38, 421-64.

Clements K.D., Raubenheimer D. \& Choat J.H. (2009) Nutritional ecology of marine herbivorous fishes: ten years on. Functional Ecology 23, 79-92.

Clements T., Gilbert M., Rainey H.J., Cuthbert R., Eames J.C., Bunnat P., Teak S., Chansocheat S. \& Setha T. (2013a) Vultures in Cambodia: population, threats and conservation. Bird Conservation International 23, 7-24.

Clements T., John A., Nielsen K., An D., Tan S. \& Milner-Gulland E. (2010) Payments for biodiversity conservation in the context of weak institutions: Comparison of three programs from Cambodia. Ecological Economics 69, 1283-91.

Clements T., Rainey H., An D., Rours V., Tan S., Thong S., Sutherland W. \& Milner-Gulland E. (2013b) An evaluation of the effectiveness of a direct payment for biodiversity conservation: the bird nest protection program in the Northern Plains of Cambodia. Biological Conservation 157, 50-9.

Clinebell II R.R., Phillips O.L., Gentry A.H., Stark N. \& Zuuring H. (1995) Prediction of neotropical tree and liana species richness from soil and climatic data. Biodiversity \& Conservation 4, 56-90.

Coley P.D. (1983) Herbivory and defensive characteristics of tree species in a lowland tropical forest. Ecological Monographs 53, 209-34.

Coley P.D. \& Barone J. (1996) Herbivory and plant defenses in tropical forests. Annual Review of Ecology and Systematics, 305-35.

Cork S.J. \& Foley W.J. (1991) Digestive and metabolic strategies of arboreal mammalian folivores in relation to chemical defenses in temperate and tropical forests. Plant Defenses Against Mammalian Herbivory, 133-66.

Coudrat C., Rogers L. \& Nekaris K. (2011) Abundance of primates reveals Samkos Wildlife Sanctuary, Cardamom Mountains, Cambodia as a priority area for conservation. Oryx 45, 427-34.

Cowles T., Olson R. \& Chisholm S. (1988) Food selection by copepods: discrimination on the basis of food quality. Marine Biology 100, 41-9.

Cowlishaw G. \& Dunbar R.I. (2000) Primate conservation biology. University of Chicago Press.

Dasilva G.L. (1992) The western black-and-white colobus as a low-energy strategist: activity budgets, energy expenditure and energy intake. Journal of Animal Ecology, 79-91. 
Davies A., Benett E.L. \&Waterman P.G. (1988) Food selection by two South-east Asian colobine monkeys (Presbytis rubicunda and Presbytis melalophos) in relation to plant chemistry. Biological Journal of the Linnean Society 34, 33-56.

De Lopez T.T. (2002) Natural resource exploitation in Cambodia: an examination of use, appropriation, and exclusion. The Journal of Environment \& Development 11, 355-79.

Demott W.R. (1989) Optimal foraging theory as a predictor of chemically mediated food selection by suspension-feeding copepods. Limnology and Oceanography 34, 140-54.

Detedcc A. \& Courchamp F. (2007) Importance of the Allee effect for reintroductions. Ecoscience 14, 440-51.

Doran-Sheehy D., Mongo P., Lodwick J. \& Conklin-Brittain N. (2009) Male and female western gorilla diet: preferred foods, use of fallback resources, and implications for ape versus old world monkey foraging strategies. American Journal of Physical Anthropology 140, 727-38.

Duarte M.H., Vecci M.A., Hirsch A. \& Young R.J. (2011) Noisy human neighbours affect where urban monkeys live. Biology Letters7, 840-2.

Duckworth J., Batters G., Belant J., Bennett E., Brunner J., Burton J., Challender D., Cowling V., Duplaix N. \& Harris J. (2012) Why South-East Asia should be the world's priority for averting imminent species extinctions, and a call to join a developing crossinstitutional programme to tackle this urgent issue. SAPI EN. S. Surveys and Perspectives Integrating Environment and Society.

Duhan A., Chauhan B. \& Punia D. (1992) Nutritional value of some non-conventional plant foods of India. Plant foods for human nutrition 42, 193-200.

Ebenhard T. (1995) Conservation breeding as a tool for saving animal species from extinction. Trends in ecology \& evolution 10, 438-43.

Elder A.A. (2009) Hylobatid diets revisited: The importance of body mass, fruit availability, and interspecific competition. In: The Gibbons (pp. 133-59. Springer).

Engel J. \& Lamprecht J. (1997) Doing what everybody does? A procedure for investigating behavioural synchronization. Journal of Theoretical Biology 185, 255-62.

Fan P.-F., Ai H.-S., Fei H.-L., Zhang D. \& Yuan S.-D. (2013) Seasonal variation of diet and time budget of Eastern hoolock gibbons (Hoolock leuconedys) living in a northern montane forest. Primates 54, 137-46.

Fan P.-F., Fei H.-L., Scott M.B., Zhang W. \& Ma C.-Y. (2011) Habitat and food choice of the critically endangered cao vit gibbon (Nomascus nasutus) in China: implications for conservation. Biological Conservation 144, 2247-54.

Fan P.-F., Ni Q.-Y., Sun G.-Z., Huang B. \& Jiang X.-L. (2008) Seasonal variations in the activity budget of Nomascus concolor jingdongensis at Mt. Wuliang, Central Yunnan, 
China: effects of diet and temperature. International Journal of Primatology 29, 1047-57.

Fan P., Fei H., Xiang Z., Zhang W., Ma C. \& Huang T. (2010) Social structure and group dynamics of the cao vit gibbon (Nomascus nasutus) in Bangliang, Jingxi, China. Folia primatologica 81, 245-53.

Fan P., Ni Q., Sun G., Huang B. \& Jiang X. (2009) Gibbons under seasonal stress: the diet of the black crested gibbon (Nomascus concolor) on Mt. Wuliang, Central Yunnan, China. Primates 50, 37-44.

Fan P.F. \& Jiang X.L. (2008) Sleeping sites, sleeping trees, and sleep-related behaviors of black crested gibbons (Nomascus concolor jingdongensis) at Mt. Wuliang, Central Yunnan, China. American Journal of Primatology 70, 153-60.

FAO (2010) Global Forest Resources Assessment 2010 - main report. FAO Forestry Paper No. 163. Rome. www.fao.org/docrep/013/i1757e/i1757e00.htm.

Fargione J., Hill J., Tilman D., Polasky S. \& Hawthorne P. (2008) Land clearing and the biofuel carbon debt. Science 319, 1235-8.

Feeny P. (1976) Plant apparency and chemical defense. In: Biochemical interaction between plants and insects (pp. 1-40. Springer.

Felton A.M., Felton A., Lindenmayer D.B. \& Foley W.J. (2009a) Nutritional goals of wild primates. Functional Ecology 23, 70-8.

Felton A.M., Felton A., Raubenheimer D., Simpson S.J., Foley W.J., Wood J.T., Wallis I.R. $\&$ Lindenmayer D.B. (2009b) Protein content of diets dictates the daily energy intake of a free-ranging primate. Behavioral Ecology, arp021.

Felton A.M., Felton A., Wood J.T., Foley W.J., Raubenheimer D., Wallis I.R. \& Lindenmayer D.B. (2009c) Nutritional ecology of Ateles chamek in lowland Bolivia: how macronutrient balancing influences food choices. International Journal of Primatology 30, 675-96.

Felton A.M., Felton A., Wood J.T. \& Lindenmayer D.B. (2008) Diet and feeding ecology of Ateles chamek in a Bolivian semihumid forest: the importance of Ficus as a staple food resource. International Journal of Primatology 29, 379-403.

Fernandes G., Yunis E. \& Good R. (1976) Influence of diet on survival of mice. Proceedings of the National Academy of Sciences 73, 1279-83.

Fraser D.J. (2008) How well can captive breeding programs conserve biodiversity? A review of salmonids. Evolutionary Applications 1, 535-86.

Frechette J. (2014) Construction and experimentally testing the impacts of animal generated dispersal kernels in a northern Cambodia. PhD thesis, University of Florida, USA. 
Frechette J., Behie A., Hon N. \& Rawson B. (in prep) Seasonal variation in diet and activity budgets of the northern yellow-cheeked crested gibbon (Nomascus annamensis) Cambodia

Freeland W.J. \& Janzen D.H. (1974) Strategies in herbivory by mammals: the role of plant secondary compounds. American Naturalist, 269-89.

Galbreath G., Mordacq J. \& Weiler F. (2006) Genetically solving a zoological mystery: was the kouprey (Bos sauveli) a feral hybrid? Journal of Zoology 270, 561-4.

Ganasia J., Ortmann S. \& Robbins M.M. (2008) Food preferences of wild mountain gorillas. American Journal of Primatology 70, 1-12.

Garber P.A. (1986) The ecology of seed dispersal in two species of callitrichid primates (Saguinus mystax and Saguinus fuscicollis). American Journal of Primatology 10, 155-70.

Garber P.A. (1988) Foraging decisions during nectar feeding by tamarin monkeys (Saguinus mystax and Saguinus fuscicollis, Callitrichidae, Primates) in Amazonian Peru. Biotropica, 100-6.

Gates J.F. (1996) Habitat alteration, hunting and the conservation of folivorous primates in African forests. Australian Journal of Ecology21, 1-9.

Geissler P., Hartmann T. \& Neang T. (2012) A new species of the genus lygosoma Hardwicke \& Gray, 1827 (Squamata: Scincidae) from northeastern Cambodia, with an updated identification key to the genus Lygosoma in mainland Southeast Asia. Zootaxa 3190, 5.

Geissmann T. (2002) Taxonomy and evolution of gibbons. Evolutionary Anthropology: Issues, News, and Reviews 11, 28-31.

Geissmann T. (2007) Status reassessment of the gibbons: results of the Asian primate red list workshop 2006. Gibbon Journal 3, 5-15.

Geissmann T., Manh Ha N., Rawson B., Timmins R. \& Traeholt C. (2008) Nomascus gabriellae. The IUCN Red List of Threatened Species. Version 2015.2.

Gentry A.H. (1988) Changes in plant community diversity and floristic composition on environmental and geographical gradients. Annals of the Missouri Botanical Garden, $1-34$.

Gerwing J.J., Schnitzer S.A., Burnham R.J., Bongers F., Chave J., DeWalt S.J., Ewango C.E., Foster R., Kenfack D. \& Martínez-Ramos M. (2006) A Standard Protocol for Liana Censuses1. Biotropica 38, 256-61.

Gittins S.P. \& Raemaekers J.J. (1980) Siamang, lar and agile gibbons. In: Malayan Forest Primates (pp. 63-106. Springer. 
Givens D.I. \& Shingfield K. (2004) Foods derived from animals: the impact of animal nutrition on their nutritive value and ability to sustain long-term health. Nutrition Bulletin 29, 325-32.

Glander K.E. (1982) The impact of plant secondary compounds on primate feeding behavior. American Journal of Physical Anthropology 25, 1-18.

Goodall J. (1986) The chimpanzees of Gombe: Patterns of behavior.

Grandison R.C., Piper M.D. \& Partridge L. (2009) Amino-acid imbalance explains extension of lifespan by dietary restriction in Drosophila. Nature 462, 1061-4.

Gray T., Phan C. \& Long B. (2010) Modelling species distribution at multiple spatial scales: gibbon habitat preferences in a fragmented landscape. Animal Conservation 13, 32432 .

Gray T.N., Phan C., Pin C. \& Prum S. (2012) Establishing a monitoring baseline for threatened large ungulates in eastern Cambodia. Wildlife Biology 18, 406-13.

Halfwerk W., Holleman L.J., Lessells C.K. \& Slabbekoorn H. (2011) Negative impact of traffic noise on avian reproductive success. Journal of Applied Ecology 48, 210-9.

Hamilton R.A. \& Galdikas B.M. (1994) A preliminary study of food selection by the orangutan in relation to plant quality. Primates 35, 255-63.

Hansen M.C., Potapov P.V., Moore R., Hancher M., Turubanova S., Tyukavina A., Thau D., Stehman S., Goetz S. \& Loveland T. (2013) High-resolution global maps of 21stcentury forest cover change. Science 342, 850-3.

Hanson J.D., Larson M.E. \& Snowdon C.T. (1976) The effects of control over high intensity noise on plasma cortisol levels in rhesus monkeys. Behavioral Biology 16, 333-40.

Hanya G. \& Bernard H. (2012) Fallback foods of red leaf monkeys (Presbytis rubicunda) in Danum Valley, Borneo. International Journal of Primatology 33, 322-37.

Hanya G. \& Bernard H. (2015) Different Roles of Seeds and Young Leaves in the Diet of Red Leaf Monkeys (Presbytis rubicunda): Comparisons of Availability, Nutritional Properties, and Associated Feeding Behavior. International Journal of Primatology, $1-17$.

Hardus M.E., Lameira A.R., Menken S.B. \& Wich S.A. (2012) Effects of logging on orangutan behavior. Biological Conservation 146, 177-87.

Harris N.L., Brown S., Hagen S.C., Saatchi S.S., Petrova S., Salas W., Hansen M.C., Potapov P.V. \& Lotsch A. (2012) Baseline map of carbon emissions from deforestation in tropical regions. Science 336, 1573-6.

Harris T.R., Chapman C.A. \& Monfort S.L. (2010) Small folivorous primate groups exhibit behavioral and physiological effects of food scarcity. Behavioral Ecology21, 46-56. 
Hassanin A., Ropiquet A., Cornette R., Tranier M., Pfeffer P., Candegabe P. \& Lemaire M. (2006) Has the kouprey (Bos sauveli Urbain, 1937) been domesticated in Cambodia? Comptes Rendus Biologies 329, 124-35.

Hill J. (2011) Review of local knowledge and uses for primates in the Veun Sai-Siem Pang Conservaion Area, northeastern Cambodia. Journal of the MSc in Primate Conservation 12, 9.

Hladik C.M. (1977) Chimpanzees of Gabon and chimpanzees of Gombe: some comparative data on the diet. Primate Ecology: Studies of Feeding and Ranging Behaviour in Lemurs, Monkeys, and Apes, 81-501.

Hon N., Neak P., Khov V. \& Cheat V. (2010) Food and habitat of Asian small-clawed otter in northeastern Cambodia. IUCN Otter Spec. Group Bull 21, 12-23.

Htun S., Timmins R., Boonratana R. \& Das J. (2008) Macaca arctoides. The IUCN Red List of Threatened Species. Version 2015.2.

ICEM (2003) Cambodia National Report on Protected Areas and Development. Review of Protected Areas and Development in the Lower Mekong River Region., Indooroopilly, Queensland, Australia. 148pp.

Irwin M.T., Raharison J.L., Raubenheimer D., Chapman C.A. \& Rothman J.M. (2014) Nutritional correlates of the "lean season": effects of seasonality and frugivory on the nutritional ecology of diademed sifakas. American Journal of Physical Anthropology 153, 78-91.

Isbell L.A. \& Young T.P. (1993) Social and ecological influences on activity budgets of vervet monkeys, and their implications for group living. Behavioral Ecology and Sociobiology 32, 377-85.

Islam M. \& Feeroz M. (1992) Ecology of hoolock gibbon of Bangladesh. Primates 33, 45164.

ITTO (2003) Annual review and assessment of the world timber situation, 2003. International Tropical Timber Association (ITTO).

IUCN (2015) International Union for Conservation of Nature (IUCN) Red List of Threatened Species. Version 2015. 1. www.iucnredlist.org. Download on 02 June 2015.

IUCN/SSC (2013) Guideline for Reintroductions and Other Conservation Translocations. Version 1.0. Gland, Switzerland: IUCN Species Survival Commission, Viiii + 57 pp.

Johns A.D. (1986) Effects of selective logging on the behavioral ecology of West Malaysian primates. Ecology, 684-94.

Johnson A., Singh S., Duangdala M. \& Hedemark M. (2005) The western black crested gibbon Nomascus concolor in Laos: new records and conservation status. Oryx 39, $311-7$. 
Johnson C., Raubenheimer D., Rothman J., Clarke D., Swedell L. \& Deschner T. (2013) Days in the life: daily nutrient balancing in a wild chacma baboon. PloS One 8, e70383.

Kao D. \& Iida S. (2006) Structural characteristics of logged evergreen forests in Preah Vihear, Cambodia, 3 years after logging. Forest Ecology and Management 225, 6273.

Keo O., Collar N.J. \& Sutherland W.J. (2009) Nest protectors provide a cost-effective means of increasing breeding success in giant ibis Thaumatibis gigantea. Bird Conservation International 19, 77-82.

King A., Behie A. \& Hon N. (in review) Patterns of salt lick use by mammal and bird species in nothern Cambodia.

Kleiman D.G., Beck B.B., Dietz J.M., Dietz L.A., Ballou J.D. \& Coimbra-Filho A.F. (1986) Conservation program for the golden lion tamarin: captive research and management, ecological studies, educational strategies, and reintroduction. In: Primates (pp. 95979. Springer.

Koenig A., Borries C., Chalise M.K. \& Winkler P. (1997) Ecology, nutrition, and timing of reproductive events in an Asian primate, the Hanuman langur (Presbytis entellus). Journal of Zoology 243, 215-35.

Konrad R. (2004) Vocal Diversity and Taxonomy of the Crested Gibbons (Genus Nomascus) in Cambodia. Anthropological Institute and Museum, University of Zürich.

Konrad R. \& Geissmann T. (2006) Vocal diversity and taxonomy of Nomascus in Cambodia. International Journal of Primatology 27, 713-45.

Kool K. (1992) Food selection by the silver leaf monkey, Trachypithecus auratus sondaicus, in relation to plant chemistry. Oecologia 90, 527-33.

Korstjens A.H., Lehmann J. \& Dunbar R. (2010) Resting time as an ecological constraint on primate biogeography. Animal Behaviour 79, 361-74.

Kumar A., Mary K. \& Bagchie P. (2009) Present distribution, population status, and conservation of western hoolock gibbons Hoolock hoolock (Primates: Hylobatidae) in Namdapha National Park, India. Journal of Threatened Taxa 1, 203-9.

Lambrick F.H., Brown N.D., Lawrence A. \& Bebber D.P. (2014) Effectiveness of Community Forestry in Prey Long Forest, Cambodia. Conservation Biology 28, 37281.

Lang C. (2001) Deforestation in Vietnam, Laos and Cambodia. Deforestation, Environment, and Sustainable Development: A comparative analysis, 111-37.

Lappan S. (2008) Male care of infants in a siamang (Symphalangus syndactylus) population including socially monogamous and polyandrous groups. Behavioral Ecology and Sociobiology 62, 1307-17. 
Lappan S. \& Whittaker D. (2009) The gibbons: new perspectives on small ape socioecology and population biology. Springer Science \& Business Media.

Laska M., Salazar L.T.H. \& Luna E.R. (2000) Food preferences and nutrient composition in captive spider monkeys, Ateles geoffroyi. International Journal of Primatology 21, 671-83.

Laval P., Rakotoarison H., Savajol N. \& Vanny T. (2011) The contribution of wild medicinal plants towards poverty alleviation and health improvements: a case study in two villages in Mondulkiri Province, Cambodia. Cambodian Journal of Natural History1, 29-39.

Le Billon P. (2000) The political ecology of transition in Cambodia 1989-1999: War, peace and forest exploitation. Development and Change 31, 785-805.

Le Billon P. (2002) Logging in Muddy Waters: The Politics of Forest Expoitation in Cambodia, Critical Asian Studies, 34:4, 563-586, DOI.

Leibold M.A. \& Wilbur H.M. (1992) Interactions between food-web structure and nutrients on pond organisms.

Lengagne T. (2008) Traffic noise affects communication behaviour in a breeding anuran, Hyla arborea. Biological Conservation 141, 2023-31.

Li H., Aide T.M., Ma Y., Liu W. \& Cao M. (2007) Demand for rubber is causing the loss of high diversity rain forest in SW China. Biodiversity and Conservation 16, 1731-45.

Licitra G., Hernandez T. \& Van Soest P. (1996) Standardization of procedures for nitrogen fractionation of ruminant feeds. Animal Feed Science and Technology 57, 347-58.

Long H.T., Tam N.A., Minh H.T., Tinh N.T. \& Van Tuan B. (2011) Survey of the northern buff-cheeked crested gibbon (Nomascus annamensis) in Kon Ka Kinh National Park, Gia Lai Province, Vietnam.

Loucks C., Mascia M.B., Maxwell A., Huy K., Duong K., Chea N., Long B., Cox N. \& Seng T. (2009) Wildlife decline in Cambodia, 1953-2005: Exploring the legacy of armed conflict. Conservation Letters2, 82-92.

Lynam A.J. (2010) Securing a future for wild Indochinese tigers: Transforming tiger vacuums into tiger source sites. Integrative Zoology 5, 324-34.

Ma S., Wang Y. \& Poirier F.E. (1988) Taxonomy, distribution, and status of gibbons (Hylobates) in southern China and adjacent areas. Primates 29, 277-86.

MacArthur R.H. \& Pianka E.R. (1966) On optimal use of a patchy environment. American Naturalist, 603-9. 
Maldonado A.M., Nijman V. \& Bearder S.K. (2009) Trade in night monkeys Aotus spp. In the Brazil-Colombia-Peru tri-border area: international wildlife trade regulations are ineffectively enforced. Endangered Species Research 9, 143-9.

Malhi Y., Roberts J.T., Betts R.A., Killeen T.J., Li W. \& Nobre C.A. (2008) Climate change, deforestation, and the fate of the Amazon. Science 319, 169-72.

Malone N., Selby M. \& Longo S. (2014) Political-Ecological Dimensions of Silvery Gibbon Conservation Efforts: An Endangered Ape in (and on) the Verge. International Journal of Sociology 44, 34-53.

Malone N.M., Fuentes A. \& White F. (2010) Ethics commentary: subjects of knowledge and control in field primatology. American Journal of Primatology 72, 779-84.

Marshall J.T. \& Marshall E.R. (1976) Gibbons and their territorial songs. Science 193, 235-7.

Matsuda I., Tuuga A., Bernard H., Sugau J. \& Hanya G. (2013) Leaf selection by two Bornean colobine monkeys in relation to plant chemistry and abundance. Scientific reports3.

Mattison J.A., Roth G.S., Beasley T.M., Tilmont E.M., Handy A.M., Herbert R.L., Longo D.L., Allison D.B., Young J.E. \& Bryant M. (2012) Impact of caloric restriction on health and survival in rhesus monkeys from the NIA study. Nature.

Mattson Jr W.J. (1980) Herbivory in relation to plant nitrogen content. Annual review of ecology and systematics, 119-61.

Mattson W.J. (1980) Herbivory in relation to plant nitrogen content. Annual review of ecology and systematics, 119-61.

McConkey K.R., Aldy F., Ario A. \& Chivers D.J. (2002) Selection of fruit by gibbons (Hylobates muellerix agilis) in the rain forests of central Borneo. International Journal of Primatology 23, 123-45.

McKenney B., Chea Y., Tola P. \& Evans T. (2004) Focusing on Cambodia's high value forests: Livelihoods and management. Cambodia Development Resource Institute and Wildlife Conservation Society, Phnom Penh.

Mckey D.B., Gartlan J.S., Waterman P.G. \& Choo G.M. (1981) Food selection by black colobus monkeys (Colobus satanas) in relation to plant chemistry. Biological Journal of the Linnean Society16, 115-46.

McPhee M.E. (2004) Generations in captivity increases behavioral variance: considerations for captive breeding and reintroduction programs. Biological Conservation115, 71-7.

Mead P.S., Slutsker L., Dietz V., McCaig L.F., Bresee J.S., Shapiro C., Griffin P.M. \& Tauxe R.V. (1999) Food-related illness and death in the United States. Emerging Infectious Diseases 5, 607.

Medley K.E. (1993) Primate conservation along the Tana River, Kenya: an examination of the forest habitat. Conservation Biology 7, 109-21. 
Milne S. \& Niesten E. (2009) Direct payments for biodiversity conservation in developing countries: practical insights for design and implementation. Oryx 43, 530-41.

Milton K. (1979) Factors influencing leaf choice by howler monkeys: a test of some hypotheses of food selection by generalist herbivores. American Naturalist, 362-78.

Milton K. (1999) Nutritional characteristics of wild primate foods: do the diets of our closest living relatives have lessons for us? Nutrition 15, 488-98.

Min B. \& Hart S. (2003) Tannins for suppression of internal parasites. Journal of Animal Science 81, E102-E9.

Mitrajit D., Sudip C., Indu S., Bhattacharjee P.C., Formicki G., Bulla J. \& Shubhadeep R. (2014) Nutritional stress in western hoolock gibbon due to adverse changes in diet pattern. Journal of Microbiology, Biotechnology and Food Sciences 4, 152-6.

Mittermeier R. (1986) A global overview of primate conservation. Primate Ecology and Conservation, Cambridge University Press, Cambridge, 325-40.

Monda K., Simmons R.E., Kressirer P., Su B. \& Woodruff D.S. (2007) Mitochondrial DNA hypervariable region-1 sequence variation and phylogeny of the concolor gibbons, Nomascus. American Journal of Primatology 69, 1285-306.

Mootnick A.R. \& Fan P.F. (2011) A comparative study of crested gibbons (Nomascus). American Journal of Primatology 73, 135-54.

Moser B., Schütz M. \& Hindenlang K.E. (2006) Importance of alternative food resources for browsing by roe deer on deciduous trees: the role of food availability and species quality. Forest Ecology and Management 226, 248-55.

Myers N., Mittermeier R.A., Mittermeier C.G., Da Fonseca G.A. \& Kent J. (2000) Biodiversity hotspots for conservation priorities. Nature 403, 853-8.

Nadler T., Rawson B.M. \& Thinh T.N. (2010) Conservation of Primates in Indochina, Frankfurt Zoological Society and Conservation International, Hanoi.

Nadler T., Timmins R. \& Richardson M. (2008) Trachypithecus germaini. The IUCN Red List of Threatened Species. Version 2015.2.

Nakamura Y., Takahashi A. \& Ota H. (2014) A new, recently extinct subspecies of the Kuroiwa's Leopard Gecko, Goniurosaurus kuroiwae (Squamata: Eublepharidae), from Yoronjima Island of the Ryukyu Archipelago, Japan. Acta Herpetologica 9, 61-73.

Nelson B. (2014) Sleeping tree selection by nothern yellow-cheeked crested gibbons (Nomascus annamensis) in Cambodia. MSc thesis, the Australian National University, Australia. 
Ngoc Thanh V., Lippold L., Timmins R. \& Manh Ha N. (2008) Pygathrix nemaeus. The IUCN Red List of Threatened Species. Version 2015.2.

Ni Q.-Y., Huang B., Liang Z.-L., Wang X.-W. \& Jiang X.-L. (2014) Dietary Variability in the Western Black Crested Gibbon (Nomascus concolor) Inhabiting an Isolated and Disturbed Forest Fragment in Southern Yunnan, China. American Journal of Primatology 76, 217-29.

Nijman V. (2001) Effects of behavioural changes due to habitat disturbance on density estimation of rain forest vertebrates, as illustrated by gibbons (primates: Hylobatidae). Forest (and) primates: conservation and ecology of the endemic primates of Java and Borneo, Tropenbos Foundation. Wageningen: Tropenbos International. p, 33-42.

Nijman V. \& Asia T.S. (2009) An assessment of trade in gibbons and orang-utans in Sumatra, Indonesia. TRAFFIC Southeast Asia Kuala Lumpur.

Nijman V., Nekaris K., Donati G., Bruford M. \& Fa J. (2011) Primate conservation: measuring and mitigating trade in primates. Endanger Species Research 13, 159-61.

Novotny V., Drozd P., Miller S.E., Kulfan M., Janda M., Basset Y. \& Weiblen G.D. (2006) Why are there so many species of herbivorous insects in tropical rainforests? Science 313, 1115-8.

NRC (2003) Nutrient requirements of nonhuman primates. 2nd rev. ed. Washington, DC: National Academy Press. 286p.

Nuñez-Iturri G. \& Howe H.F. (2007) Bushmeat and the fate of trees with seeds dispersed by large primates in a lowland rain forest in western Amazonia. Biotropica 39, 348-54.

O'Brien T.G., Kinnaird M.F., Nurcahyo A., Iqbal M. \& Rusmanto M. (2004) Abundance and distribution of sympatric gibbons in a threatened Sumatran rain forest. International Journal of Primatology 25, 267-84.

O'Kelly H.J., Evans T.D., Stokes E.J., Clements T.J., Dara A., Gately M., Menghor N., Pollard E.H., Soriyun M. \& Walston J. (2012) Identifying conservation successes, failures and future opportunities; assessing recovery potential of wild ungulates and tigers in eastern Cambodia. PloS One7, e40482.

O'Malley R.C. \& Power M.L. (2012) Nutritional composition of actual and potential insect prey for the Kasekela chimpanzees of Gombe National Park, Tanzania. American journal of physical anthropology 149, 493-503.

O'Kelly H.J. (2013) Monitoring Conservation Threats, Interventions and Impacts on Wildlife in a Cambodian Tropical Forest.

Oates J.F., Abedi-Lartey M., McGraw W.S., Struhsaker T.T. \& Whitesides G.H. (2000) Extinction of a West African red colobus monkey. Conservation Biology 14, 1526-32.

Oates J.F., Waterman P.G. \& Choo G.M. (1980) Food selection by the south Indian leafmonkey, Presbytis johnii, in relation to leaf chemistry. Oecologia 45, 45-56. 
ODC (2014a) Cambodian Forest Cover maps between 1973 - 2014. www.opendevelopmentcambodia.net/briefing/forest-cover

ODC (2014b) Cambodian Protected Area. www.opendevelopmentcambodia.net/briefing/protected-areas.

Oftedal O.T., Whiten A., Southgate D. \& Van Soest P. (1991) The Nutritional Consequences of Foraging in Primates: The Relationship of Nutrient Intakes to Nutrient Requirements and Discussion. Philosophical Transactions of the Royal Society B: Biological Sciences 334, 161-70.

Ong P. \& Richardson M. (2008) Macaca fascicularis. The IUCN Red List of Threatened Species. Version 2015.2.

Osterberg P., Samphanthamit P., Maprang O., Punnadee S. \& Brockelman W.Y. (2014) Population Dynamics of a Reintroduced Population of Captive-Raised Gibbons (Hylobates lar) on Phuket, Thailand. Primate Conservation, 179-88.

Osterberg P., Samphanthamit P., Maprang O., Punnadee S. \& Brockelman W.Y. (2015) Gibbon (Hylobates lar) Reintroduction Success in Phuket, Thailand, and Its Conservation Benefits. American Journal of Primatology 77, 492-501.

Palo R.T. \& Robbins C.T. (1991) Plant defenses against mammalian herbivory. CRC Press.

Peng-Fei F., Xue-Long J. \& Chang-Cheng T. (2009) The critically endangered black crested gibbon Nomascus concolor on Wuliang Mountain, Yunnan, China: the role of forest types in the species' conservation. Oryx 43, 203-8.

Philippart J.C. (1995) Is captive breeding an effective solution for the preservation of endemic species? Biological Conservation 72, 281-95.

Phon D. (2000) Dictionary of Plants used in Cambodia. Imprimerie Olympic, Phnom Penh.

Phoonjampa R. \& Brockelman W.Y. (2008) Survey of pileated gibbon Hylobates pileatus in Thailand: populations threatened by hunting and habitat degradation. Oryx 42, 600-6.

Pimm S.L. \& Raven P. (2000) Biodiversity: extinction by numbers. Nature 403, 843-5.

Plumptre A.J. \& Reynolds V. (1994) The effect of selective logging on the primate populations in the Budongo Forest Reserve, Uganda. Journal of Applied Ecology, 631-41.

Pollard E., Clements T., Hor N.M., Ko S. \& Rawson B. (2007) Status and conservation of globally threatened primates in the Seima Biodiversity Conservation Area, Cambodia. Wildlife Conservation Society, Cambodia Program, Phnom Penh, Cambodia.

Pontes A.R.M. \& Soares M.L. (2005) Sleeping sites of common marmosets (Callithrix jacchus) in defaunated urban forest fragments: a strategy to maximize food intake. Journal of Zoology 266, 55-63. 
Porter L.J., Hrstich L.N. \& Chan B.G. (1985) The conversion of procyanidins and prodelphinidins to cyanidin and delphinidin. Phytochemistry 25, 223-30.

Price P.W., Bouton C.E., Gross P., McPheron B.A., Thompson J.N. \& Weis A.E. (1980) Interactions among three trophic levels: influence of plants on interactions between insect herbivores and natural enemies. Annual review of ecology and systematics, 4165.

Putz F.E., Zuidema P.A., Synnott T., Peña-Claros M., Pinard M.A., Sheil D., Vanclay J.K., Sist P., Gourlet-Fleury S. \& Griscom B. (2012) Sustaining conservation values in selectively logged tropical forests: the attained and the attainable. Conservation Letters 5, 296-303.

Ratner B.D. (2006) Community management by decree? Lessons from Cambodia's fisheries reform. Society and Natural Resources 19, 79-86.

Raubenheimer D. (2011) Toward a quantitative nutritional ecology: the right-angled mixture triangle. Ecological monographs 81, 407-27.

Raubenheimer D., Machovsky-Capuska G.E., Chapman C.A. \& Rothman J.M. (2015) Geometry of nutrition in field studies: an illustration using wild primates. Oecologia 177, 223-34.

Raubenheimer D. \& Simpson S.J. (1997) Integrative models of nutrient balancing: application to insects and vertebrates. Nutrition research reviews 10, 151-79.

Raubenheimer D. \& Simpson S.J. (2004) Organismal stoichiometry: quantifying nonindependence among food components. Ecology 85, 1203-16.

Rawson B. (2010a) The status of Cambodian primates. T. Nadler, B. Rawson, and Van Ngoc Thinh, editors. Conservation of Primates in Indochina. Frankfurt Zoological Society and Conservation International, Hanoi, Vietnam, 17-26.

Rawson B., Lippold L., Timmins R., Ngoc Thanh V. \& Manh Ha N. (2008) Pygathrix nigripes. The IUCN Red List of Threatened Species. Version 2015.2.

Rawson B. \& Roos C. (2008) A new primate species record for Cambodia: Pygathrix nemaeus. Cambodian Journal of Natural History 1, 7-11.

Rawson B.M. (2009) The socio-ecology of the black-shanked douc (Pygathrix nigripes) in Mondulkiri Province, Cambodia. PhD thesis, the Australian National University.

Rawson B.M. (2010b) The status of Cambodian primates. Conservation of Primates in Indochina, 17-25.

Rawson B.M. \& Bach L.T. (2011) Preliminary observations of geophagy amongst Cambodia's Colobinae. 
Reed J.D. (1995) Nutritional toxicology of tannins and related polyphenols in forage legumes. Journal of Animal Science 73, 1516-28.

Rice W.R. (1989) Analyzing tables of statistical tests. Evolution, 223-5.

Rop O., Mlcek J., Jurikova T., Neugebauerova J. \& Vabkova J. (2012) Edible flowers-a new promising source of mineral elements in human nutrition. Molecules 17, 667283.

Rosenthal G.A. \& Berenbaum M.R. (2012) Herbivores: Their interactions with secondary plant metabolites: Ecological and Evolutionary Processes. Academic Press.

Rothman J.M., Chapman C.A. \& Pell A.N. (2008a) Fiber-bound nitrogen in gorilla diets: implications for estimating dietary protein intake of primates. American Journal of Primatology 70, 690-4.

Rothman J.M., Chapman C.A. \& Van Soest P.J. (2012) Methods in primate nutritional ecology: a user's guide. International Journal of Primatology 33, 542-66.

Rothman J.M., Dierenfeld E.S., Hintz H.F. \& Pell A.N. (2008b) Nutritional quality of gorilla diets: consequences of age, sex, and season. Oecologia 155, 111-22.

Rothman J.M., Dierenfeld E.S., Molina D.O., Shaw A.V., Hintz H.F. \& Pell A.N. (2006) Nutritional chemistry of foods eaten by gorillas in Bwindi Impenetrable National Park, Uganda. American Journal of Primatology 68, 675-91.

Rothman J.M., Raubenheimer D., Bryer M.A., Takahashi M. \& Gilbert C.C. (2014) Nutritional contributions of insects to primate diets: implications for primate evolution. Journal of Human Evolution 71, 59-69.

Rothman J.M., Raubenheimer D. \& Chapman C.A. (2011) Nutritional geometry: gorillas prioritize non-protein energy while consuming surplus protein. Biology letters, rsbl20110321.

Russo S.E., Campbell C.J., Dew J.L., Stevenson P.R. \& Suarez S.A. (2005) A multi-forest comparison of dietary preferences and seed dispersal by Ateles spp. International Journal of Primatology 26, 1017-37.

Ryan C.A. (1989) Proteinase inhibitor gene families: strategies for transformation to improve plant defenses against herbivores. BioEssays 10, 20-4.

Sasaki N. (2006) Carbon emissions due to land-use change and logging in Cambodia: a modeling approach. Journal of Forest Research11, 397-403.

Schipper J., Chanson J.S., Chiozza F., Cox N.A., Hoffmann M., Katariya V., Lamoreux J., Rodrigues A.S., Stuart S.N. \& Temple H.J. (2008) The status of the world's land and marine mammals: diversity, threat, and knowledge. Science 322, 225-30.

Schmidt L. \& Nguyen V.A. (2005) Dialium cochichinense Pierre. Seed Leaflet 91, 1-2. 
Schoener T.W. (1971) Theory of feeding strategies. Annual review of ecology and systematics, 369-404.

Serio-Silva J.C., Rico-Gray V., Hernández-Salazar L.T. \& Espinosa-Gómez R. (2002) The role of Ficus (Moraceae) in the diet and nutrition of a troop of Mexican howler monkeys, Alouatta palliata mexicana, released on an island in southern Veracruz, Mexico. Journal of Tropical Ecology 18, 913-28.

Shah N., Atallah M.T., Mahoney R.R. \& Pellett P.L. (1982) Effect of dietary fiber components on fecal nitrogen excretion and protein utilization in growing rats. J. Nutr 112, 658-66.

Sharma N., Madhusudan M.D. \& Sinha A. (2014) Local and Landscape Correlates of Primate Distribution and Persistence in the Remnant Lowland Rainforests of the Upper Brahmaputra Valley, Northeastern India. Conservation Biology 28, 95-106.

Shepherd C.R. (2010) Illegal primate trade in Indonesia exemplified by surveys carried out over a decade in North Sumatra. Endangered Species Research 11, 201-5.

Siemers B.M. \& Schaub A. (2011) Hunting at the highway: traffic noise reduces foraging efficiency in acoustic predators. Proceedings of the Royal Society of London B: Biological Sciences 278, 1646-52.

Silver S.C., Ostro L.E., Yeager C. \& Horwich R. (1998) Feeding ecology of the black howler monkey (Alouatta pigra) in northern Belize. American Journal of Primatology 45, 263-79.

Simmen B., Tarnaud L., Marez A. \& Hladik A. (2013) Leaf chemistry as a predictor of primate biomass and the mediating role of food selection: A case study in a folivorous lemur (Propithecus verreauxi). American Journal of Primatology.

Simpson S. \& Raubenheimer D. (1993) A multi-level analysis of feeding behaviour: the geometry of nutritional decisions. Philosophical Transactions of the Royal Society B: Biological Sciences 342, 381-402.

Simpson S. \& Raubenheimer D. (1995) The geometric analysis of feeding and nutrition: a user's guide. Journal of Insect Physiology 41, 545-53.

Slabbekoorn H. \& Ripmeester E.A. (2008) Birdsong and anthropogenic noise: implications and applications for conservation. Molecular Ecology 17, 72-83.

Smith E., A D., Husson S.J., C Y. \& Harrison M.E. (2013) Feeding ecology of red langurs in Sabangau tropical peat-swamp forest, Indonesian Borneo: extreme granivory in a non-masting forest. American Journal of Primatology 75, 848-59.

Speiser B. \& Rowell-Rahier M. (1991) Effects of food availability, nutritional value, and alkaloids on food choice in the generalist herbivore Arianta arbustorum (Gastropoda: Helicidae). Oikos, 306-18. 
Starr C., Nekaris K., Streicher U. \& Leung L. (2010) Traditional use of slow lorises Nycticebus bengalensis and N. pygmaeus in Cambodia: an impediment to their conservation. Endangered Species Research 12, 17-23.

Starr C., Nekaris K., Streicher U. \& Leung L.K.-P. (2011) Field surveys of the Vulnerable pygmy slow loris Nycticebus pygmaeus using local knowledge in Mondulkiri Province, Cambodia. Oryx 45, 135-42.

Stevenson P.R. (2000) Seed dispersal by woolly monkeys(Lagothrix lagothricha) at Tinigua National Park, Colombia: Dispersal distance, germination rates, and dispersal quantity. American Journal of Primatology 50, 275-89.

Stevenson P.R., Castellanos M.C., Pizarro J.C. \& Garavito M. (2002) Effects of seed dispersal by three ateline monkey species on seed germination at Tinigua National Park, Colombia. International Journal of Primatology 23, 1187-204.

Streicher U., Ngoc Thanh V., Nadler T., Timmins R. \& Nekaris A. (2008a) Nycticebus. The IUCN Red List of Threatened Species. Version 2015. 2.

Streicher U., Singh M., Timmins R. \& Brockelman W. (2008b) Nycticebus bengalensis. The IUCN Red List of Threatened Species. Version 2015. 2.

Strier K.B. (1992) Atelinae adaptations: behavioral strategies and ecological constraints. American Journal of Physical Anthropology 88, 515-24.

Strier K.B. (2007) Primate behavioral ecology. Allyn and Bacon Boston.

Sutherland W.J. (1998) The importance of behavioural studies in conservation biology. Animal Behaviour 56, 801-9.

Taylor S.S., Jamieson I.G. \& Armstrong D.P. (2005) Successful island reintroductions of New Zealand robins and saddlebacks with small numbers of founders. Animal Conservation 8, 415-20.

Te Wong S., Servheen C., Ambu L. \& Norhayati A. (2005) Impacts of fruit production cycles on Malayan sun bears and bearded pigs in lowland tropical forest of Sabah, Malaysian Borneo. Journal of Tropical Ecology 21, 627-39.

Terborgh J. (1986) Community aspects of frugivory in tropical forests. In: Frugivores and seed dispersal (pp. 371-84. Springer.

Thévenon S., Bonnet A., Claro F. \& Maillard J.C. (2003) Genetic diversity analysis of captive populations: The Vietnamese sika deer (Cervus nippon pseudaxis) in zoological parks. Zoo Biology 22, 465-75.

Thinh V., Ngoc, R A., Thanh V.N., Nadler T. \& Roos C. (2010) A new species of crested gibbon, from the central Annamite mountain range. Vietnamese Journal of Primatology 1, 1-12. 
Thompson M.E. \& Wrangham R.W. (2008) Diet and reproductive function in wild female chimpanzees (Pan troglodytes schweinfurthii) at Kibale National Park, Uganda. American Journal of Physical Anthropology 135, 171-81.

Traeholt C., Bonthoeun R., Virak C., Samuth M. \& Vutthin S. (2006) Song Activity of the Pileated Gibbon, Hylobates pileatus, in Cambodia. Primate Conservation, 139-44.

Trepanowski J.F., Canale R.E., Marshall K.E., Kabir M.M. \& Bloomer R.J. (2011) Impact of caloric and dietary restriction regimens on markers of health and longevity in humans and animals: a summary of available findings. Nutr $J$ 10, 10.1186.

Tutin C.E., Ancrenaz M., Paredes J., Vacher-Vallas M., Vidal C., Goossens B., Bruford M.W. \& Jamart A. (2001) Conservation Biology Framework for the Release of Wild-Born Orphaned Chimpanzees into the Conkouati Reserve, Congo. Conservation Biology 15, 1247-57.

Van Soest P.J. (1978) Dietary fibers: their definition and nutritional properties. The American Journal of Clinical Nutrition 31, S12-S20.

Van Soest P.v., Robertson J. \& Lewis B. (1991) Methods for dietary fiber, neutral detergent fiber, and nonstarch polysaccharides in relation to animal nutrition. Journal of Dairy Science 74, 3583-97.

Vedder A.L. (1984) Movement patterns of a group of free-ranging mountain gorillas (Gorilla gorilla beringei) and their relation to food availability. American Journal of Primatology 7, 73-88.

Veeramah K.R., Woerner A.E., Johnstone L., Gut I., Gut M., Marques-Bonet T., Carbone L., Wall J.D. \& Hammer M.F. (2015) Examining Phylogenetic Relationships Among Gibbon Genera Using Whole Genome Sequence Data Using an Approximate Bayesian Computation Approach. Genetics 200, 295-U575.

Vinh L.Q., Thinh V.T., Hai D.T., Do Quang Huy N.D.M. \& Trinh B.H. (2010) Survey of Northern Buff-cheeked Crested Gibbon (Nomascus annamensis) in Kon Cha Rang Nature Reserve.

Walston J., Robinson J.G., Bennett E.L., Breitenmoser U., da Fonseca G.A., Goodrich J., Gumal M., Hunter L., Johnson A. \& Karanth K.U. (2010) Bringing the tiger back from the brink - the six percent solution. PLoS Biology 8, e1000485.

Wasserman M.D. \& Chapman C.A. (2003) Determinants of colobine monkey abundance: the importance of food energy, protein and fibre content. Journal of Animal Ecology 72, 650-9.

Watanuki Y. \& Nakayama Y. (1993) Age difference in activity pattern of Japanese monkeys: effects of temperature, snow, and diet. Primates 34, 419-30.

WCS (2009) List of animal on the IUCN Red List Found in Cambodia. Widlife Conservation Society - Cambodia Program, Phnom Penh. 
Wells D.L. (2005) A note on the influence of visitors on the behaviour and welfare of zoohoused gorillas. Applied Animal Behaviour Science 93, 13-7.

Wendeln M.C., Runkle J.R. \& Kalko E.K. (2000) Nutritional Values of 14 Fig Species and Bat Feeding Preferences in Panama1. Biotropica 32, 489-501.

Westoby M. (1974) An analysis of diet selection by large generalist herbivores. American Naturalist, 290-304.

Whiten A., Byrne R., Barton R., Waterman P., Henzi S., Hawkes K., Widdowson E., Altmann S., Milton K. \& Dunbar R. (1991) Dietary and foraging strategies of baboons [and discussion]. Philosophical Transactions of the Royal Society B: Biological Sciences 334, 187-97.

Whitington C. \& Treesucon U. (1991) Selection and treatment of food plants by whitehanded gibbons (Hylobates lar) in Khao Yai National Park, Thailand. Natural History Bulletin of the Siam Society 39, 111-22.

Whitmore T.C. \& Burnham C.P. (1975) Tropical Rain Forests of the Far East. Clarendon Press.

Wickramagamage P. (1998) Large-scale deforestation for plantation agriculture in the hill country of Sri Lanka and its impacts. Hydrological Processes 12, 2015-28.

Wiederholt R. \& Post E. (2010) Tropical warming and the dynamics of endangered primates. Biology Letters 6, 257-60.

Wittstock U., Agerbirk N., Stauber E.J., Olsen C.E., Hippler M., Mitchell-Olds T., Gershenzon J. \& Vogel H. (2004) Successful herbivore attack due to metabolic diversion of a plant chemical defense. Proceedings of the National Academy of Sciences of the United States of America 101, 4859-64.

Woodford M.H., Butynski T.M. \& Karesh W.B. (2002) Habituating the great apes: the disease risks. Oryx 36, 153-60.

Wrangham R. \& Waterman P. (1983) Condensed tannins in fruits eaten by chimpanzees. Biotropica, 217-22.

Wrangham R.W., Chapman C.A. \& Chapman L.J. (1994) Seed dispersal by forest chimpanzees in Uganda. Journal of Tropical Ecology 10, 355-68.

Yepez P., De La Torre S. \& Snowdon C.T. (2005) Interpopulation differences in exudate feeding of pygmy marmosets in Ecuadorian Amazonia. American Journal of Primatology 66, 145-58.

Yiming L. (2006) Seasonal variation of diet and food availability in a group of Sichuan snub-nosed monkeys in Shennongjia Nature Reserve, China. American Journal of Primatology 68, 217-33. 
Zhang X., Wu J., Zhou W., Lin R. \& Li J. (2008) Diet and time budget of hoolock gibbon (Hoolock hoolock) at Nankang, Gaoligongshan mountains in spring. Sichuan Journal of Zoology 27, 193-6.

\section{Appendix}

Appendix 1: Social activities

Social activities were categorised as:

1. Calling was recorded whenever the sound of each gibbon was heard. The sound from each individual was different, and was easily recognized.

2. Copulation was recorded whenever the adult male and female showed sexual interaction.

3. Grooming was recorded whenever the focal animal was observed grooming another.

4. Playing was recorded whenever the focal animal was observed playing within the group members. 
Appendix 2: Logging activities and food items

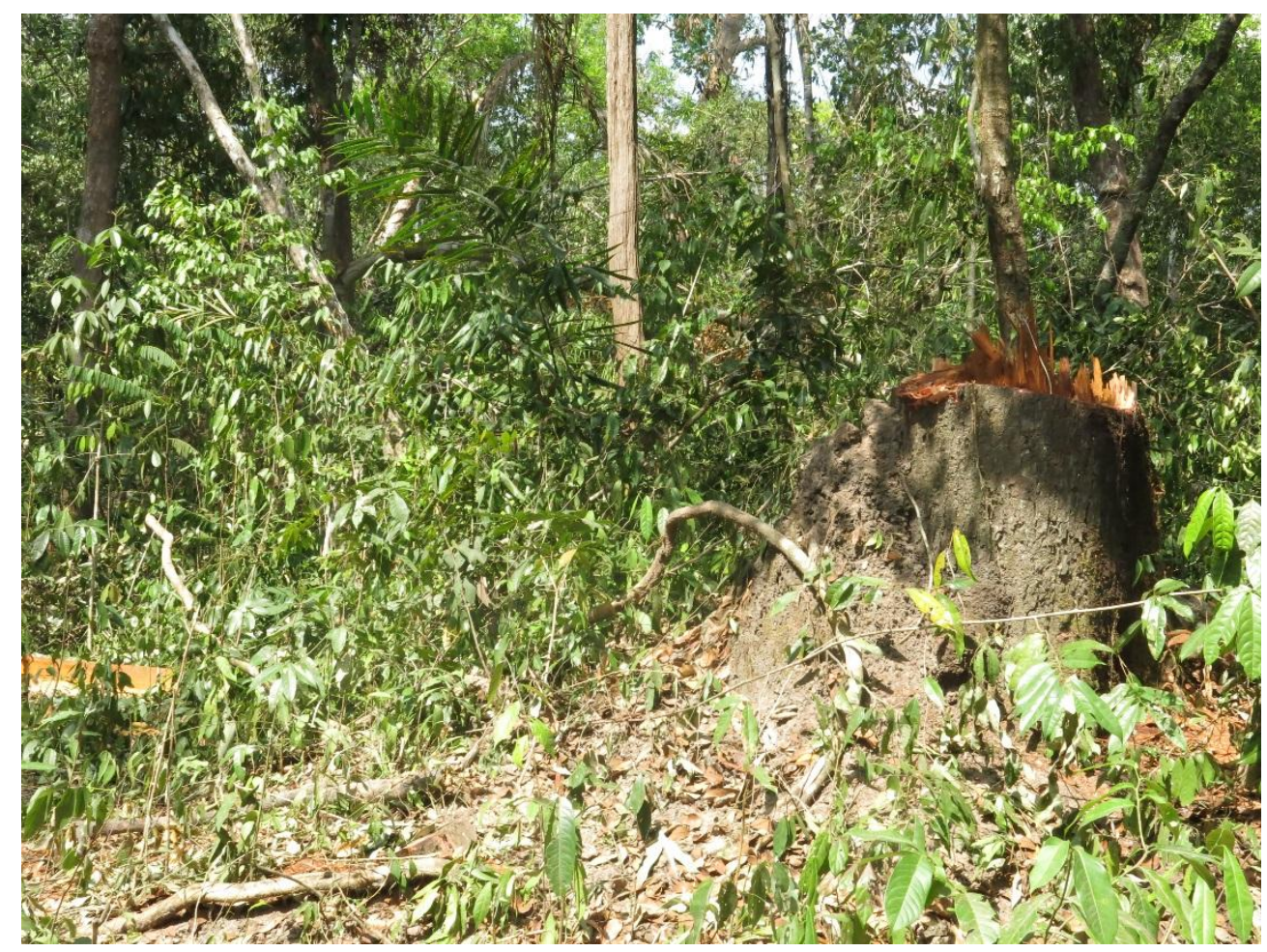

Figure 1a: A fresh remaining of an illegal logged tree (unidentified species) along the way to Veun Sai-Siem Pang Conservation Area (VSSPCA), northern Cambodia.

Photo: Naven Hon

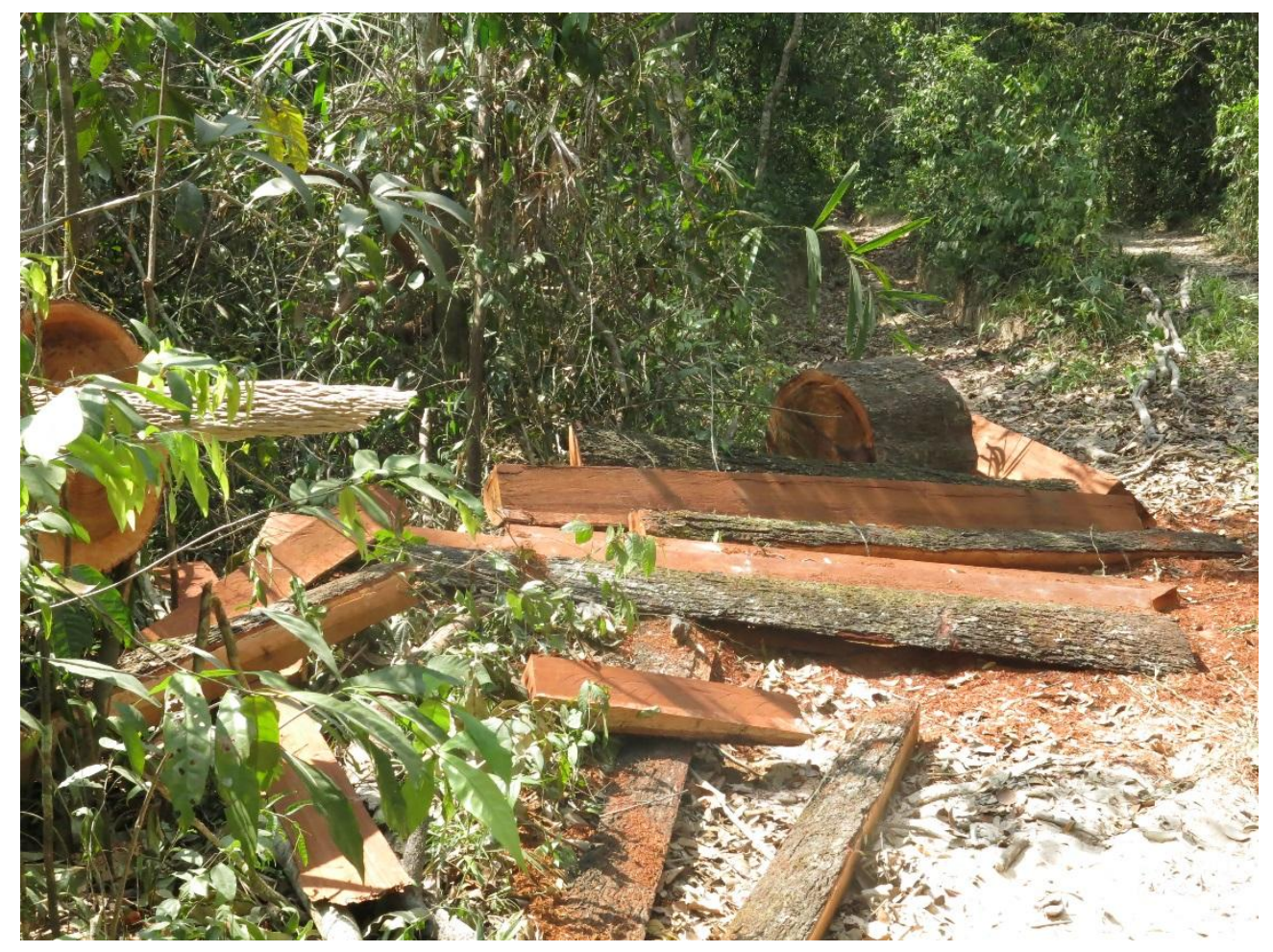

Figure 1b: Another sign of illegal logging in Veun Sai-Siem Pang Conservation Area (VSSPCA), northern Cambodia.

Photo: Naven Hon 


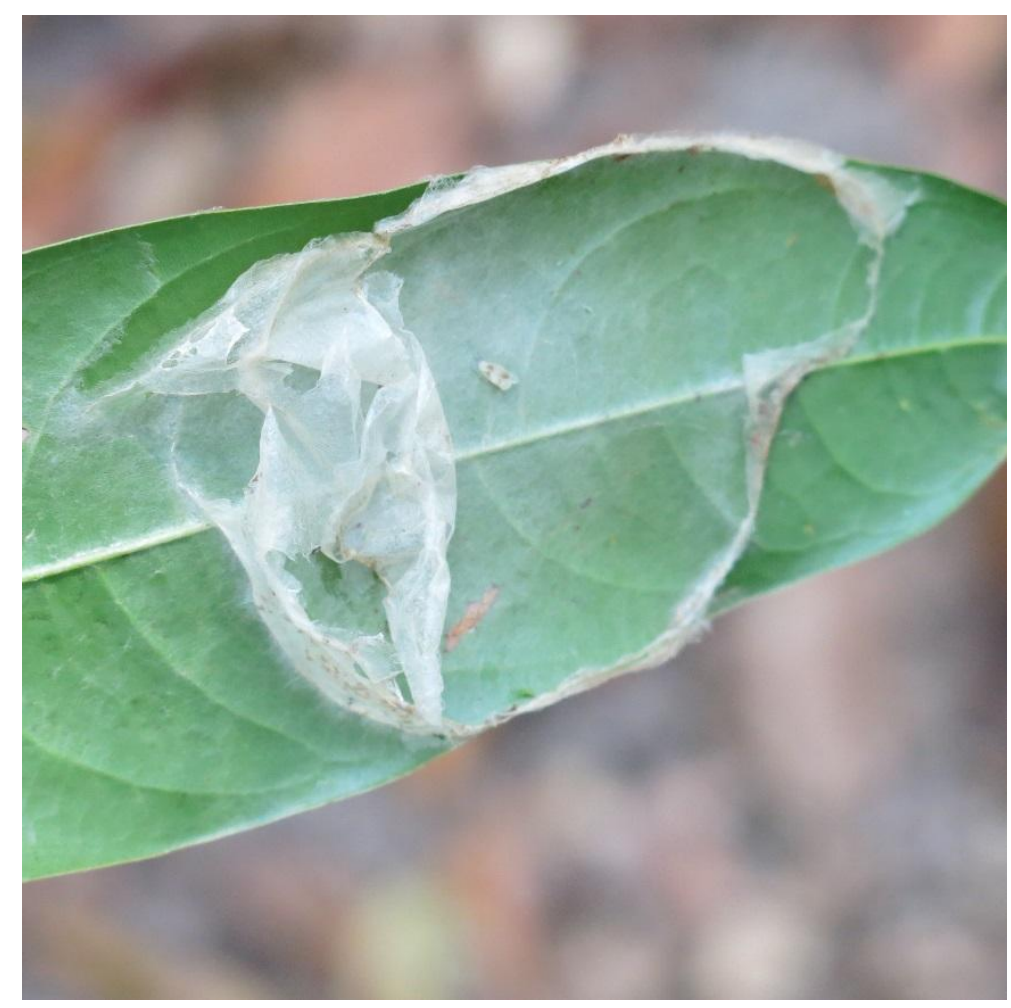

Figure 2: Unidentified insect larva eaten by the gibbons

\section{Photo: Naven Hon}

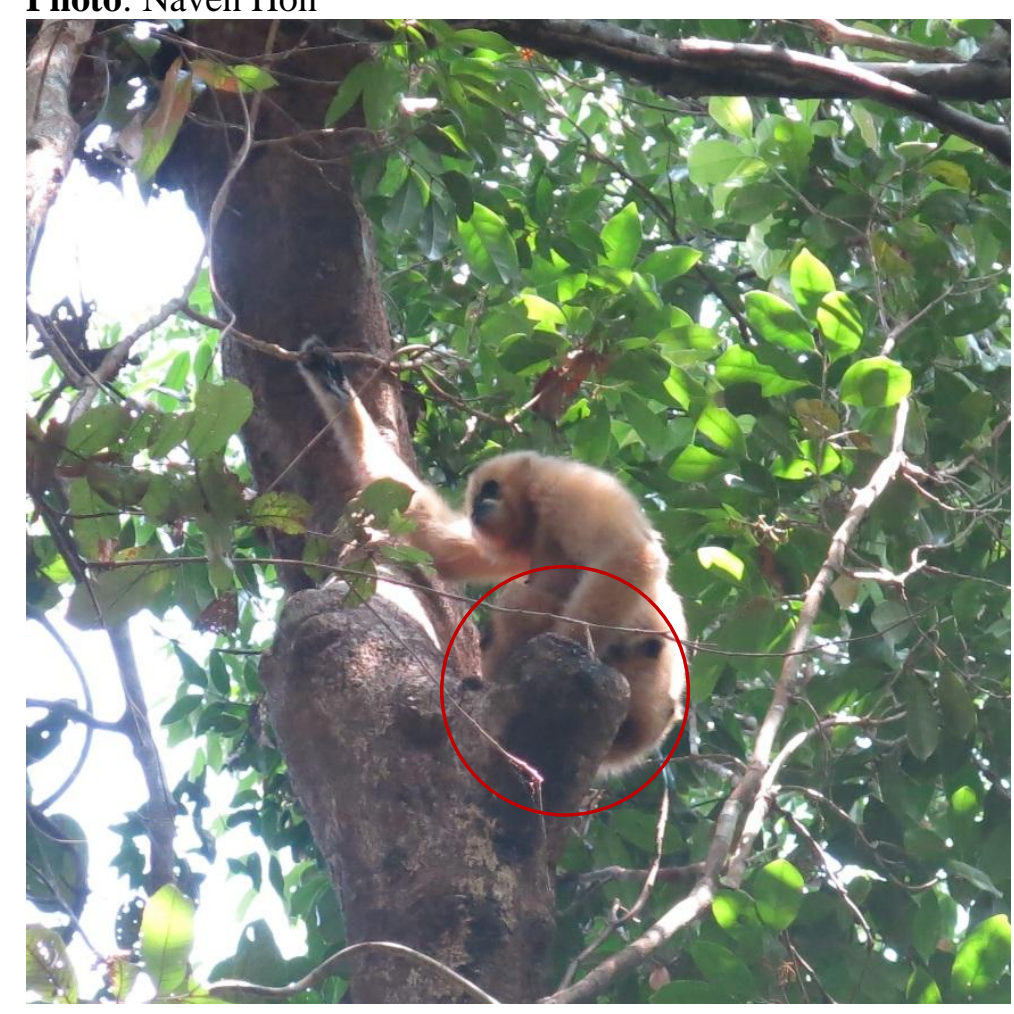

Figure 3: The adult female gibbon using her hand to get water from the cavity in the tree hole. Photo: Naven Hon 


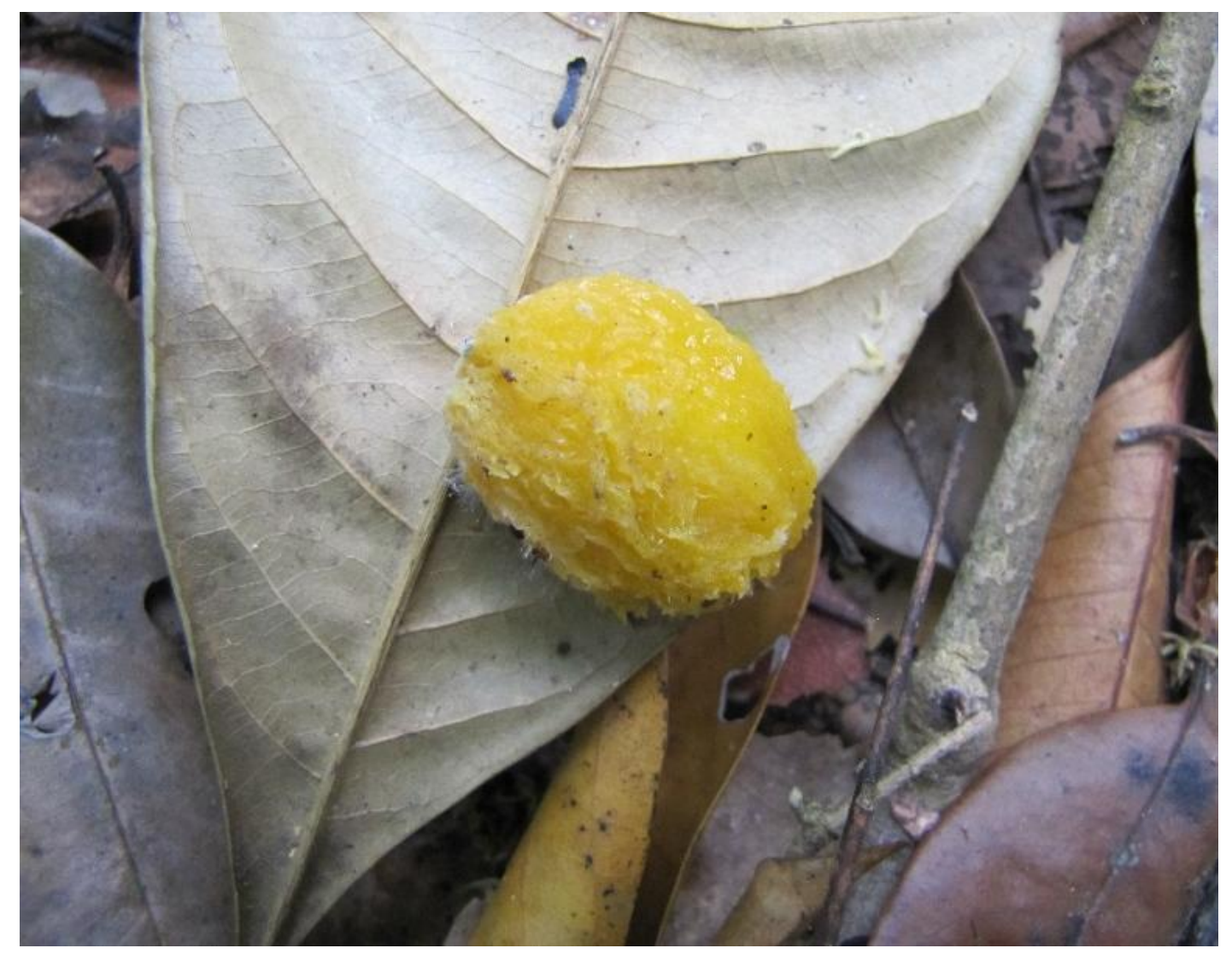

Figure 4: A seed, was spat out after its flesh, was consumed by gibbons Photo: Naven Hon

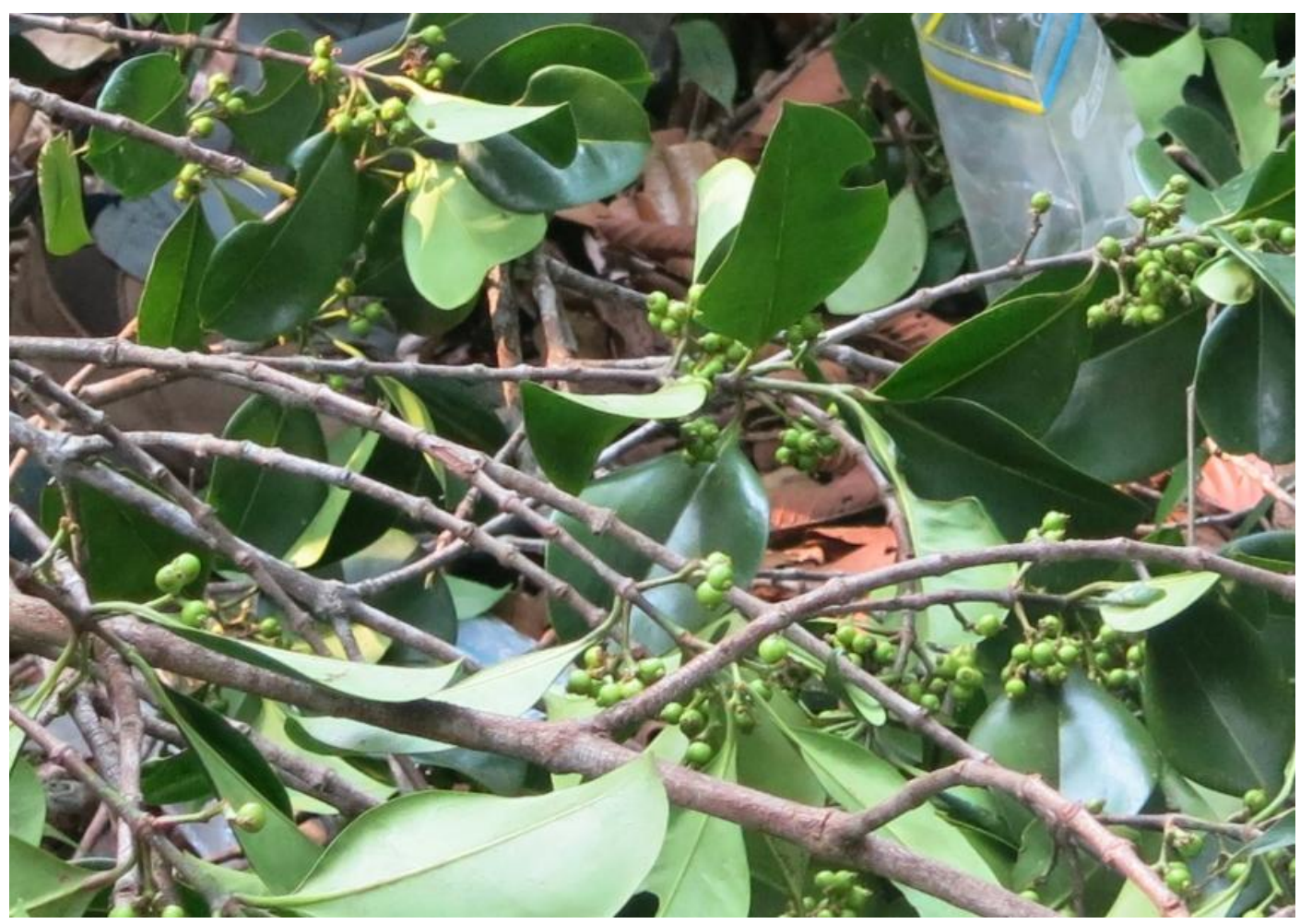

Figure 5: Unripe fruit of I. umbellulata

Photo: Naven Hon 


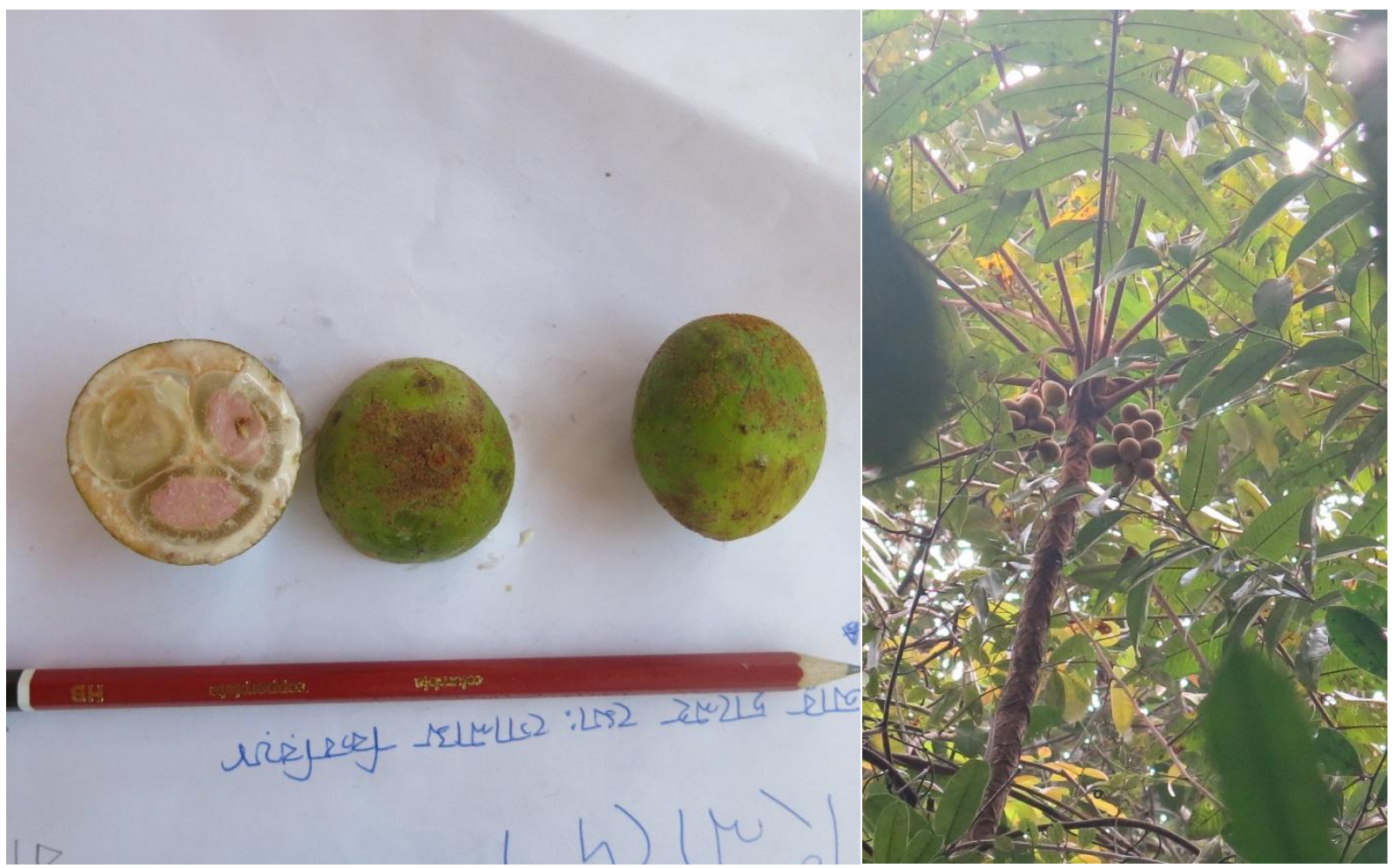

Figure 6: Mature fruit of A. grandis and its tree, which bears some of fruits during the study periods. Photo: Naven Hon

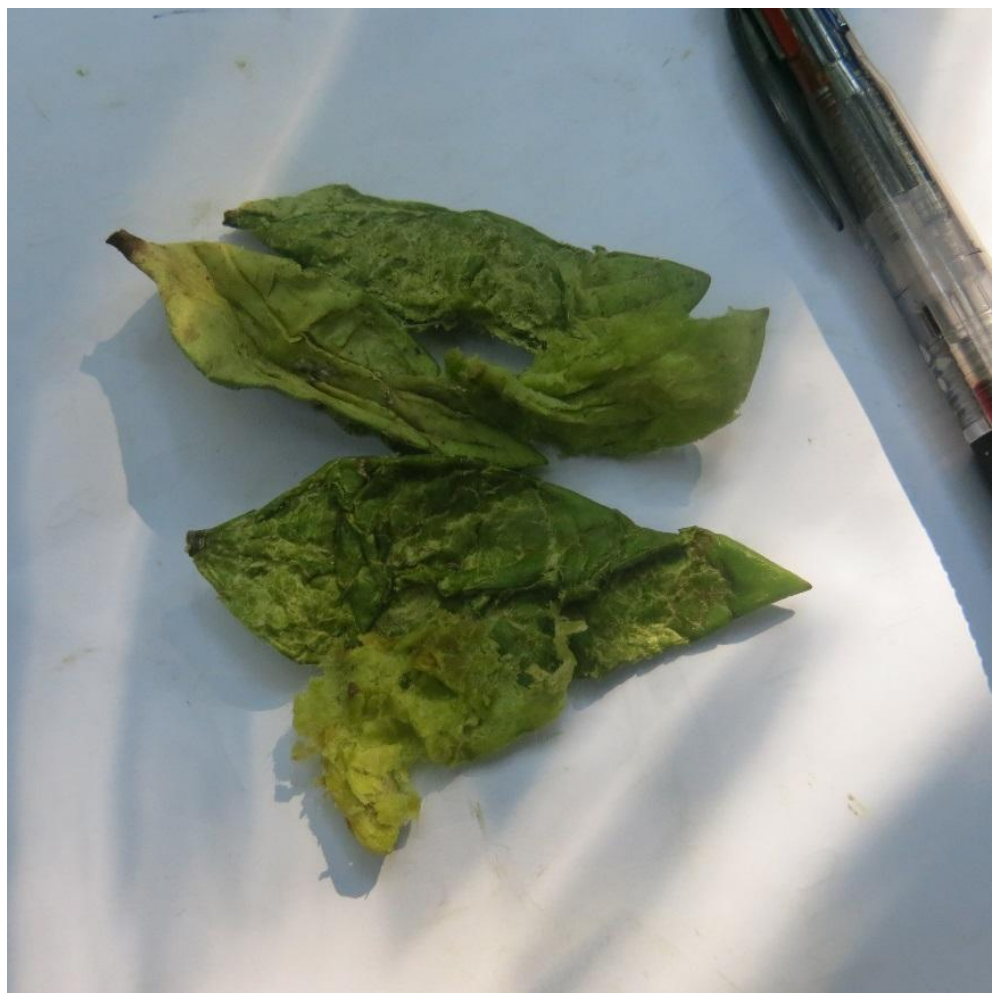

Figure 7: Leavesof large epiphyte, which were chewed and sucked by $N$. annamensis 
Photo: Naven Hon

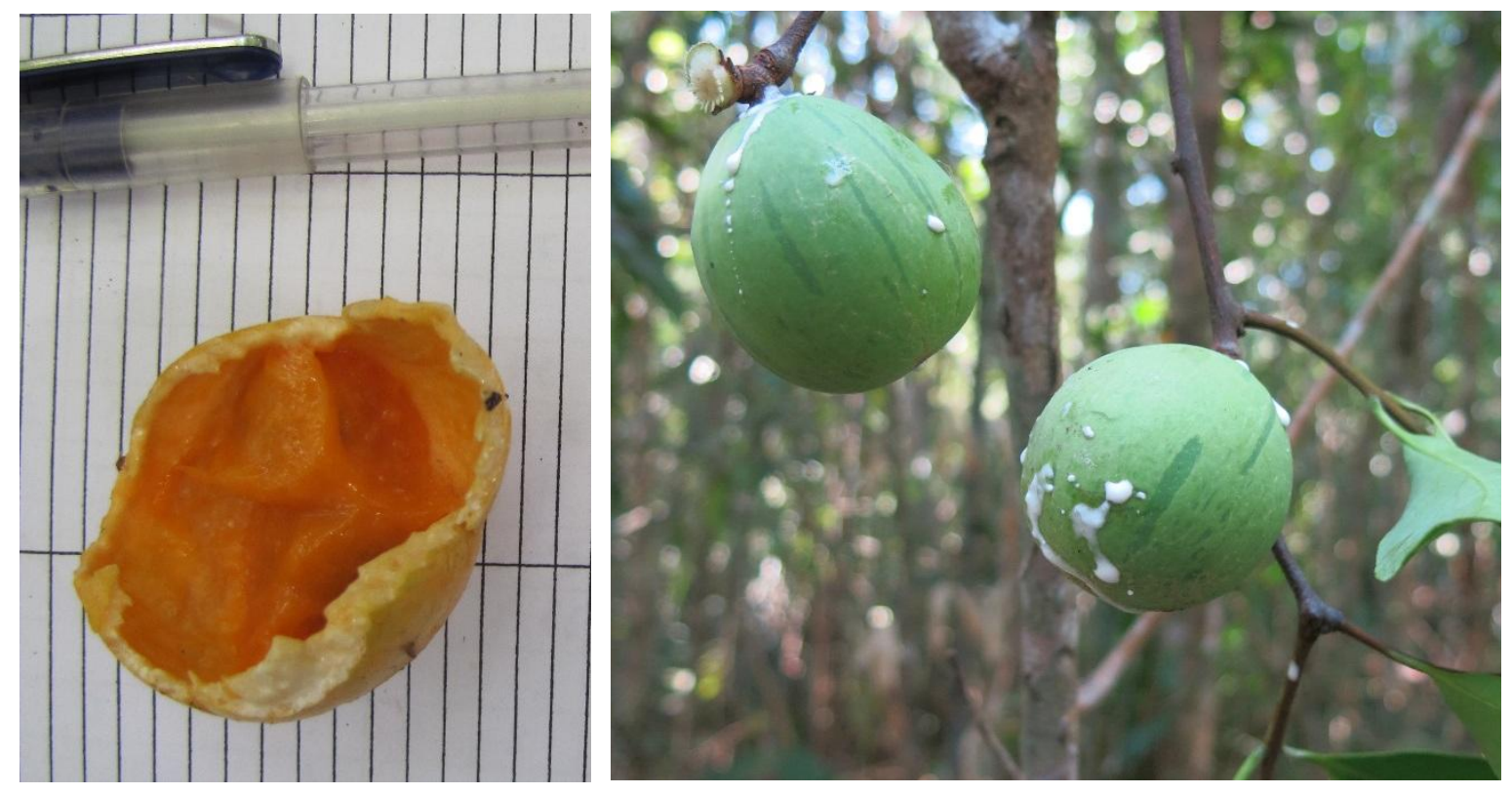

Figure 8: The remaining ripe fruit of W. edulis consumed the study group of $N$. annamensis, and green fruitof the same liana species, but was not consumed by this group of gibbons.

\section{Photo: Naven Hon}
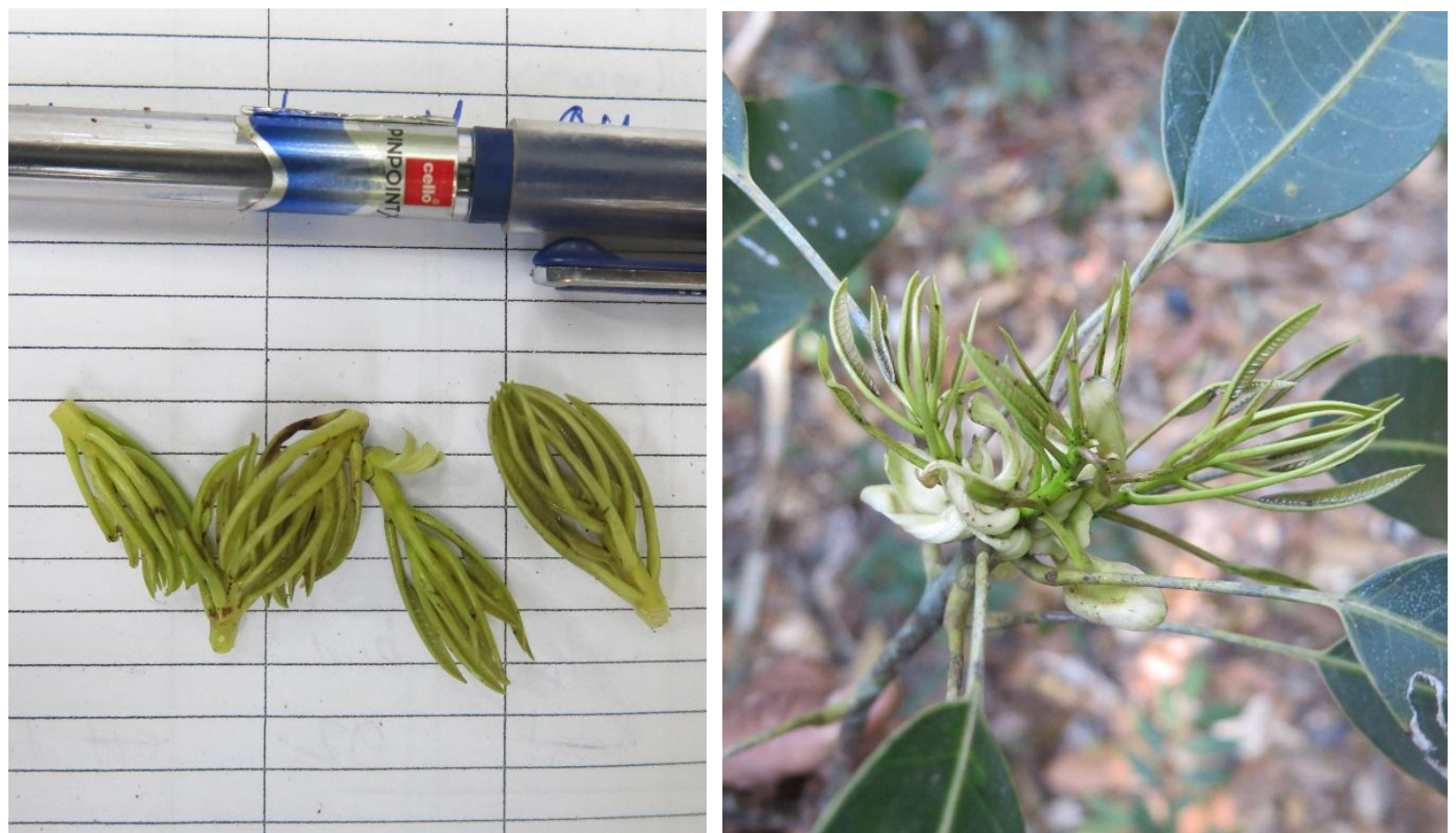

Figure 9: Young leaves of $M$. duperreana were collected for samples analyses and consumed by the study group of $N$. annamensis, this tree species provides a good source for protein.

Photo: Naven Hon 
Appendix 3: Rescues of baby northern yellow-cheeked crested gibbons (N. annamensis)

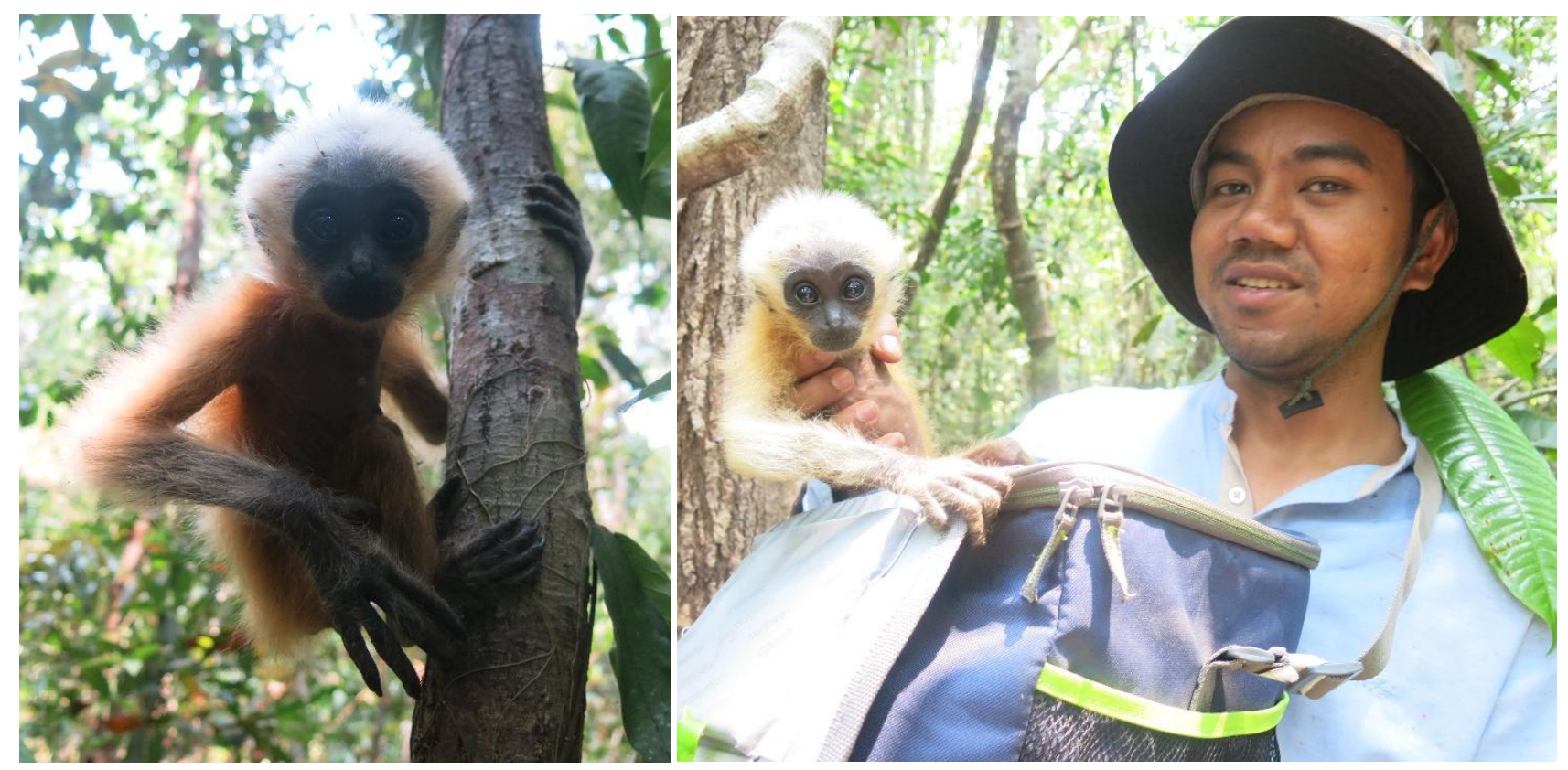

Figure 1: A baby northern yellow-cheeked crested gibbon (Nomacus annamensis) was found alone in the jungle then brought to the base camp, fed with human formula milk. It does not belong to the study group of gibbons.

Photo: N. Hon and Sy sovath.

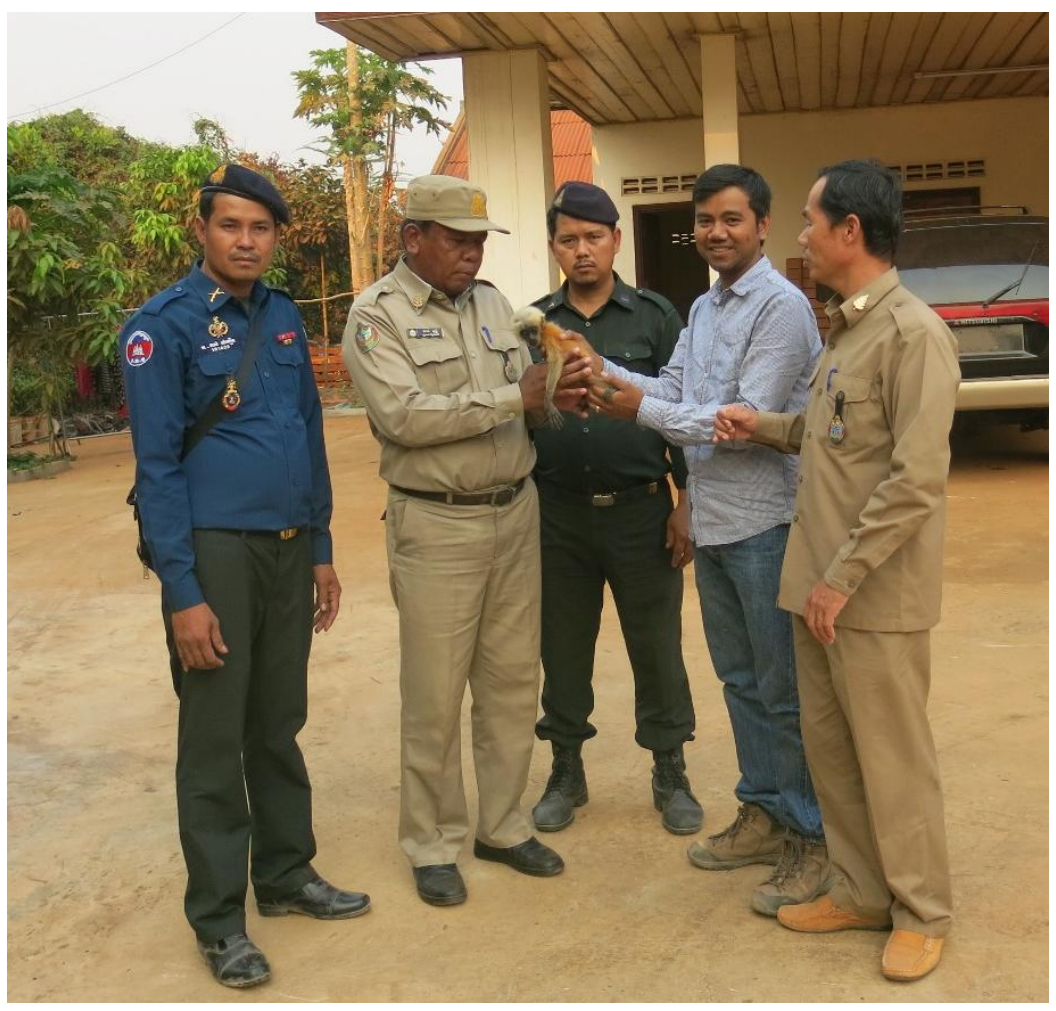

Figure 2: A law enforcement team (Forestry Administration official and military police, cooperated with Conservation International) at Veun Sai-Siem Pang Conservation Area, and MSc student from Victor University of Wellington handed baby N. annamensis to a Forestry Administration officialand the military police from Wildlife Alliance. These officials transferred the baby to the Phnom Tamao Wildlife Recuse Centre. 
Photo: Puthy Kong

Appendix 4: Statistical pairwise comparison

Table 1: Results of Mann-Whitney $U$ testscomparing each individual gibbon's activities

\begin{tabular}{llrrr}
\hline Gibbons & Pair activities & $Z$ & $U$ & $P$ value \\
\hline \multirow{4}{*}{ Adult } & Feeding and Resting & -1.32 & 32 & 0.18 \\
female & Feeding and Travelling & 3.43 & 4 & $\mathbf{0 . 0 0 0 5}$ \\
& Feeding and social activities & 3.74 & 0 & $\mathbf{0 . 0 0 0 1}$ \\
& Resting and Travelling & 3.66 & 1 & $\mathbf{0 . 0 0 0 1}$ \\
& Resting and social activities & 3.74 & 0 & $\mathbf{0 . 0 0 0 1}$ \\
& Travelling and social activities & 3.74 & 0 & $\mathbf{0 . 0 0 0 1}$ \\
\hline \multirow{4}{*}{ Adult male } & Feeding and Resting & 0.18 & 47 & 0.84 \\
& Feeding and Travelling & 3.06 & 9 & $\mathbf{0 . 0 0 2}$ \\
& Feeding and social activities & 3.74 & 0 & $\mathbf{0 . 0 0 0 1}$ \\
& Resting and Travelling & 3.36 & 5 & $\mathbf{0 . 0 0 0 7}$ \\
& Resting and social activities & 3.74 & 0 & $\mathbf{0 . 0 0 0 1}$ \\
Sub-adult & 3.74 & 0 & $\mathbf{0 . 0 0 0 1}$ \\
\hline \multirow{5}{*}{ male } & Travelling and social activities & -1.77 & 26 & 0.07 \\
& Feeding and Resting & 1.85 & 25 & 0.06 \\
& Feeding and Travelling & 3.74 & 0 & $\mathbf{0 . 0 0 0 1}$ \\
& Feeding and social activities & 3.28 & 6 & $\mathbf{0 . 0 0 1}$ \\
& Resting and Travelling & 3.74 & 0 & $\mathbf{0 . 0 0 0 1}$ \\
Resting and social activities & 3.74 & 0 & $\mathbf{0 . 0 0 0 1}$ \\
\hline \multirow{5}{*}{ mavenile } & Travelling and social activities & 0.34 & 45 & 0.72 \\
& Feeding and Resting & -2.49 & 14 & $\mathbf{0 . 0 1}$ \\
& Feeding and Travelling & 3.66 & 1 & $\mathbf{0 . 0 0 0 2}$ \\
& Feeding and social activities & 2.75 & 13 & $\mathbf{0 . 0 0 0 5}$ \\
& Resting and Travelling & 3.66 & 1 & $\mathbf{0 . 0 0 0 2}$ \\
& Resting and social activities & 3.21 & 7 & $\mathbf{0 . 0 0 1}$ \\
\hline
\end{tabular}


Table 2: Results of Mann-Whitney $U$ tests comparingeach individual gibbon's food choices

\begin{tabular}{llrrr}
\hline Gibbons & Pair activities & $Z$ & $U$ & $P$ value \\
\hline \multirow{4}{*}{ Adult } & Fruit and young leaves & 2.81 & 2 & $\mathbf{0 . 0 0 4}$ \\
female & Fruit and Flowers & 2.51 & 5 & $\mathbf{0 . 0 1}$ \\
& Fruit and Mature leaves & 2.82 & 8 & $\mathbf{0 . 0 0 4}$ \\
& Young leaves and Flowers & 1.20 & 33.5 & 0.22 \\
& Young leaves and mature leaves & 2.26 & 19.5 & $\mathbf{0 . 0 2}$ \\
& Flowers and mature leaves & 0.83 & 38.5 & 0.4 \\
\hline \multirow{4}{*}{ Adult male } & Fruit and young leaves & 2.88 & 4 & $\mathbf{0 . 0 0 3}$ \\
& Fruit and Flowers & 3.30 & 0 & $\mathbf{0 . 0 0 0 9}$ \\
& Fruit and Mature leaves & 3.09 & 2 & $\mathbf{0 . 0 0 1}$ \\
& Young leaves and Flowers & 1.62 & 28 & 0.10 \\
& Young leaves and mature leaves & 2.30 & 19 & 0.02 \\
Sub-adult & Flowers and mature leaves & 0.34 & 45 & 0.72 \\
male & Fruit and young leaves & 2.72 & 13.5 & $\mathbf{0 . 0 0 6}$ \\
& Fruit and Flowers & 2.72 & 13.5 & $\mathbf{0 . 0 0 6}$ \\
& Fruit and Mature leaves & 3.32 & 5.5 & $\mathbf{0 . 0 0 0 0}$ \\
& Young leaves and Flowers & 0.68 & 40.5 & 0.49 \\
& Young leaves and mature leaves & 2.49 & 16.5 & $\mathbf{0 . 0 1}$ \\
& Flowers and mature leaves & 1.58 & 28.5 & 0.11 \\
\hline Juvenile & Fruit and young leaves & 2.83 & 12 & $\mathbf{0 . 0 0 4}$ \\
& Fruit and Flowers & 3.43 & 4 & $\mathbf{0 . 0 0 0 9}$ \\
& Fruit and Mature leaves & 3.74 & 0 & $\mathbf{0 . 0 0 0 1}$ \\
& Young leaves and Flowers & 2.03 & 23 & 0.04 \\
& Young leaves and mature leaves & 2.91 & 11 & $\mathbf{0 . 0 0 3}$ \\
& Flowers and mature leaves & 1.24 & 33 & 0.21 \\
\hline
\end{tabular}




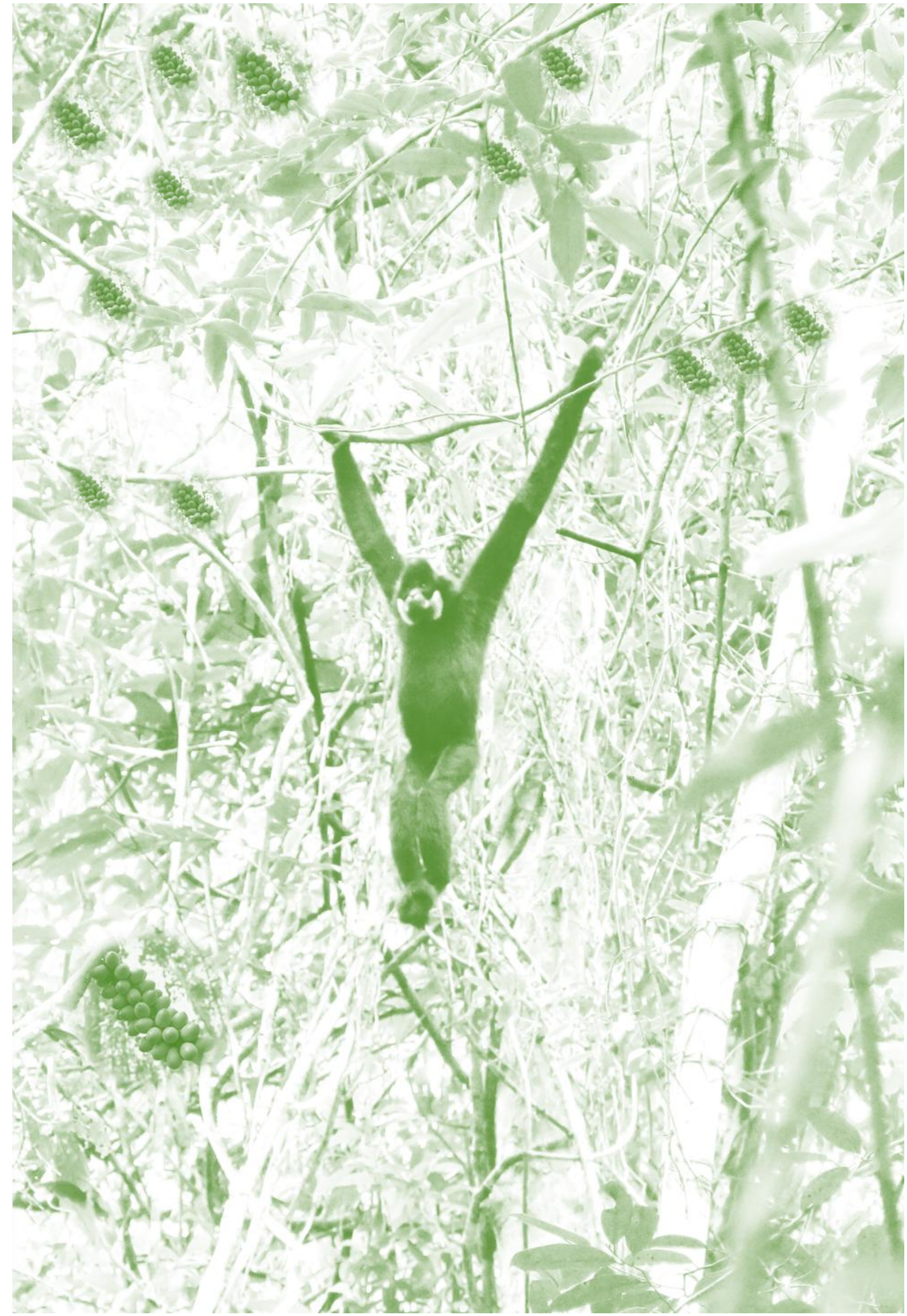

